Portland State University

PDXScholar

\title{
Black Children's Development of Self-Regulation within Stressful Contexts of Parenting: Investigating Potential Buffering Effects of a Kindergarten Social- Emotional Learning Program
}

\author{
Eli Labinger \\ Portland State University
}

Follow this and additional works at: https://pdxscholar.library.pdx.edu/open_access_etds

Part of the Early Childhood Education Commons

Let us know how access to this document benefits you.

\footnotetext{
Recommended Citation

Labinger, Eli, "Black Children's Development of Self-Regulation within Stressful Contexts of Parenting: Investigating Potential Buffering Effects of a Kindergarten Social-Emotional Learning Program" (2021). Dissertations and Theses. Paper 5789.

https://doi.org/10.15760/etd.7660
}

This Thesis is brought to you for free and open access. It has been accepted for inclusion in Dissertations and Theses by an authorized administrator of PDXScholar. Please contact us if we can make this document more accessible: pdxscholar@pdx.edu. 
Black Children's Development of Self-Regulation within Stressful Contexts of Parenting:

Investigating Potential Buffering Effects of a Kindergarten

Social-Emotional Learning Program

by

Eli Labinger

A thesis submitted in partial fulfillment of the

requirements for the degree of

\author{
Master of Science \\ in \\ Psychology
}

Thesis Committee:

Andrew J. Mashburn, Chair

Ellen A. Skinner

Karlyn R. Adams-Wiggins

Portland State University

2021 
(C) 2021 Eli Labinger 


\begin{abstract}
Children living in poverty are at an elevated risk for experiencing academic, socialemotional, and behavioral difficulties when beginning kindergarten, and early educational achievement gaps between economically disadvantaged and advantaged children are known to persist and widen over time (Fitzpatrick et al., 2014; Wanless et al., 2011). Black children face additional challenges related to racism, marginalization, minoritization, and oppression-processes which may, like poverty, impact their development by affording them fewer of the high-quality experiences that are critical for early learning (Burchinal et al., 2011; Coll et al., 1996). Fortunately, evidence-based social-emotional learning (SEL) programs offer tools to promote the social-emotional and behavioral competencies that support children's school readiness and early learning, and may counteract the adverse impacts of poverty on children's development. Using data from a randomized controlled trial that investigated the efficacy of a multi-year SEL afterschool program called WINGS, the current study tested the hypotheses that Black children $(N=85)$ growing up within stressful contexts associated with poverty (i.e., challenging parent-child relationships, stressful life events, and financial strain) would have (1) decreased self-regulatory skills at kindergarten entry and (2) slower development of self-regulation during kindergarten, and (3) that enrollment in WINGS would buffer kindergarteners' self-regulatory development from the harmful impacts of the stressful contexts of parenting. Results indicated only partial support for the hypotheses: a key finding was that parents' exposure to more stressful life events predicted slower development of children's self-regulatory competencies during kindergarten. Implications for research and practice are discussed.
\end{abstract}




\section{Acknowledgments}

This thesis was a challenging and immensely gratifying experience, and I thank my thesis committee — Andy, Ellen, and Karlyn — for their guidance, support, and expertise throughout this project. I especially would like to thank my advisor, Andy, and my labmates, Jaiya Choles and Brielle Petit, for the many hours of thoughtful conversation and council that helped shape this work. Thanks also to my friends and graduate school colleagues for their encouragement and emotional support.

Thank you to my family_-for the confidence you have in me and for the desire to make our world a little better. Special thanks to my brother, Cooper, whose technical support was essential for the success of this project.

The biggest share of thanks belongs to Miriam, my partner. Thank you for your patience with me throughout my countless late nights and for the inspiration to do this work in the first place.

Finally, I would like to thank the 85 children, their parents, and their teachers, whose participation in this study means more to me than they could ever know. I dedicate this work to them. 


\section{Table of Contents}

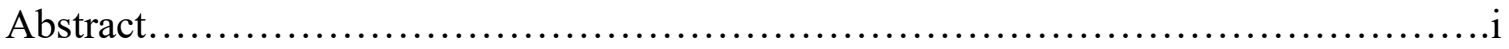

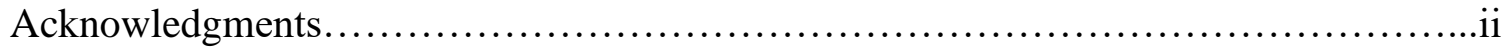

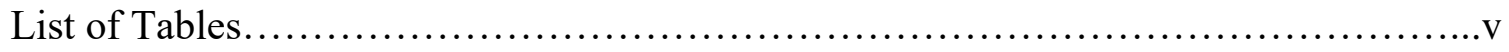

List of Figures..............................................................

Chapter 1: Problem Statement..................................................

Chapter 2: Background......................................................4

School Readiness ........................................................4

A bioecological perspective of school readiness............................6

Self-Regulation in Early Childhood............................................

Defining self-regulation..................................................... 8

Executive functioning............................................ 9

Behavioral self-regulation.........................................10

Importance of self-regulation skills during the transition to kindergarten...........11

Self-regulation and school outcomes................................13

Teaching self-regulation in schools.....................................14

Poverty and Risk in Early Childhood.......................................... 17

Contextualizing the conditions of poverty and cumulative risk exposure.........18

Stress response physiology and allostatic burden ........................20

Relational affordances...............................................22

Experiential canalization............................................23

The stressful contexts of parenting.......................................23

Financial strain and parent-child relationships: The family stress model.....25

Stressful life events...............................................28

Stressful contexts of parenting among Black families........................30

Social-Emotional Learning Programs and Curricula............................... 34

SAFE social-emotional learning afterschool programs.......................34

Summary ...........................................................

Chapter 3: Current Study................................................... 36

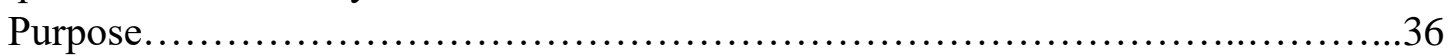

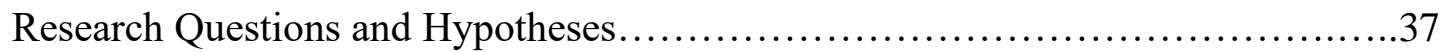

Chapter 4: Research Design and Method.........................................41

Sample................................................................. 41

Randomization procedure and study eligibility..........................42

The WINGS for Kids Afterschool Program.................................42

Control group ......................................................45

Procedure..........................................................45 
SELF-REGULATION, STRESS, AND SEL IN KINDERGARTEN iv

Pre-test data collection....................................................45

Post-test data collection.............................................46

Measures.............................................................46

Self-regulation ....................................................46

Direct assessments.............................................46

Teacher-reports.................................................48

Parent-reports.................................................48

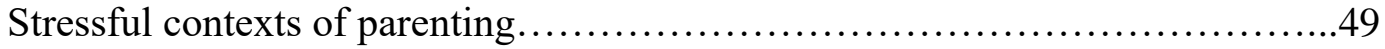

Challenging parent-child relationships................................49

Stressful life events...............................................50

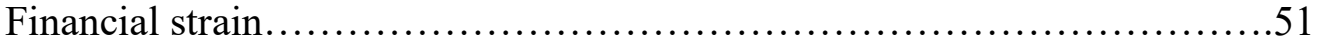

Chapter 5: Analyses and Results............................................ 51

Preliminary Analyses................................................... 51

Psychometric properties of measures...................................51

Descriptive statistics............................................... 52

Diagnostic analyses: Detecting violations of the regression assumptions.........54

Missing data.....................................................57

Assessing the missing data mechanism..............................57

Managing missing data: Full Information Maximum Likelihood................58

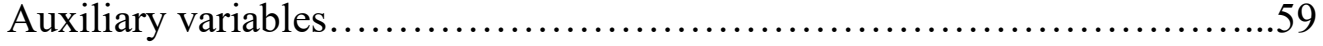

Central Analyses........................................................61

General linear models: Statistical software and model specification...........61

Research Question 1.............................................62

Research Question 2..............................................66

Research Question 3.............................................6 63

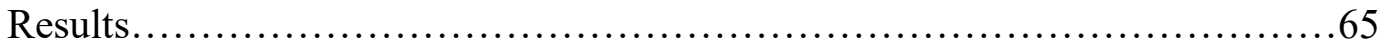

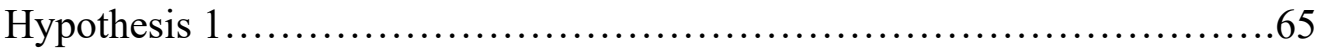

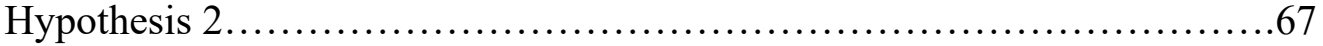

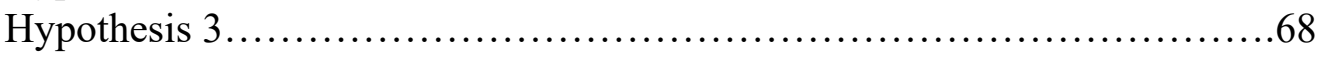

Plotting the interaction.............................................. 70

Chapter 6: Discussion..................................................... 71

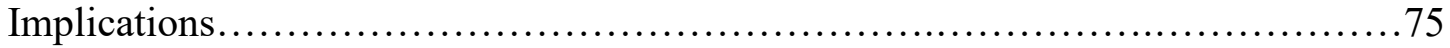

Study Strengths, Limitations, and Future Directions........................... 77

Conclusion............................................................ 81

Tables and Figures........................................................ 85

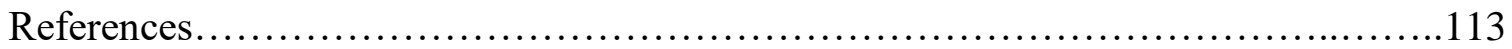

Appendix A: Teacher Survey Measure ........................................ 132

Appendix B: Parent Interview Measures.......................................133 


\section{List of Tables}

Table 1: Research on the Development and Education of Black Children..................85

Table 2: Demographic Information at Pre-test....................................92

Table 3: Descriptive Statistics and Bivariate Correlations...............................93

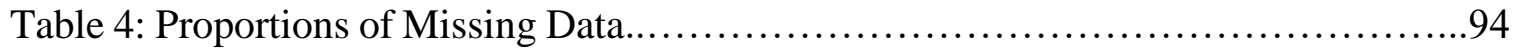

Table 5: Potential Auxiliary Variables............................................... 94

Table 6: Continuous and dichotomous correlates of missingness.........................95

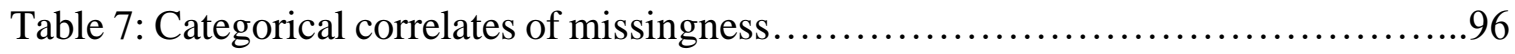

Table 8: Continuous and dichotomous correlates......................................97

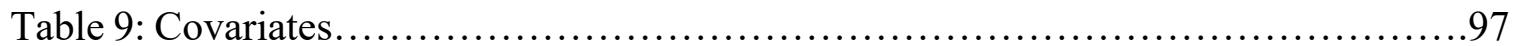

Table 10: Regression Analysis Summary, Research Question 1.........................98

Table 11: Regression Analysis Summary, Research Question 2.......................99

Table 12: Regression Analysis Summary, Research Question 3 (Direct Assessments)...100

Table 13: Regression Analysis Summary, Research Question 3 (Parent-Reports).........101

Table 14: Regression Analysis Summary, Research Question 3 (Teacher-Reports).......102

Table 15: Summary of Significant Findings............................................ 103 


\section{List of Figures}

Figure 1: Theoretical model for Research Question 1.............................. 104

Figure 2: Theoretical model for Research Question 2............................104

Figure 3: Theoretical model for Research Question 3..............................105

Figure 4: Illustrations of Interaction Effects................................. 106

A. Hypothesized Buffering Interaction Effect

B. Possible Amplifying Effect

C. Possible Compensatory Effect

Figure 5: Path Models for Research Question 1
A. Path Model for GLM 1
B. Path Model for GLM 2
C. Path Model for GLM 3

Figure 6: Path Models for Research Question 2..................................108
A. Path Model for GLM 4
B. Path Model for GLM 5
C. Path Model for GLM 6

Figure 7: Path Models for Research Question 3 (Direct Assessments).
A. Path Model for GLM 7
B. Path Model for GLM 8
C. Path Model for GLM 9

Figure 8: Path Models for Research Question 3 (Parent-Reports)
A. Path Model for GLM 10
B. Path Model for GLM 11
C. Path Model for GLM 12

Figure 9: Path Models for Research Question 3 (Teacher-Reports)
A. Path Model for GLM 13
B. Path Model for GLM 14
C. Path Model for GLM 15

Figure 10: Bar Graph Depicting the Stressful Life Events $\times$ WINGS Interaction........112 
SELF-REGULATION, STRESS, AND SEL IN KINDERGARTEN

Black Children's Development of Self-Regulation within Stressful Contexts of Parenting: Investigating Potential Buffering Effects of a Kindergarten

Social-Emotional Learning Program

\section{Chapter 1: Problem Statement}

A fundamental priority of Early childhood education (ECE) policy-makers, researchers, and practitioners is to promote children's school readiness, so that every entering kindergartener in the United States begins school ready to learn on day one (Mashburn \& Pianta, 2006; National Education Goals Panel, 1995). Despite our society's intention to guarantee children's school readiness, however, kindergarten teachers continue to report that many children begin school underprepared and lacking in the preacademic and behavioral skills they need to be ready to learn and to have positive early learning experiences (McClelland et al., 2000, 2007, 2015; McClelland \& Cameron, 2012; Rimm-Kaufman et al., 2000). Young children living in poverty are at particularly high risk for experiencing difficult kindergarten transitions and of being deemed by their teachers as unprepared for kindergarten (Zill, 1999). Low school readiness and difficult kindergarten transitions are early signals of the broader educational achievement gap that has been documented between economically advantaged and disadvantaged children. Furthermore, early socioeconomically-rooted differences in academic achievement may persist into higher grade levels and become more pronounced, contributing to adverse learning outcomes later in school, such as academic difficulties and grade retention, for children living in poverty (Burchinal et al., 2011; Duncan et al., 2007; Entwisle \& Alexander, 1999; Fitzpatrick et al., 2014; Wanless et al., 2011; Zill, 1999). Preventable 
difficulties early in school can have cascading, long-term impacts on the lives of students (particularly children in poverty) and can contribute to social stasis-the repeating cycle of poverty.

Several factors have been proposed to explain the link between children's family income and their school readiness. For example, children living in poverty are exposed to more environmental toxins and physical hazards, which may impair cognitive development, and they have decreased access to high quality preschools that would otherwise be better able to foster their cognitive abilities and promote their school readiness (Evans, 2004; Fitzpatrick et al., 2014). Additionally, parents dealing with financial struggles tend to be less involved with their children's transitions into kindergarten compared to parents who are financially well-off (McIntyre et al., 2007); Parents in poverty may be unable to invest their limited resources (including money, time, energy, and attention) in the learning materials and experiences needed to best promote their children's cognitive stimulation and social-emotional development, effectively affording children in poverty fewer opportunities to practice the skills needed to be ready to learn in kindergarten (Fitzpatrick et al., 2014; McIntyre et al., 2007; Wanless et al., 2011).

Children who grow up in conditions of poverty are also more likely to have early adverse experiences and interactions and relationships with adults that are characterized by emotional reactivity and behavioral dysregulation (Blair \& Raver, 2012; Ursache et al., 2012). The stressful experiences that children encounter in their homes and communities can alter their bodies' neurological and physiological stress response 
mechanisms, which can affect children's memory and attention in the classroom (McClelland et al., 2015). Additionally, longer time spent living in poverty is also related to lower executive functions - the cognitive underpinnings of behavioral regulation (Raver et al., 2013). Children's executive functioning is critical for their learning and development, and may help explain socioeconomic differences in children's school readiness (Fitzpatrick et al., 2014).

Numerous evidence-based social-emotional learning (SEL) programs and curricula are used by schools and teachers in efforts to promote skills that facilitate children's academic learning, such as their executive functions and behavioral regulation. SEL programs and curricula have become increasingly commonplace in ECE classrooms and other school settings, and are the subject of an abundance of research. However, more research is needed to further examine the impacts of school-based SEL programs on children's experiences beyond the classroom (e.g., on children's relationship quality with their parents). Most experimental studies of SEL programs have focused on their impacts on key academic (e.g., math, literacy) and social-emotional or behavioral (e.g., selfregulation) competencies, and on whether the benefits of SEL programs might vary based on demographic characteristics or experiences of children or teachers. Additionally, most SEL research specifically examines classroom-based curricula, as opposed to SEL programming that is delivered in ECE or community settings outside of the regular school day. Thus, there is a need for more research that specifically examines the impacts of SEL programs on naturalistic developmental processes beyond classroom-based learning. 
The current study addresses these research needs by investigating the extent to which kindergarteners' enrollment in an SEL afterschool program protects them against the adverse impacts of certain stressful contexts of parenting on their self-regulatory development. This study additionally contributes to the SEL literature by focusing on the self-regulatory development specifically of Black children, who have historically been marginalized by SEL research. To lay the groundwork for the current study, the next chapter provides a summary of previous theoretical and empirical work, beginning with a closer examination of the concept of school readiness.

\section{Chapter 2: Background}

\section{School Readiness}

School readiness has traditionally been defined as the academic, attentional, and social-emotional skills and attributes that children entering kindergarten need to possess in order to have positive early learning experiences, and which predict children's longterm academic success (Duncan et al., 2007). In line with this conceptualization, the Administration for Children and Families has developed the Head Start Early Learning Outcomes Framework, which specifies five domains of early learning and development that are crucial for children's school readiness and long-term educational success (U.S. Department of Health and Human Services, 2015). The five school readiness domains in the Early Learning Outcomes Framework are: (1) physical well-being and perceptual motor development; (2) social-emotional development, including prosocial behavior, emotional understanding, self-regulation, and aggression control; (3) approaches toward learning, including attitudes, habits, and learning styles; (4) early literacy and language 
development, including receptive and expressive language skills; and (5) cognition and general knowledge (Bierman et al., 2008; Duncan et al., 2007; Panter \& Bracken, 2000; Rimm-Kaufman et al., 2000; U.S. Department of Health and Human Services, 2015). This framework is intended to be used by Head Start programs and teachers, to inform their decisions about educational environments, learning goals, teaching strategies, classroom curricula, developmental assessments, and curricular implementation. Although the Early Learning Outcomes Framework clearly recognizes the importance of creating high quality ECE classroom resources and experiences in order to promote school readiness for every child, it also implicitly defines school readiness as a quality internal to children (U.S. Department of Health and Human Services, 2015).

Alternatively, some researchers have called for a re-imagining of the construct of school readiness to take into account the many contextual factors that are known to affect children's transitions to kindergarten and their subsequent school success-factors including the risks and resources associated with home, community, school, and peer contexts (Blair, 2002; Mashburn \& Pianta, 2006; Pianta, 1997; Rimm-Kaufman \& Pianta, 2000; Schulting et al., 2005). This explicitly contextual definition of school readiness is advantageous because it places less blame or responsibility on children and families, and instead demands greater scrutiny of ecological and systemic considerations. Thus, when evaluating children's school readiness in the context of environmental influences, researchers examine not only the skills and attributes that children need to be ready for kindergarten, but also the resources and expectations that schools need to be ready to 
support kindergarteners' school transitions and educational successes (Mashburn \& Pianta, 2006; Rimm-Kaufman \& Pianta, 2000).

A bioecological perspective of school readiness. The highly contextualized definition of school readiness just described reflects the bioecological perspective on development, which also frames the current study. The bioecological model states that children's development of the skills that support school readiness and academic success are influenced by numerous distinct yet interrelated ecological systems, including microsystems (e.g., classrooms, homes), mesosystems (e.g., schools, intersections of classroom and home life), exosystems (e.g., communities), and macrosystems (e.g., cultures). More specifically, children's school readiness skills develop through proximal processes - that is, repeated high-quality reciprocal interactions occurring between the individual and social and physical resources at the microsystem-level—which are influenced by the many ecological contexts in which a child exists (Bronfenbrenner \& Morris, 1998). Environmental factors influence children's school readiness skills and, by extension, their transitions into kindergarten and subsequent school experiences to the extent that they affect children's moment-to-moment interactions with social (e.g., parents, teachers, peers) and physical (e.g., learning materials, classroom resources) interaction partners. Therefore, children's endogenous skills and attributes are important considerations for assessing their school readiness and predicting later academic outcomes, but only to the extent that they are examined within ecological and developmental contexts - the interconnected social and physical systems within which children develop (Mashburn \& Pianta, 2006). 


\section{Self-Regulation in Early Childhood}

One developmental domain that promotes children's successful transitions to school and their early academic development is their capacity for self-regulation. As described in further detail below, children's adaptive self-regulatory skills in preschool and kindergarten may be integral to their school readiness. On the other hand, deficits in self-regulation may also contribute to the academic achievement gap between disadvantaged and advantaged children, and so promoting young children's selfregulatory skills is crucial for ensuring the long-term success, health, and well-being of all children, especially those experiencing childhood poverty. Self-regulation is a multifaceted construct with multiple conceptualizations and perspectives. However, before defining self-regulation and describing in detail the ways in which it relates to poverty and school readiness, it is important to explicate the meta-theoretical positionality of the current study as it relates to self-regulation.

Based on the theoretical underpinnings of the bioecological perspective described previously, the current study holds that children's capacity for self-regulation develops over time through proximal processes, and that contexts in which more opportunities for high-quality interactions are provided are better suited for promoting children's selfregulatory competencies (Bronfenbrenner \& Morris, 1998). Furthermore, Sameroff’s unified theory of development, which takes a dialectical approach, offers an additional relevant specification by proposing that the gradual development of self-regulation from infancy through early childhood is scaffolded by parents and teachers, who set increasingly rigorous expectations for children to self-regulate, as opposed to having their 
behaviors regulated primarily by caretakers (Sameroff, 2010). With these theoretical boundaries in place, the following sub-sections define self-regulation and provide a review of the research literature regarding the role of self-regulation in children's development at home and in ECE settings.

Defining self-regulation. In the context of ECE research, self-regulation is broadly defined as a child's abilities to intentionally select, direct, and manage his or her cognitions (e.g., thoughts and attention), emotions, and behaviors in order to adapt to classroom activities or circumstances (Blair, 2002; Blair \& Diamond, 2008; Blair \& Raver, 2012; Bowman, 1999; McClelland et al., 2015; McClelland \& Cameron, 2012). At least ten distinct (yet complementary) theoretical conceptualizations of self-regulation generally deriving from this central definition have been identified across subdisciplines in psychology. These include (1) behavioral self-regulation, (2) delay of gratification, (3) effortful control, (4) emotion regulation, (5) engagement, (6) executive function, (7) fluid cognition, (8) goal-attainment, (9) signal detection, and (10) temperament (McClelland et al., 2015). Still other approaches, such as the emotion-cognition balance model of selfregulation, emphasize the modulations made to children's emotional, motivational, and cognitive arousal in ways that promote positive adjustment and adaptation to social and academic contexts (Blair \& Diamond, 2008). More fundamentally, however, neuropsychological perspectives consider self-regulated behavior to be a product of bidirectional neural activity occurring between top-down processes controlled by the brain's prefrontal cortex and bottom-up or autonomic processes, such as the stress response activity generated by the brain's limbic system (Blair \& Raver, 2012). 
The current study employs two previously established conceptualizations of selfregulation. Specifically, it focuses on children's behavioral self-regulation and the executive functions that underlie it (McClelland et al., 2014, 2015).

Executive functioning. One perspective on self-regulation is the executive functioning (EF) framework. EF refers to the three top-down, neuro-cognitive processes that regulate attention and behavior: cognitive flexibility, working memory, and inhibitory control (Best \& Miller, 2010; McClelland et al., 2014, 2015; McClelland \& Cameron, 2012). Cognitive flexibility includes the abilities to focus one's attention on a single task or dimension while ignoring distracting information, and to shift one's attention to a new task or dimension when appropriate or necessary. Working memory refers to one's ability to keep information in mind and to recall it easily when needed. Lastly, inhibitory control refers to one's ability to resist taking an impulsive action, in favor of acting in a way that conforms to a novel set of rules (McClelland et al., 2015; Willoughby et al., 2012).

To consider children's EF skills as distinct albeit interconnected components, researchers often study EF in decontextualized and more tightly controlled laboratorylike settings, as opposed to naturalistically in ECE classrooms where observation of the individual components of EF during day-to-day class activities is challenging or impossible (McClelland et al., 2014). A direct assessment of children's EF competencies might evaluate cognitive flexibility by drawing children's attention to a single dimension (i.e., shape, size, or color) that is shared by two objects, and then instructing them to identify a characteristic of a third object that matches along a novel dimension. Children 
with strong cognitive flexibility are able to shift their attention between competing dimensions or characteristics. Working memory can be assessed by asking children to select one image at a time from a row of images, and altering the order of the images after each selection to prevent children from using the spatial location of the images to recall which have already been selected. Children who perform well on this task are able to store and recall information quickly despite changing visual information. Inhibitory control can be assessed by instructing children to tap a button as quickly as possible whenever an animal is displayed on a screen, except under a specific circumstance (for example, when the animal is a pig). Children with strong inhibitory control are better able to resist the impulse to click the button in accordance with the new rule (Willoughby et al., 2012).

Behavioral self-regulation. Behavioral self-regulation represents an alternative, though closely related definition of self-regulation. Whereas the EF framework focuses on the dynamic cognitive processes that interact to direct action, behavioral selfregulation views behavior as the manifestation of these same underlying top-down processes, but contextualized in social environments (Loomis \& Mogro-Wilson, 2019; McClelland et al., 2014; Wanless et al., 2011). Through this lens, cognitive flexibility (i.e., tuning out distractions and shifting attention when appropriate) is required for a child to focus on an art project in a noisy classroom, and to move from the art table to the rug for story time. Working memory is required to recall the words to a classroom song, or to remember where toys belong during cleanup time. Inhibitory control (i.e., selecting an adaptive behavior over an impulsive one) is needed when choosing to walk to the 
playground or lunch area instead of running (McClelland \& Cameron, 2012). In addition to the three components of EF, the behavioral self-regulation framework also specifically captures children's level of distractibility versus their focused attention (McClelland et al., 2015).

Due to its highly contextualized nature, behavioral regulation occurring in the classroom or at home is typically reported by teachers or parents, who rate the approximate frequency with which a child, on average, displays regulated versus dysregulated behaviors in one or more familiar settings or circumstances. Behavioral regulation is an important metric for researchers to capture since behaviors that might be considered appropriate and well-regulated in one context (for example, at home) may be inappropriate in another (for example, in the classroom). EF, on the other hand, captures children's global capacity for self-regulation across contexts. Taken together, cognitive measures of $\mathrm{EF}$ and contextualized measures of behavioral self-regulation can provide a balanced approximation of a child's true self-regulatory competencies.

\section{Importance of self-regulation skills during the transition to kindergarten.}

Research in early childhood development and education has demonstrated the central role of self-regulatory competencies in supporting children's successful school transitions and subsequent academic success. Kindergarten teachers themselves endorse self-regulatory skills as being as or more important for children to have at kindergarten entry compared with pre-academic skills such as early knowledge of letters and numbers (Blair, 2002; Blair \& Diamond, 2008; Blair \& Raver, 2015; Duncan et al., 2007; Rimm-Kaufman et al., 2000). However, kindergarten teachers continue to report that high percentages of 
children each year begin kindergarten with deficits in the behavioral regulation skills (e.g., sitting still and paying attention) needed to successfully navigate their classrooms and have positive early learning experiences (McClelland et al., 2000, 2007, 2015; McClelland \& Cameron, 2012; Rimm-Kaufman et al., 2000). One study found that nearly half of kindergarten teachers reported that more than $50 \%$ of the children in their classes had begun kindergarten lacking specific behavioral regulation, social-emotional, or preacademic skills needed to do well in school (Rimm-Kaufman et al., 2000).

Despite consistent efforts since the 1960s to promote children's school readiness by increasing access to high quality preschool programs, a parallel shift in teachers' expectations for children's academic and behavioral school readiness has effectively moved the goal post for what it means for children to be ready to start school (Bassok et al., 2016). Even children who have had high-quality preschool experiences may be at risk for challenging kindergarten transitions, particularly when preschool and kindergarten teachers' expectations for school readiness are misaligned with one another, or when teacher-assessments of children's school readiness inaccurately capture children's true abilities (Mashburn \& Henry, 2004; Panter \& Bracken, 2000). Children are especially at risk for challenging kindergarten transitions when they fall short of kindergarten teachers' and elementary schools' expectations for well-regulated behaviors that facilitate academic-focused learning in kindergarten-behaviors that include sitting still, paying attention, following directions, and inhibiting inappropriate, impulsive, or disruptive behaviors (McClelland et al., 2007). 
Self-regulation and school outcomes. Research on factors that promote school readiness supports early educators' intuitions that self-regulation matters-self-regulatory skills, including children's EF or behavioral regulation competencies, support smooth school transitions by promoting early academic achievement and positive social relationships (Blair, 2002; McClelland et al., 2014, 2015; McClelland \& Cameron, 2012; Wanless et al., 2011). By contrast, children who experience problems regulating their behaviors and emotions are at elevated risk for having externalizing and internalizing problem behaviors, experiencing peer rejection, and having lower social competence and prosocial attributes and behaviors (Eisenberg \& Sulik, 2012; Loomis \& Mogro-Wilson, 2019). In addition to promoting children's school readiness, self-regulatory competencies at kindergarten entry also promote longer-term academic, social-emotional, and healthrelated outcomes (Blair, 2002; McClelland et al., 2014, 2015; McClelland \& Cameron, 2012; Wanless et al., 2011). Although children's social-emotional development, their interactions and relationships with peers and teachers, and their overall health are all undoubtedly critical for children's success and well-being both in and outside of ECE settings, much of the extant literature focuses on academic skills as the developmental outcome of interest. The following passage therefore summarizes research findings regarding the empirical relationships between children's self-regulatory skills and their early academic achievement.

Research has consistently demonstrated that preschool and kindergarten children's EF and behavioral regulation skills predict both short- and long-term academic achievement and success in school (e.g., Loomis \& Mogro-Wilson, 2019; McClelland et 
al., 2015; Robson et al., 2020; Wanless et al., 2011). For example, preschoolers' performance on a direct assessment measure of EF skills (i.e., cognitive flexibility, working memory, and inhibitory control combined) has been established as a predictor of their early reading (i.e., literacy and vocabulary) and math skills (McClelland et al., 2007). Further, teachers' reports of kindergarteners' effortful control skills are related to their early academic skills, and especially to their math abilities (Blair \& Razza, 2007; Liew, 2012; McClelland et al., 2014). Some of the most persuasive evidence of these connections can be found in the strong longitudinal relationships between self-regulation and academic skills. For example, growth in preschoolers' self-regulatory abilities over one school year significantly predicted improvement of literacy, vocabulary, and math skills relative to baseline preacademic skills (McClelland et al., 2007). Similarly, a study of Head Start children's EF found that inhibitory control skills in preschool predicted early math and literacy skills in kindergarten (Blair \& Razza, 2007; Liew, 2012). A review of longitudinal studies of school readiness factors found that children's attention skills were stronger predictors of academic achievement compared to other socialemotional predictors such as adaptive social skills or low levels of internalizing or externalizing problems (Duncan et al., 2007; Liew, 2012). Although there is widespread acceptance by researchers and practitioners of the high value of promoting young children's self-regulatory skills, there is great heterogeneity in the practice of teaching these skills in ECE settings.

Teaching self-regulation in schools. Promoting children's development through social-emotional learning has been the focus of many programs and curricula which have 
been created and implemented in ECE settings for over forty years (Zins et al., 2000). In terms of self-regulation specifically, the emotion-cognition balance model suggests that classroom-based SEL curricula that teach and promote the skills relevant to children's self-regulated thoughts, behaviors, and emotions are effective in optimizing children's chances for academic success (Blair, 2002; Blair \& Diamond, 2008). Multiple randomized controlled trials have provided comprehensive support for the efficacy of classroom-based SEL curricula in promoting young children's school readiness (e.g., early social-emotional, self-regulatory, and academic competencies) in ECE classrooms, and particularly in those serving low-income families. One such efficacy study, the Chicago School Readiness Project (CSRP), found that Head Start children who received a classroom-based SEL curriculum for one academic year showed greater improvement in their self-regulatory and preacademic skills and fewer internalizing and externalizing problem behaviors compared with children in Head Start classrooms not implementing the CSRP curriculum (Blair \& Raver, 2015; Raver et al., 2011). Likewise, children in low-income Head Start, kindergarten, and first grade classrooms in which Dinosaur School (the SEL curriculum used by the Incredible Years Teacher Classroom Management training series) was implemented showed increased social competence and emotion regulation skills, and decreased conduct problems compared to children in the control group (Webster-Stratton et al., 2008). The REDI (REsearch based, Developmentally Informed) Project found that lessons in social-emotional competencies, language, and literacy skills delivered in Head Start classrooms led to greater improvements in preschoolers' self-regulatory skills, emotion knowledge, social 
problem-solving skills, vocabulary, emergent literacy skills, and academic engagement (Bierman et al., 2008; Blair \& Raver, 2015). Finally, Tools of the Mind (Bodrova \& Leong, 2007), an ECE classroom curriculum that promotes socially-constructed and playbased learning of self-regulatory, math, and literacy skills, has been found to support EF skills and social development, and to reduce behavior problems among preschoolers (Barnett et al., 2008; Liew, 2012) and kindergarteners (Blair \& Raver, 2015). Tools of the Mind has also been found to support increased classroom and instructional quality (e.g., more use of scaffolded teaching strategies, higher quality literacy environment) as well as modest improvements in children's cognitive development and academic skills, including improved language, reading, and, math skills (Barnett et al., 2008; Blair \& Raver, 2015; Liew, 2012).

Children enter kindergarten with a broad range of self-regulatory competencies that vary in the extent to which they support or hinder children's school readiness and subsequent school outcomes. Multiple factors contribute to the development of selfregulation, and there are many possible explanations for the individual differences observed in children's self-regulatory skills, and for the individual variation in the rate of improvement of these skills during early childhood. Additionally, while children's selfregulatory skills exist in and are informed by numerous social ecologies (including homes, classrooms, schools, communities, and cultures), interactions and experiences at home and in the classroom are particularly relevant for children's social and behavioral development (Bronfenbrenner \& Morris, 1998; Mashburn \& Pianta, 2006, 2010; Serpell $\&$ Mashburn, 2012). The current study is primarily concerned with the contributions of 
children's home and community experiences on the development of the self-regulatory skills that support children's school readiness. More specifically, risk factors related to the broader context of childhood poverty are considered.

\section{Poverty and Risk in Early Childhood}

According to the National Center for Education Statistics and the Pew Research Center, between 11 and 14 million children and youth in the United States were living in poverty in the year 2013, representing approximately $21 \%$ of children younger than 18 years-old at the time (NCES, 2015; Thomas \& Fry, 2020). Black and Latinx children were overrepresented among children living in poverty in 2013 - a trend, steeped in systemic inequality, that persists today (Thomas \& Fry, 2020).

Beyond the immediate as well as long-term threats to children's health and wellbeing, poverty also endangers children's social-emotional and academic learning and the processes that underlie self-regulatory development. Research shows that children experiencing poverty are rated by their parents and teachers as less able to control their own behaviors, and that they do not perform as well on delayed gratification tasks or on direct assessments of their inhibitory control and working memory (Blair \& Raver, 2012; Evans \& Kim, 2013). Several theoretical perspectives attempt to identify and explain the developmental pathways through which poverty adversely affects children's selfregulatory competencies over time. However, a broader understanding of the nature of poverty in the United States is required before these developmental theories can be applied. 


\section{Contextualizing the conditions of poverty and cumulative risk exposure.}

Most educational research conducted with low-income samples has concluded that poverty, or being of 'low socioeconomic status,' places children at risk for adverse school outcomes_-for instance with poor, 'at-risk' children scoring lower on academic achievement measures compared with their socioeconomically advantaged peers (Blair \& Diamond, 2008; Blair \& Raver, 2015; Evans, 2004; McClelland et al., 2015; Panter \& Bracken, 2000; Raver et al., 2013; Wanless et al., 2011). Although blanket statements such as these are not necessarily inaccurate, they often reflect the decontextualized and oversimplified view of poverty that is held by dominant perspectives in the literature.

A truly bioecological perspective of childhood poverty must recognize that poverty is multifaceted - numerous contexts compose poverty, including physical and psychosocial environments, each with numerous developmental pathways to learning and health-related outcomes (Bronfenbrenner \& Morris, 1998; Evans, 2004). For example, the physical environment of childhood poverty is associated with greater risk of exposure to environmental toxins and pollutants, less access to and fewer options for nutritious foods, a greater likelihood of attending underfunded and overcrowded schools with decrepit or insufficient facilities and materials, less access to affordable, permanent, or safe housing, and a host of other hazards to children's health and well-being. The psychosocial factors associated with environments of childhood poverty include inconsistent and unpredictable housing and schooling, fewer cognitively enriching experiences and literacy activities, less interpersonal trust and perceived support, and less warmth and responsiveness from ECE caregivers (Evans, 2004). The physical and 
psychosocial environments of poverty tend also to provide fewer opportunities for the high-quality interactions that are crucial to children's language acquisition and their development of other skills supporting self-regulation and early academic success (Blair et al., 2011; Blair \& Raver, 2015; Raver et al., 2013). Within this web of adverse factors, there are myriad pathways through which poverty may shape children's self-regulatory development.

In sum, children living in poverty are exposed to more hardships-in quantity, in range, and in severity - compared with their socioeconomically advantaged peers (Evans, 2004). Exposure to numerous physical and psychosocial risk factors, such as those enumerated above, has been found to have a negative cumulative effect on children's daily experiences and long-term well-being, including their social-emotional, cognitive, and physical health and development (Evans, 2004; Evans \& Kim, 2007, 2013; Panter \& Bracken, 2000; Zins et al., 2000). Cumulative risk exposure has also been specifically related to lower self-regulatory skills (Loomis \& Mogro-Wilson, 2019; McClelland et al., 2015; Raver et al., 2013; Wanless et al., 2011). For instance, research has found that children who have endured a greater number of adverse childhood experiences (ACEs) have lower teacher-rated self-regulation competencies (Loomis \& Mogro-Wilson, 2019). Additionally, research shows that cumulative or multiple risk exposure explains the effects of chronic childhood poverty on physiological stress dysregulation (Evans \& Kim, 2007). For example, Evans and English (2002) found that poverty was more strongly associated with cumulative risk than to any single risk factor, and that the effects of childhood poverty on children's stress response physiology and emotion regulation were 
fully mediated by exposure to multiple risks (Evans, 2004). The damaging impacts of poverty and cumulative risk on children's physiological stress response system are discussed in further detail in the following section. Two additional concepts which will contribute to a stronger understanding of the ways in which childhood poverty and cumulative risk exposure impact the development of children's self-regulatory competencies are "relational affordances" and "experiential canalization."

Stress response physiology and allostatic burden. Exposure to the cumulative risks associated with childhood poverty places children at additional risk for altered activity of their neurophysiological stress response system, through a process called allostasis (Blair et al., 2011; Blair \& Raver, 2015; Evans \& Kim, 2007, 2013; Raver et al., 2013; Wadsworth, 2015). In allostasis, the basal or resting point of an individual's stress response system is effectively recalibrated to be more sensitive, or in some cases less sensitive, to various environmental stressors in an effort to maintain homeostasis within the body (Blair et al., 2011). However, allostasis can have lasting harmful effects on the body: an individual's allostatic burden, or allostatic load, refers to the aggregate damage incurred over time by one's body as a result of the continuous activation of the stress response system by risk or adversity. Allostatic burden can affect one's neural, metabolic, and immune system functioning, and can alter the ways in which they respond to stressors in the future, through allostasis (Evans \& Kim, 2013; Wadsworth, 2015). An individual's allostatic burden may include damage to the body's hypothalamic pituitary adrenal (HPA) axis, a primary stress response system (Blair et al., 2011; Evans \& Kim, 2007, 2013). Under circumstances of low environmental risk and good physical health, 
the HPA axis is activated only in stressful situations and produces small amounts of stress hormones such as norepinephrine and cortisol, which help the individual navigate the dangerous or stressful situation (e.g., through fight or flight responses) and, once safe, quickly regain homeostatic balance. When the HPA axis is repeatedly activated, however, such as under conditions of chronic poverty or environmental unpredictability, allostatic mechanisms may overwhelm the body with stress hormones and manifest symptoms of chronic stress (Blair et al., 2011; Blair \& Raver, 2012; Evans \& Kim, 2007, 2013; McClelland et al., 2015). In addition, children's allostatic burdens resulting from cumulative risk may alter the structures and functioning of the brain areas and neural pathways responsible for their EF. A child's executive functions may be dysregulated to the extent that cumulative stress exposure alters their body's stress response physiology through allostasis (Blair \& Raver, 2015; Evans \& Kim, 2013; Raver et al., 2013).

However, some behavioral symptoms of chronic stress, such as hyperarousal and hyperactive startle responses, or conversely, muted emotional arousal and restricted startle responses, may serve an evolutionary function to protect the individual from imminent harm. According to the adaptive calibration model, the process of allostatic recalibration - the lowering or raising of the resting point of the stress response system to be more or less sensitive to environmental threats - is a necessary and potentially lifesaving functional adaptation to adverse or threatening circumstances (Duran et al., 2018; Wadsworth, 2015). From this perspective, lower self-regulatory abilities, such as poor performance on a delay of gratification task, may in actuality be indicative of an adaptive calibration in response to anticipated resource scarcity—-for instance, children who have 
experienced cumulative risks related to poverty may opt to take a tangible and immediate (albeit smaller) reward rather than accept the risk of foregoing it in favor of a larger but less certain reward (Blair \& Raver, 2012; McClelland et al., 2015). However, although the adaptive allostatic recalibration may serve a protective function in the short-term, it also contributes to long-term health disparities between those living in poverty and those with socioeconomic advantages (Wadsworth, 2015).

In sum, the allostatic load theory emphasizes the lasting physiological damage and biobehavioral dysregulation that can result from individuals' exposure to the unsafe and unpredictable conditions of poverty. The adaptive recalibration model views dysregulated behaviors as functional adaptations that can, under conditions of high cumulative risk, protect children from immediate environmental or interpersonal threats at the expense of their long-term health, well-being, and social-emotional success.

Relational affordances. Despite their focus on the physiological toll of the cumulative stresses of poverty, neither allostatic load theory nor the adaptive calibration model contradicts the core tenet of the bioecological perspective - that self-regulatory competencies develop through repeated high-quality interactions in supportive and predictable environments. Self-regulatory competencies are diminished for children in high-risk contexts because the unpredictable or hazardous nature of impoverished physical and psychosocial environments offers constrained relational affordances - that is, the environments of poverty provide fewer opportunities for high-quality interactions with the people and resources that are critical for the development of self-regulation (Pianta, 1997). 
Experiential canalization. Developmental systems perspectives suggest that characteristics internal to the individual (e.g., genes, physiology, allostatic burden, temperament) and environmental factors (e.g., material resources, relational affordances) contribute to the development of all outcomes (McClelland et al., 2015). In experiential canalization theory, for instance, development is viewed as the dynamic, interactive, and bidirectional processes that occur between elements of the individual and those of the environment, involving every level of the developing system, ranging from cellular to sociocultural (Gottlieb, 1991; McClelland et al., 2015; Raver et al., 2013). In this aspect, experiential canalization is closely related to Bronfenbrenner and Morris's (1998) Bioecological theory, as well as Coll and colleagues' (1996) integrative model, each of which holds that development occurs through the dynamic interplay between the child and proximal social ecologies, and is shaped by the distal ecologies in which the child is embedded. Therefore, whereas self-regulatory skills develop through the daily, proximal processes afforded to children across numerous microsystems, the emergence of individual differences in children's self-regulatory competencies may be attributed to the experiential canalization of their stress response physiologies within certain physical and psychosocial environments (Blair \& Raver, 2012; McClelland et al., 2015).

The stressful contexts of parenting. While innumerable factors have the potential to contribute to or protect against the allostatic burdens experienced by children living in poverty, a critical consideration in the context of early childhood is parenting and parenting behaviors. Early childhood is a sensitive period during which caregiverchild interactions and relationships exert a particularly strong influence on children's 
development and school outcomes, including their self-regulatory development and school readiness (Blair \& Raver, 2012; Pianta, 1997). However, parents' capacities to promote their young children's development through warm, structured, and supportive interactions with their children are not impervious to the influences of ecological circumstances and stressors. Rather, sub-optimal or maladaptive parenting conditions and behaviors can be understood as products of "developmentally challenging circumstances," which include (among many other factors) poverty and racism (Bradley, 2007; Skinner \& Zimmer-Gembeck, 2016). To be sure, many parents do an extraordinary job of nurturing their children despite living and parenting under the stressful and hazardous conditions of poverty and other developmentally challenging circumstances. Parents who, despite these circumstances, resiliently provide their children with warmth, structure, and support may act as a shelter against the torrent of adversity their children also face. The impacts of developmentally challenging circumstances may nonetheless, in varying degrees, affect parenting behaviors, parents' relationships with their children, and children's developmental outcomes.

To highlight the attention on factors specifically related to parenting and parentchild relationships (as opposed to the broader impacts on children and families who are experiencing developmentally challenging contexts), the current study refers instead to the "stressful contexts of parenting"- that is, some of the conditions and experiences which make adaptive parenting more difficult and which are thought to have negative consequences for children's social-emotional learning and self-regulatory development. Specifically, the current study focuses on three stressful contexts of parenting- 
challenging (i.e., distant and conflictual) parent-child relationships, parents' recent stressful life events, and their financial strain — each of which is described in further detail in the following sections. The developmentally challenging (higher-order) factors of poverty and racism that were discussed previously, are clearly relevant to these stressful contexts of parenting, but are not the focus of the current study. While challenging parent-child relationships, parents' stressful life events, and caregivers' financial strain are not unique to those experiencing poverty or racism, these higher-order factors often result in poor and minoritized children having more frequent or more severe exposure to the stressful contexts of parenting than their socioeconomically privileged peers. The following sections explore the ways in which the material and psychosocial conditions of poverty, the stressful contexts of parenting, and children's development of self-regulatory skills may be related.

Financial strain and parent-child relationships: The family stress model. The conditions of poverty are likely to produce experiences of financial strain — that is, the psychological pressures experienced by individuals regarding the perceived sufficiency of their financial resources relative to their material needs. Parents and other caregivers experiencing poverty may be especially prone to feelings of financial strain, due to the increased pressures of meeting the basic needs of those in their care. In addition to experiencing more financial strain, parents in poverty may also be at an elevated risk of having more challenging relationships with their children, which can be characterized by emotional distance and interpersonal conflict. Theory and research suggest that these stressful contexts of parenting (i.e., parent's financial strain and their challenging 
relationships with their children) may be causally related (Conger et al., 2000; Duran et al., 2018; Landers-Potts et al., 2015; Neppl et al., 2016; Raver et al., 2013).

The family stress model suggests that a primary mechanism through which children experience adversity involves caregivers' psychosocial responses to poverty (Conger \& Conger, 2002; Duran et al., 2018; Neppl et al., 2016). Specifically, the family stress model posits that the adverse effects of poverty on children's development are mediated by family processes, including increases in parents' financial strain. (Conger et al., 2000; Duran et al., 2018; Landers-Potts et al., 2015; Neppl et al., 2016; Raver et al., 2013). In response to economic hardship, caregivers' financial strain creates a cascading effect, generating stress processes in caregivers (e.g., feelings of stress, lack of control, and unpredictability in life), conflict in their interactions with their children, and ultimately, dysregulation and maladjustment in their children (Conger et al., 2000; Conger \& Conger, 2002; Duran et al., 2018). The family stress model also hypothesizes that social resources both within the family (e.g., effective problem-solving strategies to resolve family disputes) and in the larger community (e.g., direct aid from extended family or community members) may buffer children's developmental processes and outcomes against the adverse impacts of poverty and caregivers' financial strain (Conger \& Conger, 2002). This may be especially true of minoritized and specifically Black and African American children and families, for whom extended family occupies a more central caregiving position and plays a more direct role in protecting children from socioeconomic hardships and oppression (Coll et al., 1996). While the family stress model was initially conceptualized and tested in research with White parents and 
adolescents in a rural setting, more recent applications have found support for aspects of the model among Black families in samples of adolescents (Landers-Potts et al., 2015) and kindergarten-aged children (Duran et al., 2018). For example, prior research on the family stress model with a predominantly Black sample found that decreases in parentchild conflict over kindergarteners' first year of school was related to greater increases in their EF skills, providing some support for the family stress model (Duran et al., 2018).

In operationalizing interpersonal conflict and emotional distance in parent-child relationships, it is important to understand the nature of parent-child (and indeed all dyadic) relationships and interactions. The relationship between a parent and child is more than just the sum of interactions between them, but is rather understood as the dynamic patterns of expectations, beliefs, emotions, and memories that the parent and child each hold of their interactions with the other (Pianta, 1997). Other factors, such as the consistency and predictability of parent-child interactions are also important when capturing the quality of parent-child relationships. Parent-child conflict is typically characterized by unresponsive, harsh, and irritable interactions, less attunement to emotional needs, and a greater use of punishment by parents (Driscoll \& Pianta, 2011; Evans \& Kim, 2013; Pianta, 1992). Emotional distance in parent-child relationships is perhaps best understood simply as the lack of emotional closeness - that is, the lack of warmth, trust, physical affection, emotional attunement, and verbal praise between parent and child. Studies that have assessed parent-reported interpersonal conflict and emotional closeness between parents and their preschool-aged children have demonstrated greater interrater agreement of mothers' and fathers' perceptions of conflict, as opposed to their 
perceptions of closeness, in their relationships with their children (Driscoll \& Pianta, 2011). Research has also found that individual differences in conflict and closeness between parent-child dyads are relatively stable during early childhood. Within parentchild relationships, however, perceptions of closeness tend to increase while perceptions of conflict tend to decrease over time (Driscoll \& Pianta, 2011).

While parent-child relationships are important in and of themselves, they are also critical in fostering children's social-emotional and self-regulatory development. The potential for increased parent-child conflict and emotional distance that arises from parents' financial strain may explain some of the adverse consequences of poverty on children's self-regulation, school readiness, and early academic success (Blair \& Diamond, 2008).

Stressful life events. In addition to experiencing greater interpersonal conflict and emotional distance in their relationships, parents and children living in poverty are also more likely to experience adverse life events, including eviction, health problems, and police brutality (McLoyd, 1990). While negative experiences are both more frequent and more severe among individuals living in poverty, not all stress-inducing events are necessarily adverse (Evans, 2004). The current study draws on a broader category of experiences, referred to in the literature as "stressful life events," which are defined as discrete incidents or experiences that directly or indirectly result in personal loss, social upheaval, or a notable change in daily functioning, or that require substantial adjustment for a family or individual (Evans, 2004; Holmes \& Rahe, 1967; Rahe et al., 1970). Unlike negative life events and ACEs, stressful life events do not necessarily connote 
undesirable or traumatic events - any event, even a generally positive one, can have adverse consequences if it causes stress, creates a notable change in daily life, or requires getting used to. Children also do not necessarily need to directly experience stressful life events for them to disrupt their daily lives or impact their development. The current study focuses on stressful experiences in the lives of parents. However, parents' stressful life experiences may also directly or indirectly result in loss, upheaval, change, or adjustment in the lives of their children.

While stressful life events are a reality of the human experience, children living in poverty tend to experience more numerous stressful life events, which are also characterized by greater severity, compared with their socioeconomically advantaged peers (Evans, 2004). Stressful life events have negative implications for children's developing self-regulatory skills: The demands of stressful life events and their immediate consequences compete for children's attention and other executive functions - resources that might otherwise be used to foster regulated behaviors and support longer-term goals (McClelland et al., 2015). Similarly, parents attending to their own recent stressful experiences may understandably have limited resources (including time, energy, attention, money, and patience) when interacting with or providing for their children. Adults who experience a greater number of stressful life events are more likely to also experience adverse health outcomes, such as earlier onset of disease (Holmes \& Rahe, 1967; Rahe et al., 1970). Additionally, parents' increased exposure to (and severity of) stressful life events may lead to the proliferation of psychological distress, which has 
been proposed as a key mediator of the negative relationship between economic hardship and adaptive parenting behaviors (McLoyd, 1990).

Stressful contexts of parenting among Black families. Individuals from minoritized groups face additional, uniquely stressful life events, through sociohistorical marginalization and systemic oppression, for example on the basis of race and ethnicity. Cynthia García Coll and colleagues' (1996) integrative model of minoritized children’s development can be used to frame the stressful life events experienced by Black children and parents in the context of structural inequality and racism. According to the integrative model, elements of social stratification (i.e., individuals' relative social statuses, the social structures of racism, and the segregationist policies embedded in institutions) can contribute to the contextual demands placed on Black children and families in ways that are unique to people of color. Contextual demands are broadly defined by the integrative model to include, among other factors, the adverse economic, social, and safety conditions that may create stressful contexts of parenting. Therefore, while the integrative model emphasizes the importance of examining the indirect impacts of higher-order sociocultural factors on children's development, it also identifies the stressful contexts of parenting as possible down-stream mediators. For example, the integrative model proposes that processes related to racism, prejudice, discrimination, and oppression impact the learning outcomes of ethnically minoritized children by limiting the number and the quality of interactions afforded them by their environments (Coll et al., 1996). Stemming from increased contextual demands, adverse interactions between children and parents may lead to conflictual and distant parent-child relationships, which may suppress 
children's social-emotional and self-regulatory development. Similarly, lower-quality healthcare and unsafe neighborhoods derived from sociocultural inequities may lead to more stressful life events for parents and families, and less access to safe, secure, and well-paying jobs may lead to financial hardship and economic strain for Black parents.

While the adverse consequences of anti-Black racism are evident, the research literature on the development and education of Black children is much more wideranging. Table 1 presents a summary of key findings on the development and education of Black children, with an emphasis on the roles of parents and families during preschool and elementary school, and with particular focus on the work of researchers Iheoma Iruka and Vonnie McLoyd. This body of research has studied the developmental pathways through which stressful contexts of parenting, such as economic hardship, caregiver stress, and challenging parent-child interactions, can adversely impact Black children's school readiness, academic success, and social-emotional competence, as in the family stress model (Baker \& Iruka, 2013; Dotterer et al., 2012; Duran et al., 2018; LandersPotts et al., 2015; Mistry et al., 2002) and similarly, in an analytic model proposed by McLoyd (1990). The effects of poverty on young Black children's development have also been studied extensively in the specific context of their school readiness and kindergarten transitions (Baker \& Iruka, 2013; Barbarin et al., 2013; Burchinal et al., 2011; Duran et al., 2018; Iruka et al., 2014, 2020). In addition, school readiness has been studied in boys of color (Barbarin et al., 2013; Iruka et al., 2014), Black girls (Iruka et al., 2020), and in terms of children's self-regulatory competencies specifically (Barbarin et al., 2013; Duran et al., 2018; Holochwost et al., 2020). 
The literature on Black children's development has also focused on aspects of early learning environments, including children's classroom activities and experiences (Burchinal et al., 2011; Early et al., 2010), ECE program quality (Iruka \& Morgan, 2014), teachers' ethnicities and teacher-child interactions (Iruka et al., 2010), and teachers' implicit biases about race and gender (Gilliam et al., 2016). The confluence of home factors (e.g., cognitively enriching home environments) and community factors (e.g., neighborhood safety) in predicting Black children's academic school readiness has also been studied (Iruka et al., 2015). Finally, the protective roles of parents and extended family in Black children's development have been established by studies including those examining close child-mother relationships (Iruka et al., 2010), maternal warmth versus intrusiveness (Baker \& Iruka, 2013; Holochwost et al., 2020), and parents' financial strain and psychological distress (Landers-Potts et al., 2015; Mistry et al., 2002).

Research on the development and education of Black children indicates that Black (and especially economically disadvantaged Black) children attend poorer and lowerquality schools and childcare facilities, and are afforded fewer opportunities to participate in child-led classroom activities (Burchinal et al., 2011; Early et al., 2010). Their parents experience elevated financial strain, psychological distress, and inter-partner conflict, which can lead to lower quality caregiver-child interactions (Baker \& Iruka, 2013; Dotterer et al., 2012; Duran et al., 2018; Landers-Potts et al., 2015; Mistry et al., 2002). However, parents' family and social networks, parental warmth and sensitivity, children's cognitive stimulation at home, and high-quality ECE programs can protect children and parents from at least some of the dangers of poverty, including its threats to 
children's social-emotional and self-regulatory development (Baker \& Iruka, 2013; Holochwost et al., 2020; Iruka et al., 2010, 2015; McLoyd, 1990).

In summary, Black children and children living in poverty are exposed to a range of stressors and risks, which have a cumulative effect on their health and development. The physical and psychosocial environments of poverty impact children's self-regulatory development by creating an allostatic burden that can rewire individuals' stress response physiologies, and by affording children fewer opportunities to engage in the high-quality interactions with teachers and caregivers that promote the development of adaptive selfregulatory skills (Blair et al., 2011; Blair \& Diamond, 2008; Blair \& Raver, 2015; McClelland et al., 2015; Raver et al., 2013). The stressful contexts of parenting (specifically challenging parent-child relationships, parents' stressful life events, and their financial strain) are exacerbated by poverty and are thought to contribute to children's physiological stress responses, their opportunities for high-quality interactions with caregivers, and finally, their executive functions and behavioral regulation.

Fortunately, the many pathways through which the stressful contexts of parenting may impact children's self-regulatory development also reveal numerous potential points of prevention and intervention that exist within these complex systems. While efforts to reduce the impacts of the stressful contexts of parenting may indeed benefit parents and children navigating stressful contexts, this type of work treats the symptoms, rather than the underlying problem conditions themselves. However idyllic, the required solution to combatting the detrimental effects of poverty is simply to eliminate poverty. Similarly, the required solution to ensuring that each child begins school ready to learn at the 
kindergarten level is to ensure that kindergartens are ready to teach each child at his or her own starting place and learning pace. These system-level solutions, though highly optimistic, are indeed possible through the creation and implementation of robust, evidence-based, and person-centered social programs. In the meantime, while policymakers, researchers, educators, and parents must continue fighting for social progress, smaller-scale prevention and intervention solutions can and should be used to promote children's development through proximal levers of change. Many of these points of prevention and intervention can be accessed through school-based programs and curricula that target children's social and emotional development.

\section{Social-Emotional Learning Programs and Curricula}

High quality social-emotional learning programs have proven to be effective in promoting positive developmental outcomes among school-aged children (Durlak et al., 2011; Payton et al., 2008). Research shows that school-based SEL curricula successfully promote young children's self-regulatory and academic abilities, especially among those who are at heightened risk for adverse school outcomes, such as those living in poverty (Blair \& Raver, 2015). Among kindergarten children specifically, classroom-based SEL curricula are often integrated with daily play-based and academic activities. However, school-based SEL can also occur outside of the classroom: Afterschool programming offers additional opportunities to foster children's social-emotional and self-regulatory development.

SAFE social-emotional learning afterschool programs. Not all SEL programs are effective in promoting children's school readiness. High quality and effective SEL 
afterschool programs are characterized by the acronym SAFE, which describes effective programs as Sequenced, Active, Focused, and Explicit. More specifically, SAFE SEL afterschool programs deliver scaffolded instruction in which subsequent lessons build upon previous ones (sequenced), provide opportunities for children to engage with lessons (active), present a single SEL competency at a time (focused), and specify unambiguous goals for learning outcomes (explicit; Durlak et al., 2010, 2011; Payton et al., 2008). Additionally, multi-year SEL programs are likely to be more effective in promoting and sustaining benefits to children's outcomes compared with programs that are delivered on a short-term basis (Greenberg et al., 2003).

The efficacy of SAFE SEL afterschool programs has empirical support. For example, results of a meta-analysis of 75 studies of 69 SEL afterschool programs indicated that programs adhering to the SAFE criteria promoted a range of positive school outcomes among children and adolescents, including increased prosocial behaviors, decreased problem behaviors, and increased academic achievement, whereas afterschool programs not characterized as SAFE failed to promote such outcomes (Durlak et al., 2010). Furthermore, by offering increased social and emotional supports, and by affording children more opportunities to develop and practice their self-regulatory competencies through high-quality interactions with teachers and peers, ECE programs (including those administered in preschool and kindergarten classrooms and in afterschool programs) promote children's social, emotional, self-regulatory, and academic development (Hamre \& Pianta, 2007; Mashburn et al., 2008; Mashburn \& Pianta, 2006; Wanless et al., 2011). 


\section{Summary}

In summary, research has demonstrated that adaptive self-regulatory skills are critical for children's positive early school transitions and subsequent academic and social-emotional success, but these skills can be undermined by the adverse consequences associated with poverty and cumulative risk (McClelland et al., 2015), as well as by the stressful contexts of parenting, including challenging parent-child relationships, parents' stressful life events, and their financial strain. Multi-year afterschool programs for young children that teach social-emotional competencies in ways that are sequenced, active, focused, and explicit have proven to be effective levers of intervention in promoting children's self-regulatory skills and improving the likelihood of future school success (Durlak et al., 2010). These SAFE SEL afterschool programs may therefore interrupt the adverse impacts of poverty on children by buffering children's self-regulatory development against the stressful contexts of parenting that are associated with economic hardship.

\section{Chapter 3: Current Study}

\section{Purpose}

The purpose of the current study was two-fold. Specifically, this study sought to (1) examine the relationships between the stressful contexts of parenting (i.e., challenging parent-child relationships, parents' stressful life events, and their financial strain) and Black children's self-regulatory skills at kindergarten entry as well as their development of self-regulation during kindergarten; and (2) to investigate whether enrollment in an afterschool program that targeted SEL buffered young Black children against the 
presumed negative impacts of the stressful contexts of parenting on their development of self-regulatory competencies.

\section{Research Questions and Hypotheses}

Specifically, this study addressed the following three research questions:

Research Question 1. Do the stressful contexts of parenting (i.e., challenging parent-child relationships, stressful life events, and financial strain) relate to Black children's self-regulatory skills at kindergarten entry?

Hypothesis 1a. More challenging parent-child relationships will be associated with lower self-regulatory skills at kindergarten entry, as rated by parents, teachers, and direct assessment (Figure 1).

Hypothesis $1 b$. Greater exposure of parents to stressful life events will be associated with lower self-regulatory skills for children at kindergarten entry, as rated by parents, teachers, and direct assessment (Figure 1).

Hypothesis 1c. Greater parents' financial strain will be associated with lower selfregulatory skills for children at kindergarten entry, as rated by parents, teachers, and direct assessment (Figure 1).

Research Question 2. Do the stressful contexts of parenting (i.e., challenging parent-child relationships, stressful life events, and financial strain) relate to Black children's development of self-regulatory skills during the kindergarten year?

Hypothesis $2 a$. More challenging parent-child relationships will be associated with lower rates of development of Black children's self-regulatory skills during kindergarten, as rated by parents, teachers, and direct assessment (Figure 2). 
Hypothesis $2 b$. Greater exposure of parents to stressful life events will be associated with lower rates of development of Black children's self-regulatory skills during kindergarten, as rated by parents, teachers, and direct assessment (Figure 2).

Hypothesis $2 c$. Greater parents' financial strain will be associated with lower rates of development of Black children's self-regulatory skills during kindergarten, as rated by parents, teachers, and direct assessment (Figure 2).

Hypotheses 1 and 2 are consistent with the family stress model, which posits that disrupted parent-child relationships have adverse consequences for children's socialemotional skills and development (Blair \& Diamond, 2008; Conger et al., 2000). These hypotheses are also consistent with the notion of experiential canalization, which stipulates that individual differences in children's self-regulatory development are attributable to differences in children's experiences and environments (Blair \& Raver, 2012; McClelland et al., 2015). Prior empirical evidence also supports Hypotheses 1 and 2: For instance, a longitudinal study testing the family stress model found that the harsh parenting behaviors that may characterize parent-child conflict predicted increases in children's subsequent externalizing behaviors (Neppl et al., 2016). Additionally, many empirical studies have established the cumulative impact that stressful life experiences and living conditions may have on children's physiological stress response systems and ultimately, on their self-regulatory development. (Blair \& Raver, 2015; Evans \& Kim, 2013; McClelland et al., 2015; Raver et al., 2013).

Research Question 3. Does the impact of the stressful contexts of parenting on Black children's development of self-regulatory skills during kindergarten depend on 
whether kindergarteners were enrolled in a social-emotional learning afterschool program?

Hypothesis $3 a$. The negative impact of challenging parent-child relationships on Black children's development of self-regulatory skills as rated by parents, teachers, and direct assessment, will be reduced among kindergarteners enrolled in the afterschool program but not among those who were not enrolled in the intervention (Figure 3).

Hypothesis $3 b$. The negative impact of parents' stressful life events on Black children's development of self-regulatory skills as rated by parents, teachers, and direct assessment, will be reduced among kindergarteners enrolled in the afterschool program but not among those who were not enrolled in the intervention (Figure 3).

Hypothesis 3c. The negative impact of parents' financial strain on Black children's development of self-regulatory skills as rated by parents, teachers, and direct assessment, will be reduced among kindergarteners enrolled in the afterschool program but not among those who were not enrolled in the intervention (Figure 3).

Hypothesis 3 is supported by theory and research indicating that high-quality, school-based, SAFE SEL programs can effectively promote children's development of self-regulatory competencies (Blair \& Raver, 2015; Durlak et al., 2010, 2011; Payton et al., 2008). This hypothesis describes a moderating effect of the SEL afterschool program on the relationship between the stressful contexts of parenting and on children's selfregulatory development. However, a moderator can generally take several forms. A moderating variable has a 'buffering interaction effect' when it reduces the magnitude of the relationship between predictor and outcome variables (Fairchild \& McQuillin, 2010). 
Buffering effects can also be thought of as a moderator's protective effect on the adverse impacts of a predictor on an outcome. Findings supporting Hypothesis 3, for instance, would suggest the presence of a beneficial buffering effect of program enrollment on the impacts of the stressful contexts of parenting on decreased self-regulatory development. That is, enrollment in a social-emotional learning afterschool program should buffer children against (i.e., protect them from) the hypothesized negative impacts of the stressful contexts of parenting on their development of self-regulatory competencies. More specifically, Hypothesis 3 states that after one year of enrollment in the afterschool program, children's self-regulatory skills are predicted to be approximately equal regardless of level of early exposure to the stressful contexts of parenting. On the other hand, self-regulatory development is predicted to be adversely impacted by high levels of early exposure to the stressful contexts of parenting among children who are not enrolled in the afterschool program. Figure 4 (panel A) presents a schematic depiction of the hypothesized buffering interaction effect of enrollment in the SEL afterschool program on the impacts of early exposure to the stressful contexts of parenting.

Protective or buffering interaction effects can be distinguished from 'amplifying' or 'compensatory' effects, which suggest differences in the rates of change over time between groups. For example, enrollment in an SEL afterschool program could be hypothesized to have an amplifying or boosting effect on children's self-regulatory development over time, as depicted in Figure 4 (panel B). Similarly, a compensatory hypothesis states that children with greater initial risk or lower baseline abilities will experience more rapid development under ideal learning conditions because they have 
more room to meet their true potential, as depicted in Figure 4 (panel C; McClelland et al., 2017; Wanless et al., 2011).

Of course, these types of moderating effects are not necessarily mutually exclusive - it is feasible that a moderator's effect on a developmental relationship could be described as buffering, amplifying, and/or compensatory. However, while amplifying or compensatory effects are equally possible, the current study tested only for a buffering interaction effect between children's exposure to the stressful contexts of parenting and their enrollment in an SEL afterschool program on their self-regulatory development (Figure 4, panel A). The hypothesized buffering effect of enrollment in an SEL afterschool program would have two potential explanations: First, it may be evidence of the efficacy of the program in teaching social-emotional skills that compensate for the self-regulatory skills which children at home may not otherwise acquire. Second, it may be evidence that attending an afterschool program lessens the amount of time during which children are potentially exposed to home stressors.

\section{Chapter 4: Research Design and Method}

\section{Sample}

The current study used archival data collected from a randomized controlled trial that was conducted in elementary schools in Charleston, South Carolina between 2012 and 2015. Participants consisted of Black or African American kindergarten children $(N$ $=85$ ), their parents, and their teachers. The children attended one of three public elementary schools in Charleston County School District, each of which offered WINGS for Kids, an afterschool program that targeted SEL. Children participating in the study 
were an average of 5-and-a-half years old at the start of kindergarten $(M=5.45$ years, $S D$ $=.34$ ), and 54\% were female. Most children's mothers (76\%) had a high school degree or higher, but fewer than 5\% held a bachelor's degree or higher. More notably, nearly as many mothers had less than a high school education (24\%) as had completed at least some college (25\%). Most children in the sample qualified for free or reduced school lunches $(91 \%)$ and many parents reported receiving other forms of public assistance (83.5\%). Details of the demographic composition of the sample at children's kindergarten entry are reported in Table 2.

Randomization procedure and study eligibility. Families were recruited into the WINGS for Kids afterschool program's 2013-2014 cohort in the spring and fall of 2013, when children were finishing preschool or just beginning kindergarten, respectively. Parents indicated that they were interested in enrolling their children in WINGS and consented to participate in the study, although enrollment in the program was not contingent on participation in the study. A lottery system was used to randomly assign the sample: Of the 85 children participating in the study, 58\% $(n=49)$ were randomly assigned to the WINGS treatment group, and the remaining $42 \%$ of children ( $n$ =36) were assigned to a business-as-usual control group. The lottery procedure intentionally disproportionately favored assignment to the treatment group in order to compensate for potential attrition from the WINGS program due to low attendance or other reasons.

The WINGS for Kids Afterschool Program. The WINGS for Kids afterschool program currently serves elementary school children at Title 1 schools - those receiving 
supplemental federal funds to support high concentrations of low-income families-in South Carolina, North Carolina, and Georgia. The WINGS organization operates several additional programs to support children, parents, teachers, and communities.

WINGS was developed based on empirical findings about characteristics of effective SEL programs. Specifically, WINGS is a multi-year program that offers afterschool care and education to elementary school children from kindergarten through grade five, at no cost to families. The program encourages high attendance rates of enrolled children by requiring attendance for 3 hours per day after school, 5 days per week, for the duration of the school year. As incentive or compensation to families for this demanding afterschool schedule, WINGS children are provided a snack and dinner each evening. The WINGS afterschool program focuses on promoting children's academic and social-emotional development by providing homework help as well as SEL lessons. Over the course of each year in WINGS, children receive weekly lessons that focus on one or more of the five SEL competencies (i.e., self-awareness, selfmanagement, social awareness, relationship skills, and responsible decision-making; Collaborative for Academic, Social, and Emotional Learning, 2005; Payton et al., 2008) across 30 unique learning objectives. This SEL instruction adheres to the SAFE criteria for effective SEL programming described previously: the WINGS afterschool program's SEL learning objectives are (1) sequenced: children's learning is scaffolded and graduated, (2) active: children engage with the lessons as active participants, (3) focused: learning objectives focus on one SEL competency at a time, and (4) explicit: lessons and goals are presented with a stated, unambiguous purpose. Collectively, these SEL learning 
objectives are embodied by the WINGS Words to Live by: a mantra that WINGS children and staff recite together daily (WINGS for Kids, 2020).

WINGS children were assigned to small groups called "nests," which were separated by grade level and gender. Each nest was assigned a WINGS leader, who served as the nest's teacher and mentor for the school year. During the WINGS afterschool program at each school, children would gather in their nests in a single large communal space such as the school gymnasium or cafeteria, where nests had some room to spread out from the other nests.

The "active ingredient" in the WINGS afterschool program that is thought to be primarily responsible for promoting children's social-emotional and self-regulatory development is the SAFE curriculum of SEL learning objectives. However, several other WINGS components may also contribute to children's development of these skills. For example, no-cost afterschool care for children may serve as a respite for their working parents, who may experience reduced stress and more positive interactions with their children. Similarly, the daily meals provided to WINGS children may support children's social-emotional and self-regulatory development by promoting their health and nutrition. The homework help that children receive during the WINGS afterschool program may also be an important factor, particularly for providing increased academic support. While understanding the ways in which various aspects WINGS may affect children's development would be an intriguing and useful direction for additional research, these research questions warrant a larger-scale study that would permit closer examination of aspects of the implementation of the WINGS afterschool program, including fidelity, 
dosage, quality, and adaptation (Durlak, 2010). The focus of the current study, however, was not to identify the intervention's active ingredient or to assess its implementation, but rather to determine whether adverse consequences of the stressful contexts of parenting on children's self-regulatory development depended upon whether they were randomly assigned to the WINGS afterschool program as opposed to the business-as-usual control group.

Control group. Children randomly assigned to the control group did not participate in the WINGS afterschool program. These children spent their time after school with their families or other caregivers, or attended other afterschool programs. The afterschool activities and experiences of control group children were not monitored, measured, or assessed by the current study.

\section{Procedure}

Data for each measure were collected at two time points during the 2013-2014 academic year. Sources of data included parents, teachers, and direct assessments of children conducted by the research team.

Pre-test data collection. Direct assessments of children's baseline self-regulatory competencies were conducted by researchers in the summer and fall of 2013 , just before or at the beginning of kindergarten. Similarly, parent-reported baseline data were collected in the summer and fall, just before or at the start of their children's kindergarten year. All parent-reported data were collected through interviews that were conducted by a researcher in a private room at the school. Teacher ratings of children's baseline abilities were collected via surveys completed in the fall of 2013, at least four weeks after the 
beginning of the academic year. Pre-test scores for children's self-regulatory competencies therefore represented children's self-regulatory school readiness-the skills children possessed at kindergarten entry. The WINGS afterschool program was implemented after the administration of pre-test measures.

Post-test data collection. To assess the skills children acquired during kindergarten, a second round of data collection was conducted at the end of the kindergarten year, after the conclusion of the WINGS afterschool program for that school year. Post-test direct assessments of children's self-regulation and post-test parent interviews were conducted by researchers in the summer and fall of 2014, just before or at the beginning of participating children's first grade year. Post-test teacher surveys were completed by children's kindergarten teachers in the spring of 2014, at the end of children's kindergarten year.

\section{Measures}

Self-regulation. Participating children's self-regulatory competencies were assessed through direct assessments of children by researchers, surveys of teachers, and interviews with parents.

Direct assessments. Children's self-regulatory competencies were assessed using the Head-Toes-Knees-Shoulders task (HTKS), which required children to engage the three components of EF (i.e., short-term memory, cognitive flexibility, and inhibitory control) during a short game (McClelland et al., 2014; McClelland \& Cameron, 2012). The HTKS was administered by a trained assessor from the research team with each participating child individually. Interruptions and distractions were minimized where 
possible by conducting the assessment away from other classroom and school activities. The HTKS included a brief warm-up phase, and up to three testing sections, each of which was preceded by a practice phase to introduce children to a new set of the game's rules.

During the practice phases, assessors explained to participants that they should touch the opposite part of the body than what the assessor instructed (e.g., "when I say touch your head, instead of touching your head, you touch your toes. When I say touch your toes, you touch your head"). Section 2 added similar rules pertaining to knees and shoulders (e.g., "when I say touch your knees, you touch your shoulders"), and section 3 altered the rules such that head was paired with knees, and toes was paired with shoulders. During the practice phases, assessors demonstrated the correct response and offered corrections and reminders, but they did not give any feedback during the testing sections.

Each testing section consisted of 10 items, each of which resembled the format, “touch your [head, toes, knees, or shoulders]." For each test item, participants scored zero points for touching an incorrect location, one point for touching or attempting to touch an incorrect location before self-correcting and touching the correct location, or two points for touching the correct location without error. Thus, possible total scores for each of the three testing sections ranged from 0 to 20 , and the range of possible total scores for the full HTKS task was from 0 to 60 . Children who scored at least four points on testing sections 1 or 2 continued to the next testing section. The assessment ended after testing 
section 3, or after children scored less than four points during testing sections 1 or 2 . The HTKS took no longer than 5-10 minutes to administer.

Teacher-reports. Each child's ability to manage their behaviors in the classroom was rated by their kindergarten teacher using the Devereux Student Strengths Assessment (DESSA) self-management subscale (LeBuffe et al., n.d., 2009). The subscale included 11 items describing children's behavior during the four weeks prior to teachers' completion of the survey. Sample items included, "during the past 4 weeks, how often did the child stay calm when faced with a challenge?" and "during the past 4 weeks, how often did the child wait for her/his turn?" Teachers responded on a scale ranging from 1 ("Never") to 5 ("Very Frequently"). Respondents also had the option to respond "Don't know" or to refuse to answer the question. See Appendix A for the complete list of items on the DESSA self-management subscale. Item-level responses for each participant were aggregated into a subscale-level average score.

Parent-reports. Like teachers, parents of participating children responded to the 11 items on the DESSA self-management subscale (see Appendix B). During their inperson interview with a member of the research team, parents used a 5-point scale to rate the frequency with which their child exhibited each of the self-management behaviors during the four weeks prior to the interview date. As with the surveyed teachers, parents were permitted to respond "I don't know" or to refuse to answer each question, and an average of their item-level responses was computed.

Teachers and parents each completed the full DESSA questionnaire, however the current study focuses on the 11-item self-management subscale due to its conceptual 
overlap with behavioral regulation, one of the key constructs of self-regulation that was hypothesized to relate to children's exposure to the stressful contexts of parenting.

Stressful contexts of parenting. Through parent interviews, three components of children's exposure to the stressful contexts of parenting were assessed-specifically, challenging parent-child relationships (i.e., distant and conflictual parenting), parents' recent stressful life events, and their financial strain.

Challenging parent-child relationships. Parents answered interview questions about the overall quality of their relationship with their child during the four weeks prior to the date of the interview. The 15-item Child Parent Relationship Scale (CPRS) was used to assess parent-child relationship quality (Driscoll \& Pianta, 2011; Pianta, 1992). The CPRS was composed of an 8-item Conflict subscale and a 7-item Closeness subscale. Example items included "dealing with my child drains my energy" and "it is easy to be in tune with what my child is feeling." Parents rated each item on a scale ranging from 1 ("Definitely does not apply") to 5 ("Definitely applies"). Parents also had the option to respond "I don't know" or to refuse to answer the question. See Appendix B for the complete list of items on the CPRS.

Item-level responses were aggregated into subscale-level scores representing the average level of recent interpersonal conflict and emotional closeness present in children's relationships with their parents. Emotional distance in parent-child relationships was calculated by reverse scoring the Closeness subscale, which was achieved by subtracting each participant's mean Closeness score from 6 (i.e., one greater than the maximum scale response value). An aggregate variable representing the average 
recent conflict and distance in children's relationships with their parents was created by calculating the weighted mean of each child's parent-reported scores on the 8-item Conflict subscale and the reversed-scored 7-item Closeness subscale.

Stressful life events. Parents also answered questions about their recent stressful experiences, using the Holmes-Rahe Life Stress Inventory (LSI), previously known as the Schedule of Recent Experience (SRE) or the Social Readjustment Rating Scale (SRRS). The Holmes-Rahe LSI conceptualizes stressful life events as an individual's recent stressful experiences that involved a degree of unpredictability, change from the status quo, or instability in one's life. (Holmes \& Rahe, 1967; Noone, 2017; Rahe et al., 1970, 1972).

In the current study, parents were asked if, during the calendar year prior to the date of the interview, they experienced each of the 37 items that comprise the HolmesRahe LSI, and were instructed to respond "yes" or "no" to each item. The items spanned a breadth of potentially stressful experiences, including changes in parents' home lives (e.g., major change in free time or social activities, eviction); work lives (e.g., changing jobs, major changes in working hours or conditions); family relationships (e.g., marriage, death of a close friend); and health (e.g., major change in eating habits, major personal injury or illness). See Appendix B for the complete list of items. The Holmes-Rahe LSI measured both the quantity of parents' recent stressful experiences and the relative severity of those life stressors. Severity of stressful life events was determined using Life Change Units (LCUs) — weighted values that were assigned to each item by the creators of the scale, and which varied relative to other items on the scale (Noone, 2017; Rahe et 
al., 1970). For example, 'minor violations of the law (traffic tickets, jaywalking, disturbing the peace, etc.)' carries a LCU of 11, whereas 'death of a romantic partner' carries a LCU of 100. Scores on the Holmes-Rahe LSI are traditionally interpreted in terms of an individual's relative chance of experiencing stress-related health problems: a score of 150 or less suggests a low amount of recent life changes and a low risk of stressinduced health problems, whereas a score of 300 or greater suggests a large amount of recent life changes and an elevated risk of stress-induced health problems (Noone, 2017; The American Institute of Stress, 2020).

Financial strain. Finally, parents' financial strain — that is, the difficulty with which they anticipated making ends meet on their current total household income-was assessed using a three-item scale. Parents rated each item on a scale ranging from 1 ("Not at all difficult") to 5 ("Very difficult"), or they had the option to respond "I don't know" or to refuse to answer the question. The items used for the financial strain scale are listed in Appendix B.

\section{Chapter 5: Analyses and Results}

\section{Preliminary Analyses}

Psychometric properties of measures. The predictor and outcome variable

measures included in the current study were largely supported in the literature as having evidence of validity and reliability. The HTKS (Duran et al., 2018; McClelland et al., 2014), the DESSA (and the DESSA self-management subscale specifically, for use with both parents and teachers; LeBuffe et al., n.d.; Nickerson \& Fishman, 2009), and the CPRS (Driscoll \& Pianta, 2011; Duran et al., 2018) had evidence supporting their 
psychometric validity and reliability. Psychometric information was more limited, however, for the Holmes-Rahe Life Stress Inventory. The original version of the scale was first validated as a predictor of illness onset among White men (see Noone, 2017), and it has not been validated among school-aged children or for the purpose of predicting outcomes related to children's self-regulation. The updated scale has been revised to be appropriate for modern and diverse samples, and is generally thought to be an acceptable measure despite cross-cultural differences in stressful life events and attitudes towards stress (Noone, 2017). Information about the validity and reliability of the items used to capture parents' financial strain was unavailable.

Descriptive statistics. Preliminary descriptive analyses were conducted for predictor and outcome variables at pre-test. On average, parents reported relatively low levels of conflictual and distant parent-child relationships $(M=1.44$ out of $5, S D=.39)$, and of financial strain $(M=2.00$ out of $5, S D=.97)$. By contrast, parents reported levels of recent stressful life events that the Holmes-Rahe LSI would consider high and indicative of elevated risk for stress-related illness, and which also considerably varied across families in the study $(M=248.65, S D=145.57$; Noone, 2017). On average, parents and teachers each reported that, at kindergarten entry, children's self-regulated behaviors occurred with moderate frequency (parent-report: $M=3.87$ out of 5, $S D=.60$; teacher-report: $M=3.44, S D=.70)$. However, kindergarteners' scores on direct assessments of their self-regulatory competencies were comparatively low $(M=18.36$ out of 60 possible points, $S D=17.76$ ). More specifically, children's direct-assessment scores at kindergarten entry resembled the self-regulatory skills displayed by 
preschoolers one year prior to kindergarten entry in a previous study (McClelland et al., 2014).

Descriptive analyses were also conducted for outcome variables at post-test. On average, parents and teachers each reported that, at the end of kindergarten, children demonstrated self-regulated behavior with moderate frequency (parent-report: $M=3.96$, $S D=.57$; teacher-report: $M=3.72, S D=.77)$, relative to the anchors of the 5-point DESSA self-management subscale. Direct assessments similarly indicated that children demonstrated, on average, a moderate degree of self-regulatory skills at the end of kindergarten $(M=32.44, S D=17.05)$, relative to the range of possible scores on the HTKS.

Pearson correlation coefficients were then examined to assess the relatedness among the predictor variables at pre-test and outcome variables at both time points. The preliminary descriptive analyses and the correlation matrix are summarized in Table 3. As anticipated, the three post-test measures of children's self-regulation were all significantly and positively related with one another, $r s=.29$ to $.31, p s<.05$. Also as expected, each post-test measure of children's self-regulation was significantly and positively correlated with its corresponding measure at pre-test, $r \mathrm{~s}=.32$ to $.71, p s<.05$. Pre-test measures of self-regulation, however, were unexpectedly not related with one another. Several significant bi-variate relations between pre-test stressful contexts of parenting and pre-test self-regulation were observed, as predicted. Specifically, challenging parent-child relationships were negatively correlated with both parent- and teacher-reports of children's self-regulated behavior at kindergarten entry, $r s=-.26$ to - 
$.28, p$ s $<.05$. Parents' financial strain and their pre-test ratings of children's selfregulation were also negatively related, $r=-.22, p<.05$. However, the remaining correlations between the stressful contexts of parenting and children's self-regulation at kindergarten entry did not reach levels of statistical significance. Pre-test measures of children's exposure to the stressful contexts of parenting were unexpectedly unrelated with one another, with the exception of stressful life events and parents' financial strain, which were significantly positively correlated, $r=.36, p<.01$. Children's pre-test exposure to the stressful contexts of parenting and their self-regulatory abilities at posttest were also unexpectedly unrelated (see Table 3 ).

Diagnostic analyses: Detecting violations of the regression assumptions. Prior to conducting the analyses, the data were examined for violations of the assumptions implicit to multiple linear regression. Specifically, multiple regression assumes that independent and dependent variables are linearly related, that the dependent variables' residuals are normally distributed, that residuals are independently distributed (i.e., that residuals are uncorrelated with one another), and that the distributions of $X$ are identical across values of $Y$ (i.e., that there is homogeneity of variance; Hayes, 2018).

Leverage and Studentized Residuals values were first examined for outliers on independent and dependent variables, respectively, but no extreme data points were identified on $X$ or $Y$. Histograms, Q-Q plots, skewness, and kurtosis, were then examined to identify univariate violations of normality on each outcome variable. Two DVs were identified as having potentially concerning non-normal distributions: Histograms and QQ plots indicated that the HTKS (direct assessment measure of children's self-regulation) 
at pre-test and at post-test each appeared to be skewed. Descriptive statistics also suggested that these variables had non-normal distributions, with the pre-test HTKS moderately positively skewed and platykurtic (skewness $=.61$, kurtosis $=-.84$ ) and the post-test HTKS moderately negatively skewed and slightly platykurtic (skewness $=-.65$, kurtosis $=-.42$ ). However, the multiple linear regression assumption of normality specifically refers to the distribution of the outcome variables' residuals. An examination of histograms of the outcome variables' residuals indicated that the normality assumption was in fact met by all DVs. Thus, the observed departures from normality on the HTKS variables were not thought to pose serious problems for the subsequent statistical tests. Multivariate diagnostic analyses were also conducted. Scatterplots and residual plots were examined to determine whether relationships between IVs and DVs were linear, to identify instances of heteroscedasticity (non-constant variance), and to identify extreme or influential data points. No non-linear relationships were identified among independent and dependent variables, and the residual plots showed no signs of nonconstant variance. There were also no clear outliers in the data, as indicated by the scatterplots, residual plots, and low Cook's Distance values. Finally, tolerance values were assessed for instances of multicollinearity, or high associations among IVs. All Tolerance values were high (.81 to .97$)$, suggesting that the IVs were not highly linearly related. All told, the multiple linear regression assumptions appear to have been met by the data.

In addition to the assumptions made by multiple linear regression, significance testing also makes an implicit assumption about the nature of data that are missing from 
the data set. Specifically, analyses of incomplete data (i.e., data containing at least one case that has one or more missing values) assume that data are missing unsystematically — that is, that missingness cannot be predicted. However, this ideal circumstance does not always occur in practice, and violations of the missingness assumption (i.e., failing to account for systematic explanations of missingness) can introduce substantial bias to analyses. Rubin (1976) proposed three distinct missing data mechanisms that can be used to describe the nature of a modeled variable based on patterns of incomplete or non-response data. First, data are missing completely at random (MCAR) if a variable's missingness is unrelated to all measured variables, such that incomplete data can be thought of as a random sample of the theoretically complete data set. Second, data are missing at random (MAR) if a variable's missingness is independent from its theoretical values if the data were complete, but is dependent on other measured variables outside of the statistical model. Third, data are missing not at random (MNAR) if the variable's missingness is systematically related to its theoretical values if the data were complete (Baraldi \& Enders, 2010; Collins et al., 2001; C. K. Enders, 2010, 2013; Peugh \& Enders, 2004; Rubin, 1976; Schafer \& Graham, 2002). MNAR is considered a 'nonignorable' missing data mechanism, and can introduce considerable bias in interpretations of findings if not treated appropriately (Collins et al., 2001). Therefore, preliminary analyses were conducted to examine the precise nature of the missing data and to determine the most appropriate course of action for reducing any bias brought on by the missingness. 
Missing data. First, the proportions of missing data in the sample were examined. The non-response rate at pre-test was minimal (missingness $\leq 2.4 \%$ ), with most independent and dependent variables containing no missing data. However, as is common in longitudinal field-based research, missingness was much more substantial at post-test, reaching as high as $29.4 \%$ missingness. In addition, proportions of missingness varied greatly between the teacher-report ( $2.4 \%$ missing), direct assessment (15.3\% missing), and parent-report measures (29.4\% missing) at post-test. Nonresponse rates for each independent and dependent variable at both time points are reported in Table 4.

Assessing the missing data mechanism. The data were then examined to determine whether the data were MCAR - that is, whether the probability of variables containing missing versus observed values was indeed unsystematic. It is important to note that MCAR is the only missing data mechanism that can be empirically tested, since both the MAR and MNAR mechanisms rely on unobserved data (Baraldi \& Enders, 2010; Enders, 2010; Little, 1988; Peugh \& Enders, 2004). Nonetheless, useful tools are available for examining the nature of incomplete data, such as Little's MCAR test, which tests the null hypothesis that the data are MCAR. Because Little's MCAR test produces a single test statistic, it is preferable to conducting numerous hypothesis tests which may be subject to problems arising from multiple comparisons, such as alpha inflation (Little, 1988).

Each of the three independent and six dependent variables of interest were included in Little's MCAR test. Additionally, several potential auxiliary variables were included in the test. These potential auxiliary variables included information about the data collection (e.g., time of data collection) as well as demographic variables that were 
not the focus of the hypothesized statistical models, but which could conceivably relate to the model variables or explain some of the variables' missingness. Thirteen such variables were included in Little's MCAR test, and are summarized in Table 5. Little's MCAR test statistic was not significant, $\chi^{2}(91)=101.74, p=n s$, allowing for the retention of the null hypothesis that the data were missing completely at random.

Managing missing data: Full Information Maximum Likelihood. Although deletion methods for dealing with missing data (e.g., listwise deletion, pairwise deletion) are arguably acceptable when data are MCAR and when the sample size is sufficiently large, research has found that deletion approaches still tend to create substantial bias (Cheema, 2014; C. K. Enders, 2013). By comparison, more sophisticated techniques, such as multiple imputation (MI) or maximum likelihood (ML) estimation, rely on the more lenient MAR mechanism, and can provide unbiased estimates without further reducing statistical power by deleting incomplete cases. For example, Full Information Maximum Likelihood (FIML), an extension of ML estimation, is an implicit imputation technique which, under the assumption of multivariate normality, uses all available data to estimate a likelihood function for each individual case, (Anderson, 1957; Enders, 2011; Enders \& Bandalos, 2001). Many researchers have argued for the abandonment of deletion methods in favor of modern and more principled techniques such as ML (Cheema, 2014; Collins et al., 2001; Dong \& Peng, 2013; Enders, 2011, 2013; Enders \& Bandalos, 2001; Lang \& Little, 2018; Little et al., 2014; Peugh \& Enders, 2004; Schafer \& Graham, 2002). FIML is particularly effective when dependent variables contain incomplete data, such as in the current study (Enders, 2013). Given the body of work 
supporting ML (and FIML more specifically), and given the evidence from Little's MCAR test that the data were MCAR, FIML was determined to be an appropriate and unbiased method for recapturing some of the information and statistical power lost through non-responses in the data.

Auxiliary variables. The results of Little's MCAR test provided sufficient evidence that there was not systematic missingness in the data, and justified the use of FIML to increase power and decrease bias. However, the FIML procedure can be improved further by the addition of auxiliary variables — variables that, as stated previously, are not necessarily central to the hypothesized models, but which may relate to the probability of missing data. When chosen strategically, auxiliary variables (which can be treated as outcome variables or covariates) serve to reduce bias and increase statistical power by maximizing the information specified by the model (Baraldi \& Enders, 2010; Collins et al., 2001; Enders, 2013; Lang \& Little, 2018; Peugh \& Enders, 2004). There are two main characteristics of ideal auxiliary variables: (1) auxiliaries that are related to the model variable(s) containing missing values, and (2) auxiliaries that are related to the probability that data are missing versus observed - that is, variables that are statistically related to the missingness itself. For either of these cases, research suggests that correlates with associations of greater than .4 or less than -.4 be selected as auxiliary variables (Collins et al., 2001; Dong \& Peng, 2013; Enders, 2010). In a foundational study on the use of auxiliary variables in MI and ML, Collins and colleagues (2001) found that FIML is most successful when inclusive strategies of auxiliary variable selection are used. Unlike restrictive selection strategies, which limit auxiliary variables 
to those that are both correlates of missingness and correlates of the variables containing missing values, inclusive strategies also adopt auxiliary variables that only meet one of these criteria, and may even include auxiliary variables that do not strongly correlate with either the model variables or with their missingness.

To help identify auxiliary variables to be included in the analyses, dichotomous dummy variables were created to indicate whether cases had missing or complete data on the model variables of interest. Correlates of missingness were then identified (from the list of thirteen potential auxiliary variables included in Little's MCAR test, see Table 5) using Pearson correlations and Cramer's Vs. More specifically, point-biserial correlations between the dichotomous missingness indicators and continuous and dichotomous variables were conducted (Table 6). Although associations between any two dichotomous variables could alternatively have been assessed using Phi coefficients produced by $2 \times 2$ chi-square analyses, the point-biserial correlation for these comparisons is equivalent to the Phi coefficient, and both are equivalent to Pearson's $r$ (Myers et al., 2010). However, associations between two categorical variables that require larger than a $2 \times 2$ contingency table are better suited to chi-square analyses. Cramer's V coefficients were therefore used to examine associations between the dichotomous missingness indicators and categorical demographic variables with three or more values (Table 7). Lastly, associations between the model variables that contained missing values and continuous and dichotomous variables were assessed using Pearson correlation coefficients and point-biserial correlation coefficients, respectively (Table 8). 
The significant associations indicated several clear choices for auxiliary variables: Children's age at pre-test was significantly and moderately correlated with five of the eight dummy-coded missingness indicators that were examined, and whether children attended preschool was significantly and moderately correlated with three missingness indicators. In other words, whether children's data were complete or incomplete on several key variables in the hypothesized models was statistically related to their age at pre-test and to their preschool enrollment status. Similarly, children's biological sex was significantly associated with two dependent variables at post-test. Children's age at pretest, biological sex, and preschool enrollment status were therefore each included as auxiliary variables. Although none of the associations reached an absolute effect size of greater than .4, an inclusive approach to the selection of auxiliary variables was taken, following recommendations from the literature (Collins et al., 2001). Two additional dichotomous auxiliary variables were therefore added to the models as covariates. Specifically, children's free or reduced school lunch status and parents' public assistance status were used as proxies for socioeconomic status, which was thought to be a potentially undetected correlate of missingness.

\section{Central Analyses}

\section{General linear models: Statistical software and model specification. A} multiple linear regression framework was used to test fifteen regression equations. To accommodate the FIML procedure, "lavaan” (version .6-8; Rosseel, 2021), a structural equation modeling software package in $\mathrm{R}$, was used to specify the regression models (see Dong \& Peng, 2013; Little et al., 2014; Peugh \& Enders, 2004). Huber-White robust 
standard errors and scaled test statistics were used to further adjust for incomplete data and for nonnormality present in the continuous variables (Yuan \& Bentler, 2006).

Research Question 1. The relationships between each stressful context of parenting (i.e., challenging parent-child relationships, stressful life events, and financial strain) and Black children's self-regulation skills at kindergarten entry (i.e., direct assessments, parent-reports, and teacher reports) were tested using general linear models (GLMs) 1-3. In each model, self-regulation is abbreviated as "SR," and each variable's subscript denotes either pre-test ("T1") or post-test ("T2"). Five covariates were included in each analysis (GLMs 1-15), and are listed in Table 9. Descriptive statistics for these covariates are summarized in Table 2.

SR Direct ${ }_{\mathrm{T} 1} \sim$ Relationships $_{\mathrm{T} 1}+$ Events $_{\mathrm{T} 1}+$ Financial $_{\mathrm{T} 1}+$ Covariates

SR Parent $_{\mathrm{T} 1} \sim$ Relationships $_{\mathrm{T} 1}+$ Events $_{\mathrm{T} 1}+$ Financial $_{\mathrm{T} 1}+$ Covariates

SR Teacher ${ }_{\mathrm{T} 1} \sim$ Relationships $_{\mathrm{T} 1}+$ Events $_{\mathrm{T} 1}+$ Financial $_{\mathrm{T} 1}+$ Covariates

(GLM 3)

Research Question 2. The effects of the stressful contexts of parenting on Black children's self-regulatory abilities at the end of kindergarten (controlling for their baseline self-regulatory abilities and for whether they had been randomly assigned to attend the WINGS afterschool program) was tested using general linear models 4-6.

SR Direct $_{\mathrm{T} 2} \sim$ Relationships $_{\mathrm{T} 1}+$ Events $_{\mathrm{T} 1}+$ Financial $_{\mathrm{T} 1}+$ SR Direct $_{\mathrm{T} 1}$ + WINGS + Covariates

SR Parent ${ }_{\mathrm{T} 2} \sim$ Relationships $_{\mathrm{T} 1}+$ Events $_{\mathrm{T} 1}+$ Financial $_{\mathrm{T} 1}+$ SR Parent $_{\mathrm{T} 1}$ + WINGS + Covariates

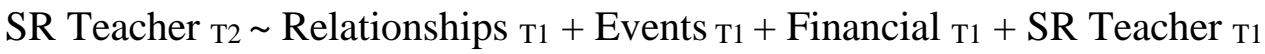
+ WINGS + Covariates 
Research Question 3. General linear models 7-15 tested whether the impacts of the stressful contexts of parenting on the development of Black children's self-regulatory competencies during kindergarten was buffered by participation in WINGS. In each of the following regression models, children's self-regulatory abilities at post-test were predicted by the three stressful contexts of parenting, controlling for children's baseline self-regulatory abilities and covariates. Additionally, the binary moderator (enrollment in the WINGS afterschool program) and an interaction term between the moderator and a single stressful context of parenting was included in each model.

SR Direct $\mathrm{T}_{2} \sim$ Relationships $\mathrm{T} 1+$ Events $_{\mathrm{T} 1}+$ Financial $_{\mathrm{T} 1}+$ SR Direct $_{\mathrm{T} 1}$ + WINGS + Relationships 1 *WINGS + Covariates

SR Direct ${ }_{\mathrm{T} 2} \sim$ Relationships $_{\mathrm{T} 1}+$ Events $_{\mathrm{T} 1}+$ Financial $_{\mathrm{T} 1}+$ SR Direct $_{\mathrm{T} 1}$ + WINGS + Events ${ }_{1} *$ WINGS + Covariates

SR Direct ${ }_{\mathrm{T} 2} \sim$ Relationships $_{\mathrm{T} 1}+$ Events $_{\mathrm{T} 1}+$ Financial $_{\mathrm{T} 1}+$ SR Direct $_{\mathrm{T} 1}$ + WINGS + Financial $\mathrm{T} 1^{*}$ WINGS + Covariates

SR Parent ${ }_{\mathrm{T} 2} \sim$ Relationships $_{\mathrm{T} 1}+$ Events $_{\mathrm{T} 1}+$ Financial $_{\mathrm{T} 1}+$ SR Parent $_{\mathrm{T} 1}$ + WINGS + Relationships ${ }_{\mathrm{T} 1}^{*}$ WINGS + Covariates

SR Parent $\mathrm{T}_{2} \sim$ Relationships $\mathrm{T} 1+$ Events $_{\mathrm{T} 1}+$ Financial $_{\mathrm{T} 1}+$ SR Parent $\mathrm{T} 1$ + WINGS + Events ${ }_{\mathrm{T} 1}^{*}$ WINGS + Covariates

SR Parent ${ }_{\mathrm{T} 2} \sim$ Relationships $_{\mathrm{T} 1}+$ Events $_{\mathrm{T} 1}+$ Financial $_{\mathrm{T} 1}+$ SR Parent $_{\mathrm{T} 1}$ + WINGS + Financial ${ }_{\mathrm{T} 1}^{*}$ WINGS + Covariates

SR Teacher $_{\mathrm{T} 2} \sim$ Relationships $_{\mathrm{T} 1}+$ Events $_{\mathrm{T} 1}+$ Financial $_{\mathrm{T} 1}+$ SR Teacher $_{\mathrm{T} 1}$ + WINGS + Relationships ${ }_{\mathrm{T} 1}^{*}$ WINGS + Covariates

SR Teacher $_{\mathrm{T} 2} \sim$ Relationships $_{\mathrm{T} 1}+$ Events $_{\mathrm{T} 1}+$ Financial $_{\mathrm{T} 1}+$ SR Teacher $_{\mathrm{T} 1}$ + WINGS + Events ${ }_{\mathrm{T} 1}^{*}$ WINGS + Covariates

(GLM 14)

SR Teacher $\mathrm{T}_{2} \sim$ Relationships $\mathrm{T}_{1}+$ Events $_{\mathrm{T} 1}+$ Financial $_{\mathrm{T} 1}+\mathrm{SR}_{\text {Teacher }} \mathrm{T}_{1}$ + WINGS + Financial $\mathrm{T} 1^{*}$ WINGS + Covariates 
Each regression equation used to answer Research Question 3 (i.e., GLMs 7-15) modeled the interaction between the WINGS enrollment moderator and one stressful context of parenting. Because these lower-order predictors were simultaneously modeled, and due to the differential scaling of the variables, excessive correlations between the predictors and the interaction term were likely to be introduced in each model. However, this so-called "nonessential multicollinearity" (which would result in inflated standard errors and reduced accuracy of the regression estimates) was easily preventable by rescaling the variables using a simple linear transformation. More specifically, the two lower-order predictors involved in each model's interaction were mean-centered prior to analyses (Cohen et al., 2003; Fairchild \& McQuillin, 2010). All additional continuous covariates (i.e., the remaining stressful contexts of parenting and children's age at pretest) were also centered around their respective means prior to the analyses, per recommendations from the literature (Cohen et al., 2003). The remaining dichotomous covariates were left with their original dummy-codes.

Linear transformations for continuous predictors were achieved by subtracting the variable's mean from each case's observed score (Centered $\left.X=X_{\text {observed }}-\bar{X}\right)$, such that the centered variables' means equaled zero. Because treatment and control groups were unequal in size, the dummy-coded dichotomous WINGS enrollment moderator was mean-centered by re-coding values to Treatment $=.42$ and Control $=-.58$, such that the centered moderator's mean equaled zero. The three interaction terms used in GLMs 7-15 (i.e., Relationships $\times$ WINGS, Events $\times$ WINGS, and Financial $\times$ WINGS) were 
calculated by taking the products of the centered moderator and each respective centered predictor.

Results. The following sections, organized by hypothesis, describe the results of the 15 regression models that were tested, as well as the results of follow-up analyses.

Hypothesis 1. Hypotheses 1 was that the stressful contexts of parenting would relate to Black children's self-regulatory skills at kindergarten entry. Results of the first regression analysis (GLM 1) provided partial support for Hypothesis 1. Parents' stressful life events significantly and negatively related to direct assessments of children's selfregulatory abilities at kindergarten entry after controlling for children's age, biological sex, preschool enrollment status, and socioeconomic status (Table 10; Figure 5, panel A). Specifically, for each standard deviation increase in stressful life events, there was a corresponding .29 standard deviation decrease in children's self-regulation as measured by direct assessments, $B=-.04, \mathrm{SE}=.01, \beta=-.29,95 \% \mathrm{CI}[-.06,-.01], p<.01$. Neither challenging parent-child relationships nor parents' financial strain was significantly related to direct assessments of children's self-regulation. However, biological sex was a significant predictor: boys scored 9.42 points lower on direct assessments of selfregulation compared to girls, $B=-9.42, \mathrm{SE}=3.70, \beta=-.26,95 \% \mathrm{CI}[-16.68,-2.16], p<$ .05 . This finding is consistent with the self-regulation literature on early childhood gender differences in self-regulation (Kochanska et al., 2001; McClelland et al., 2015). Overall, the model explained approximately $17 \%$ of the variance in direct assessments of children's self-regulatory skills at kindergarten entry, $R^{2}=.17$. 
Results of GLM 2 provided no additional support for Hypothesis 1. None of the predictors of interest were significantly related to parent-reports of children's selfregulation at kindergarten entry (Table 10; Figure 5, panel B). However, $15 \%$ of the variance in parents' pre-test reports of their children's self-regulation was accounted for, $R^{2}=.15$.

Results of GLM 3 were partially consistent with Hypothesis 1. Challenging parent-child relationships were significantly and negatively related to teacher-reports of children's self-regulatory abilities at kindergarten entry, after controlling for children's age, biological sex, preschool enrollment status, and socioeconomic status (Table 10; Figure 5, panel C). Specifically, for one standard deviation increase in challenging parent-child relationships (i.e., as more conflict and distance were present in the relationships), there was a corresponding .24 standard unit decrease in teachers' assessments of children's self-regulatory abilities at kindergarten entry, $B=-.43, \mathrm{SE}=$ $.17, \beta=-.24,95 \%$ CI $[-.76,-.10], p<.05$. Overall, the model explained approximately $18 \%$ of the variance in teachers' reports of children's self-regulation at kindergarten entry, $R^{2}=.18$. An additional finding of interest was that teacher-reports of children's self-regulation at kindergarten entry were also significantly related to whether children attended preschool during the prior academic year. Teachers rated children who attended preschool as showing significantly better self-regulatory skills at baseline compared to children who did not attend preschool-a difference of approximately .6 units on the 5point rating scale used by teachers, $B=.59, \mathrm{SE}=.16, \beta=.23,95 \% \mathrm{CI}[.27, .91], p<.01$. This apparent advantage of having attended preschool on children's self-regulatory skills 
is consistent with the known benefits of preschool on children's social-emotional and behavioral school readiness (Mashburn et al., 2008; Mashburn \& Pianta, 2006;

McClelland et al., 2015; Wanless et al., 2011). Nonetheless, it is curious that this benefit was detected by teachers but not by assessors or parents.

Hypothesis 2. Hypothesis 2 was that the stressful contexts of parenting would relate to Black children's development of self-regulatory skills during kindergarten. The second set of regression analyses examined the associations between stressful contexts of parenting and changes in children's self-regulation from the beginning to the end of kindergarten by modeling children's post-test self-regulation (direct assessment, parentreport, and teacher-report) as the outcome measures for GLMs 4, 5, and 6, respectively, and controlling for the corresponding measure of self-regulation at pre-test. However, Hypothesis 2 was largely unsupported by GLMs 4-6. After controlling for baseline selfregulation, WINGS enrollment status, children's age, biological sex, preschool enrollment status, and socioeconomic status, the stressful contexts of parenting did not significantly predict children's self-regulation at the end of kindergarten as measured by direct assessment (Table 11; Figure 6, panel A) or by teacher report (Table 11; Figure 6, panel C). Parents' stressful life events did, however, significantly predict slower rates of improvement in children's parent-reported self-regulation, as predicted: For each standard deviation unit increase in parents' stressful life events, there was a corresponding .27 standard deviation decrease in their reports of their children's selfregulation at post-test, $B=.001, \mathrm{SE}=.000, \beta=-.27,95 \% \mathrm{CI}[-.002,-.000], p<.05$ (Table 11; Figure 6, panel B). 
Overall, however, the predictors accounted for a sizable portion of the variance of the self-regulatory outcome modeled by each regression equation. Specifically, approximately $35 \%$ of the variance in post-test direct assessments of children's selfregulation was accounted for by the predictors modeled by GLM $4, R^{2}=.35$. Likewise, approximately $35 \%$ of the variance in post-test parent-reports of children's self-regulation was accounted for by the predictors modeled by GLM $5, R^{2}=.35$. Approximately $55 \%$ of the variance in post-test teacher-reports of children's self-regulation was accounted for by the predictors modeled by GLM $6, R^{2}=.55$. The large proportions of variance explained by each model is largely due to the strong significant predictive relationships between the pre-test and post-test measures of self-regulation in each model: For each standard deviation increase in direct assessment scores of children's self-regulation at pre-test, there was a corresponding .42 standard unit increase in post-test direct assessment scores, $B=.42, \mathrm{SE}=.09, \beta=.42,95 \% \mathrm{CI}[.24, .60], p<.01$. For each standard deviation increase in children's parent-reported self-regulation at pre-test, there was a corresponding .25 standard unit increase in their parent-reported scores at post-test, $B=$ $.25, \mathrm{SE}=.12, \beta=.25,95 \% \mathrm{CI}[.01, .49], p<.05$. Finally, for each standard deviation increase in children's teacher-reported self-regulation at pre-test, there was a corresponding .70 standard unit increase in their teacher-reported scores at post-test, $B=$ $.75, \mathrm{SE}=.08, \beta=.70,95 \% \mathrm{CI}[.60, .90], p<.01$.

Hypothesis 3. Hypothesis 3 was that the predicted negative impacts of the stressful contexts of parenting on Black children's development of self-regulatory skills during kindergarten would be moderated by whether children had been assigned to the 
WINGS afterschool program. Thus, measures of children's post-test self-regulation (direct assessment, parent-report, and teacher-report) were modeled as the outcome measures for GLMs 7-9, 10-12, and 13-15, respectively, with each model controlling for the corresponding measure of self-regulation at pre-test. WINGS enrollment status was included in each model as the moderator, and an interaction term was added to each, representing the interaction between WINGS enrollment and a single stressful context of parenting. As described previously, all continuous predictors (including main predictors and covariates) and the dichotomous moderator were mean-centered prior to conducting the third set of regression analyses, to reduce nonessential multicollinearity in the models. The terms representing the interactions between each stressful context of parenting and children's WINGS enrollment status on their self-regulatory outcomes were not altered by the scaling of the predictors (Cohen et al., 2003; Fairchild \& McQuillin, 2010).

Overall, results generally did not support Hypothesis 3. Children's enrollment status in the WINGS afterschool program did not significantly moderate the relationships between stressful contexts of parenting and children's self-regulatory development as assessed by direct assessments (Table 12; Figure 7), parent-reports (Table 13; Figure 8), and teacher-reports (Table 14; Figure 9). Similarly, all but one of the interaction terms tested by GLMs 7-15 did not significantly predict children's self-regulatory development. However, the interaction between parents' stressful life events and children's WINGS enrollment was a statistically significant predictor of children's teacher-reported selfregulatory development, $B=-.003, S E=.001, \beta=-.27, p<.001$ (GLM 14; Table 14; Figure 9, panel B). Approximately $62 \%$ of the variance in teacher-reported self- 
regulation at post-test was accounted for by the predictors modeled by GLM 14, $R^{2}=.62$. A summary of findings for the current three research questions is included in Table 15.

Plotting the interaction. Follow-up analyses were conducted to further examine the differential impacts of parents' stressful life events on children's teacher-reported self-regulatory development between the WINGS and control groups. Specifically, a simple slopes test was conducted to determine whether the relationships between parents' stressful life events and teacher-reported self-regulation for each group were statistically significant, and a bar graph was created to visualize the nature of the interaction. Before the follow-up analyses were conducted, however, z-score transformations were conducted on all continuous independent variables, such that the variable means were equal to zero, and their standard deviations were equal to one. The z-score transformations simplified the next step, which was to manually plot data for children whose parents had experienced the average level of stressful life events, who had experienced low levels of stressful life events (one standard deviation below the mean), and who had experienced high levels of stressful life events (one standard deviation above the mean). Additionally, data were plotted for children who had been randomly assigned to the WINGS afterschool program and for those who had been randomly assigned to the control group. The model intercept and unstandardized regression coefficients from GLM 14 were used to calculate the expected teacher-reported selfregulation scores at post-test for the six groups made up by the WINGS-by-stressful life events interaction. 
Results of the simple slopes test indicated that there was no relationship between parents' stressful life events and teachers' ratings of children's self-regulation among children in the treatment group, $B=-.01, S E=.00, p=n s$, as would be expected if assignment to the WINGS afterschool program buffered children's self-regulatory development from exposure to stressful life events, as hypothesized. However, rather than the expected negative relationship for the control group, there was a very small but significant positive relationship between parents' stressful life events and teachers' ratings of children's self-regulation among children in the control group, $B=.02, S E=$ $.01, p<.001$. These relationships are depicted in Figure 10. The results of the follow-up analyses appear to contradict Hypothesis 3, which stated that enrollment in WINGS would buffer against or compensate for the negative impacts of the stressful contexts of parenting on children's self-regulatory development. By contrast, the results indicated that having parents who reported experiencing more stressful life events predicted more growth of children's self-regulatory skills, not less growth. Furthermore, children who were not randomly assigned to the WINGS afterschool program appeared to have been rated by their teachers as showing better self-regulation at post-test compared to WINGS children.

\section{Chapter 6: Discussion}

The current study's hypotheses were largely unsupported by the data. However, there were several compelling results, especially when examining the standardized coefficients and considering the small sample size which may have accounted for statistically non-significant findings despite clear trends in the data. The primary insight 
gained by the current study was that parents' stressful life events were the best predictor of children's diminished self-regulation at kindergarten entry as well as slower rates of development of self-regulation during kindergarten. Parents' stressful life events were also the only stressful context of parenting that interacted with children's enrollment in the WINGS afterschool program to predict development of self-regulation during kindergarten. However, the role that WINGS played in buffering children from the negative effects of stressful life effects was in the opposite direction compared to what was hypothesized. More specifically, higher parental stressful life events predicted greater self-regulation at post-test among children not assigned to WINGS compared to children enrolled in WINGS. There are several possible explanations for this apparent iatrogenic effect of the WINGS intervention on children's self-regulatory development for this subset of children. For example, the day-to-day atmosphere of the WINGS afterschool program has been described as chaotic and disorganized, as many large-group afterschool programs may be. Children attending the afterschool program may not have benefited from the SEL instruction as much as predicted, or the benefits may have been undermined by the playful chaos that characterized the program. Another possible explanation is that children attending the WINGS afterschool program may have missed out on valuable time at home with their families, during which they may otherwise have been able to rest and recover from the school day and practice their social and emotional skills with parents, siblings, and other family members. This interpretation of the current findings is in line with theory and research on the strengths of Black families. These sociocultural strengths of ethnic-minoritized families, which include strong extended- 
family bonds as well as childrearing values, beliefs, and goals, may have protected children in the current sample (and especially those in the control group) from the developmental hazards associated with poverty (Baker \& Iruka, 2013; Coll et al., 1996). Nonetheless, it would seem unreasonable to conclude from the current findings alone that assignment to or participation in the WINGS afterschool program had an unintended iatrogenic effect on children's self-regulatory development. It is notable that this unexpected interaction effect was observed only with respect to the teacher-reported self-regulation outcome, and not for direct-assessments or parent-reports of children's self-regulatory development. An alternative explanation for the observed relationship, therefore, is that at the end of kindergarten, teachers may have held higher expectations for self-regulated behaviors among WINGS children than they did for children who were not assigned to attend the afterschool program.

This explanation is in line with the conceptual framework provided by shifting standards theory, which states that teachers judge children's behaviors relative to the group to which they belong (Gilliam et al., 2016). In the context of the current findings, shifting standards theory would suggest that teachers may have been more lenient when assessing the behaviors of children who were not granted the opportunity to attend the (presumably beneficial) afterschool program and who were being raised under more stressful contexts of parenting, because teachers held lower expectations for these children. This possible explanation aside, the very small effect size of the interaction effect and the fact that just one out of the twelve interactions tested yielded significant 
results indicate that the results of the simple slopes test should be interpreted with caution.

An additional finding of interest was that the measures of children's selfregulatory abilities at pre-test (i.e., direct assessments, parent-reports, and teacherreports) were unrelated with one another, despite significant positive correlations at posttest (Table 3). This apparent contradiction can be explained by the fact that, at kindergarten entry, children's behavioral regulation cannot reasonably be expected to be consistent across three unique settings - their behavior may in fact be different at home versus in the classroom versus in a lab assessment setting. After one year of school, however, teachers' and parents' expectations for children's regulated behaviors may be more aligned with one another. Children's self-regulatory experiences and practice during kindergarten may also then translate to the less naturalistic context of a direct assessment of their self-regulation competencies by research assistants.

A final finding of interest was that parents' financial strain did not significantly relate to children's self-regulatory skills or development in any of the tested models. On the other hand, children's eligibility for their schools' free and or reduced lunch programs — a proxy for low socioeconomic status or financial hardship — was a strong and consistent predictor of slower self-regulatory development during kindergarten (Table 11). This apparent contradiction in the data also reflects a contradiction with the family stress model, which suggests that heightened financial strain mediates the adverse impacts of financial hardship on children's development. The results of the current study, however, indicate that while financial hardship (i.e., children's free/reduced lunch status) 
predicted slower self-regulatory development, parents' financial strain had no impacts on children's outcomes. One potential explanation for this finding is that the negative consequences of poverty are more proximal to children's developmental outcomes - that is, that the effects of financial hardship are felt directly by children and are visible in their slower self-regulatory development. Additionally, parents surprisingly reported relatively low financial strain $(M=2$ out of $5, S D=.97)$, possibly suggesting that the financial strain scales used were not sensitive to the full range of parents' psychological responses to financial hardship. More optimistically, however, it is possible that parents in fact experienced low financial strain despite the high poverty rates in the sample — a sign of resilience among economically disadvantaged parents. Still, low parental financial strain despite high economic hardship may be insufficient in protecting children from the adverse impacts of poverty. Future work should continue to explore relationships between economic hardship, financial strain, and child outcomes, in the theoretical context of the family stress model as well as in alternative theoretical models.

\section{Implications}

The results of the current study have several key implications for research, practice, and policy. First, the results demonstrated that parents living in poverty experience extremely elevated levels of stressful life events, which is consistent with previous findings of the hazardous ecological conditions and experiences related to poverty (Evans, 2004). Additionally, parents' heightened stressful life events predicted lower self-regulatory skills at kindergarten entry and slower rates of development of selfregulatory skills during kindergarten. Interpretations of these findings that attribute blame 
for children's dysregulated behaviors to parents who are navigating recent stressful experiences would be unjust and imprudent; such interpretations would fail to recognize the downward pressures exerted on both parents and children by sociopolitical systems of wealth inequality, racism, and oppression. On the contrary, results of the moderation analyses suggested that parents who had experienced greater stressful life events and whose children were not enrolled in the presumably beneficial SEL afterschool program, may have had tools with which to better support their children's self-regulatory development. More work is certainly warranted to better understand the parenting and family processes that appeared in the current study to support Black children's development in spite of the stressful contexts in which parents and children lived.

Secondly, parents in the current study also reported relatively low levels of interpersonal conflict and emotional distance in their relationships with their children, as well as low financial strain, despite the economic hardships and stressful life events they experienced. These findings are profoundly encouraging; they suggest that parents may have protected children against some of the harmful effects of poverty by providing emotionally supportive and warm relationships. Social programs and SEL interventions should continue working to alleviate parents of financial hardship and the psychological distress associated with stressful life events. Interventions that provide instrumental and social-emotional supports for parents of young children in poverty can be critical resources for promoting the quality of their relationships with children as well as their children's educational outcomes. Additionally, interventions should provide resources 
that promote parents' adaptive psychological responses to daily stressors and that target the sources of those stressors directly.

\section{Study Strengths, Limitations, and Future Directions}

This study had three key strengths. First, by narrowing the sample to examine the development and educational experiences of Black children specifically, this study answered longstanding calls from researchers to conduct non-comparative research of Black children and families. More specifically, this study avoided making comparisons based on racial identity by evaluating within-group variance of participants' experiences, as opposed to making between-group comparisons in which marginalized groups are evaluated against standards that favor more privileged groups (Coll et al., 1996). Second, the current study's use of multiple indicators and multiple data sources to triangulate on children's self-regulatory competencies (i.e., direct assessment of EF, and parent- and teacher-reports of behavioral regulation) at two time points was a strength of the study design. Finally, the current may strengthen the SEL program literature, which lacks research that specifically examines the roles of social-emotional learning in naturalistic developmental processes that occur in contexts beyond the classroom. The current study addressed these gaps by examining children's development of self-regulation in multiple contexts, as well as by examining the interacting developmental roles of stressful contexts of parenting and enrollment in an afterschool (as opposed to a classroom-based) SEL program.

This study also had several limitations, most evidently of which was its small sample size, which may have resulted in underpowered analyses. With the exception of 
parents' financial strain, the relationships between the stressful contexts of parenting and children's self-regulatory skills and development, although not statistically significant, were largely in the hypothesized directions. It is possible that these relationships would reach levels of statistical significance with a larger sample.

Secondly, an additional possible explanation for the lack of evidence supporting the hypotheses is that the study design relied exclusively on parent-reports of the stressful contexts of parenting. Parents may be unreliable or biased informants related to their parenting styles or behaviors and their relationships with their children. This may be particularly true for parents who (justifiably) harbor mistrust towards researchers, or for those who wish to cast themselves in a socially desirable light for educators, for example by exaggerating the extent to which they are good, responsible, and nurturing parents. This consideration may be especially pertinent given the power dynamics that were likely at play during the administration of the current study - the sample of Black children and parents were assessed and interviewed by White researchers. In future work, direct assessments of children's exposure to the stressful contexts of parenting (e.g., observations of parent-child interactions in a naturalistic or laboratory setting) would yield potentially useful information for assessing the reliability and robustness of corresponding parent-reported measures. Just as parents may be unreliable or biased informants of their relationships with their children, parents, teachers, and assessors may each be unreliable or biased sources of information about children's self-regulatory functioning. However, the current study's use of multiple perspectives of children's self- 
regulation, and the fact that the three sources converged at post-test, suggest that interrater agreement of children's self-regulation was not problematic.

A third limitation of the current study was that the measures of families' socioeconomic status and financial strain were relatively limited in scope, a deficit which may have resulted in restriction of range of the financial hardships and strain variables. On the other hand, chronic poverty (i.e., economic hardship assessed longitudinally), has been found to be a much stronger predictor of children's EF compared to indicators of poverty or financial strain taken at a single time point (Raver et al., 2013). Chronic poverty should therefore be modeled in future work.

A fourth limitation of the current study was that the direct assessment measure of children's self-regulatory competencies was unable to distinguish among the individual executive functions responsible for children's regulated behavior (i.e., cognitive flexibility, working memory, and inhibitory control). Unlike other lab-based direct assessments which can be more attuned to these individual cognitive processes, the HTKS task is a measure of children's global EF.

Fifth, the current study did not account for attendance or participation in the afterschool program, and was therefore unable to control for individual variations in program dosage received by children enrolled in WINGS. Likewise, afterschool activities of the control group children were not measured and therefore could not be modeled (Durlak, 2010). The current study used an intent-to-treat (ITT)—as opposed to a treatment-on-treated (TOT) — design. While the current study was not a randomized control trial and was not beholden to the same design-related demands of an efficacy 
study, it would have been bolstered by statistically accounting for the effects of WINGS program dosage. Future research on the WINGS program would benefit by explicit and principled examinations of the many dimensions of implementation fidelity (Durlak, 2010).

There are also several clear future directions for follow-up analyses using the WINGS data currently available, extending beyond the scope of the current study. For example, future work would should use mediational models to examine causal relationships between children's exposure to the stressful contexts of parenting and their self-regulatory development. Specifically, the family stress model should be used to test the cascading effects of chronic poverty on children's development, via family stress processes such as financial strain, psychological distress, and interpersonal conflict. At least three timepoints would be required for the cascading effects of poverty on family and child outcomes to be modeled. However, the data collected through the multi-year WINGS study would meet this minimum requirement.

Secondly, the variables used to assess the stressful contexts of parenting should be investigated in greater detail. For example, future work should examine parent-child conflict and closeness (or emotional distance) as distinct constructs. Parents' stressful life events should similarly be examined in greater detail, for instance by grouping life stress inventory items into qualitatively distinct sub-dimensions (e.g., changes or unpredictability in individuals' home life, work life, family relationships, and health) and investigating which particular aspects of parents' stressful life events predict their young children's self-regulatory development. 
Third, the current study's inclusion of both financial hardship (i.e., SES) and financial strain variables in the statistical models may have resulted in each indicator masking the effects of the other. Future re-analyses of the current models should disentangle these constructs by removing the financial hardship indicators (i.e., children's free/reduced lunch status and parents' other public assistance status) to better capture families' economic need. A re-analysis of this nature would also help elucidate the paradoxical current finding that financial hardship (but not financial strain) predicted lower self-regulatory competencies.

Finally, person-centered analyses (e.g., cluster analyses, latent class analyses) should be used in future work to investigate the relationships between poverty, stressful contexts of parenting, and self-regulation among children with empirically distinct patterns of exposure to specific stressful contexts of parenting, or alternatively, among caregivers with distinct parenting behavior profiles. In addition to self-regulatory development, other important learning outcomes for children should be studied, including other social-emotional skill domains, such as emotion knowledge or quality of peer relationships and interactions.

\section{Conclusion}

This study supplemented past research by investigating whether Black kindergarteners' enrollment in an SEL afterschool program buffered the adverse consequences of stressful contexts of parenting on children's self-regulatory development during kindergarten. As hypothesized, parents' elevated stressful life events predicted children's lower self-regulatory abilities at kindergarten entry and slower development of 
self-regulatory skills during kindergarten. However, other stressful contexts of parenting (specifically, challenging parent-child relationships and parents' financial strain) largely did not predict children's self-regulatory skills or development in kindergarten, contrary to hypotheses. Also unexpectedly, children's enrollment in the WINGS afterschool program did not moderate the relationships between stressful contexts of parenting and self-regulatory development, with one exception: parents' stressful life events interacted with children's WINGS enrollment status to predict teacher-reported self-regulatory development during kindergarten. Although statistically significant, this lone interaction effect occurred in the opposite direction than was hypothesized, such that higher parental stressful life events predicted greater self-regulation at post-test among children who were not assigned to the intervention group, whereas children assigned to the WINGS program received no such benefit.

These puzzling results may be due to the limited sample size and insufficient statistical power, or due to psychometric problems related to the measures or informants used. Alternatively, the results of the current study may be an accurate depiction of the role of Black children's enrollment in the WINGS afterschool program on the adverse effects of their parents' stressful life events on their own self-regulatory development. The WINGS program may be less effective in promoting children's social-emotional skills than previously thought due to the chaotic nature of the day-to-day afterschool program activities or because WINGS children had fewer afterschool learning opportunities at home. Whatever the explanation, the current finding that the WINGS program may have had an iatrogenic effect on children's self-regulatory development 
should be interpreted with caution, because the interaction effect was only present when predicting teacher-reports of children's self-regulatory development. Shifting standards theory provides a plausible explanation for this finding (Gilliam et al., 2016)—it is possible that teachers held higher behavioral standards for children enrolled in WINGS than they did for children who did not receive the social-emotional supports that WINGS provided, and therefore rated the behavior of WINGS children more harshly.

Moreover, the current study demonstrated that, despite the hazardous and stressful material and psychosocial conditions of poverty, parents shared warm and supportive relationships with their children and showed resilience despite economic hardships. However, the harmful effects of parents' stressful life events were nonetheless able to reach their children's self-regulatory learning outcomes—controlling for children's enrollment in the WINGS afterschool program, increased stressful life events predicted slower self-regulatory development for kindergarteners. These findings are congruent with a fundamental notion - that protecting children from the harmful impacts of poverty does not require interventions that seek to correct poor children's classroom behaviors or to correct poor caregivers' parenting behaviors. Rather, to protect children from the impacts of poverty, our society - the wealthiest in the world - must eliminate poverty. In partial pursuit of this goal, SEL afterschool programs such as WINGS should continue to provide social-emotional supports - tools with which children and parents can be better equipped to navigate and overcome the hazardous and stressful conditions of poverty. However, more research is needed to evaluate the efficacy of such programs in promoting the full breadth of outcomes relevant to young children's school readiness and positive 
early learning experiences. Ongoing research must also examine the core components of SEL afterschool programs to determine which "active ingredients" contribute most substantially to children's development. Finally, as in the current study, future SEL prevention and intervention research should be devoted to understanding the specific ways in which the social-emotional and self-regulatory development of young Black children and children living in poverty can best be promoted and protected, to ensure their positive kindergarten transitions and long-term educational success. 
Tables and Figures

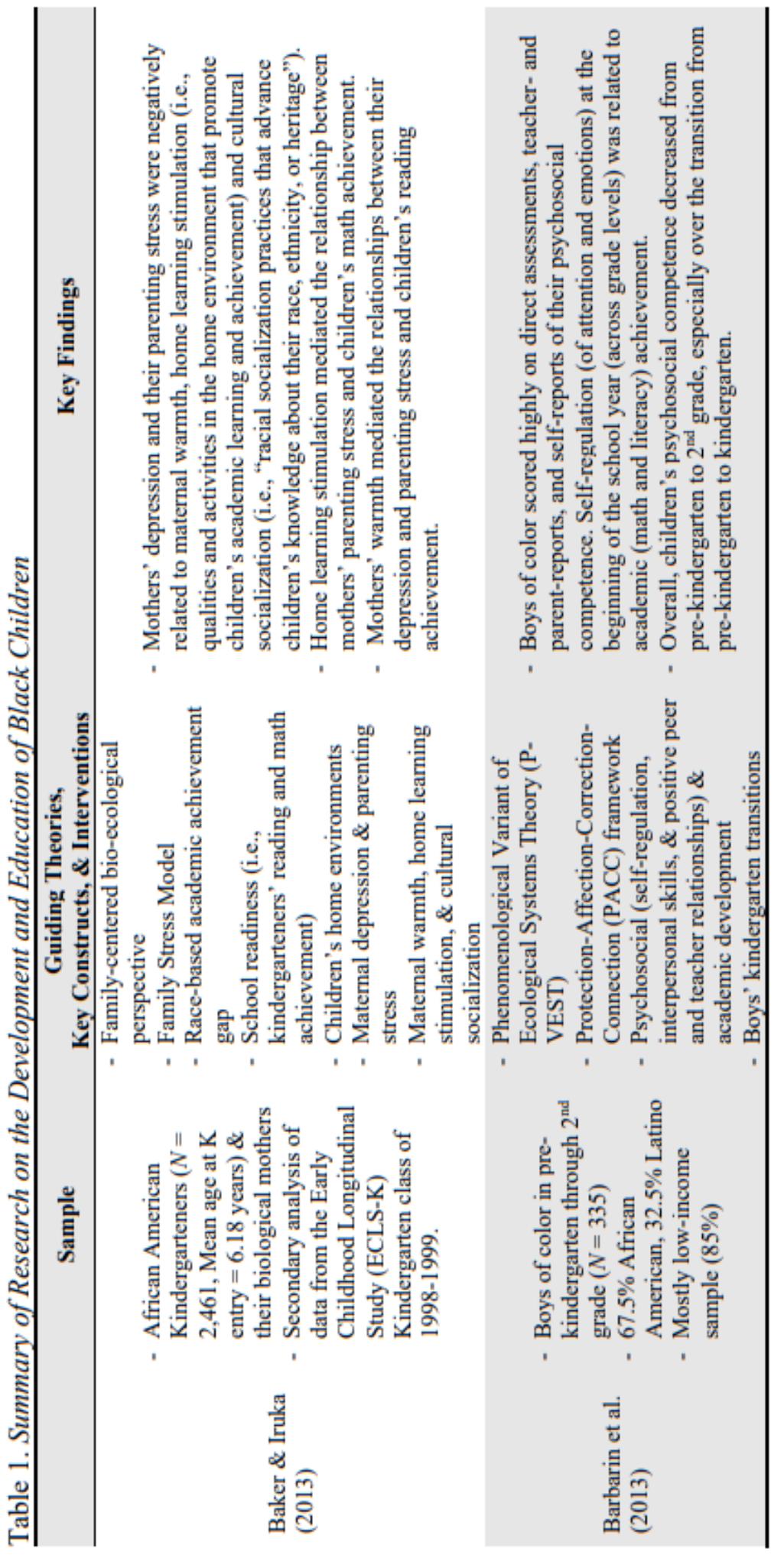




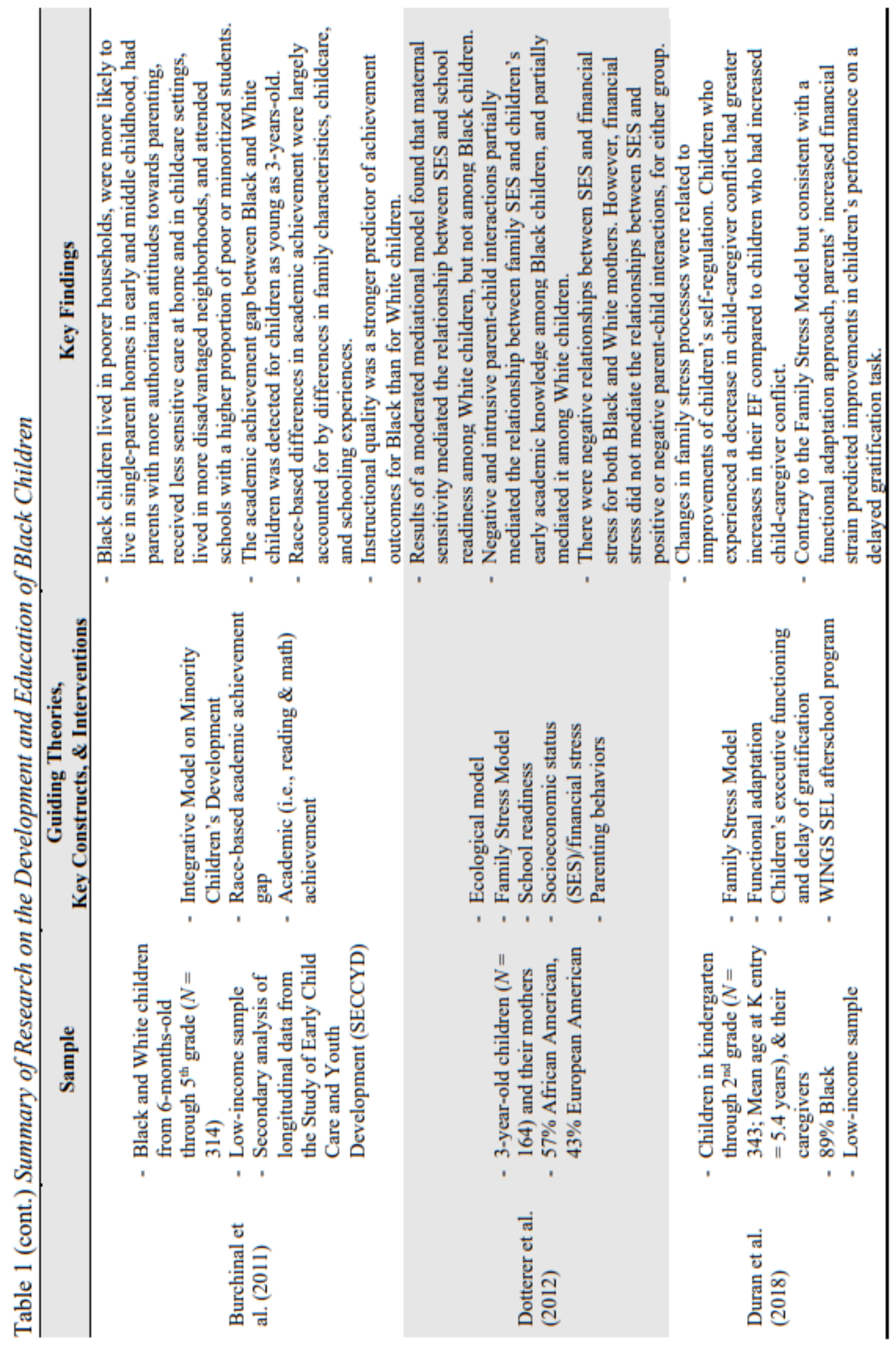




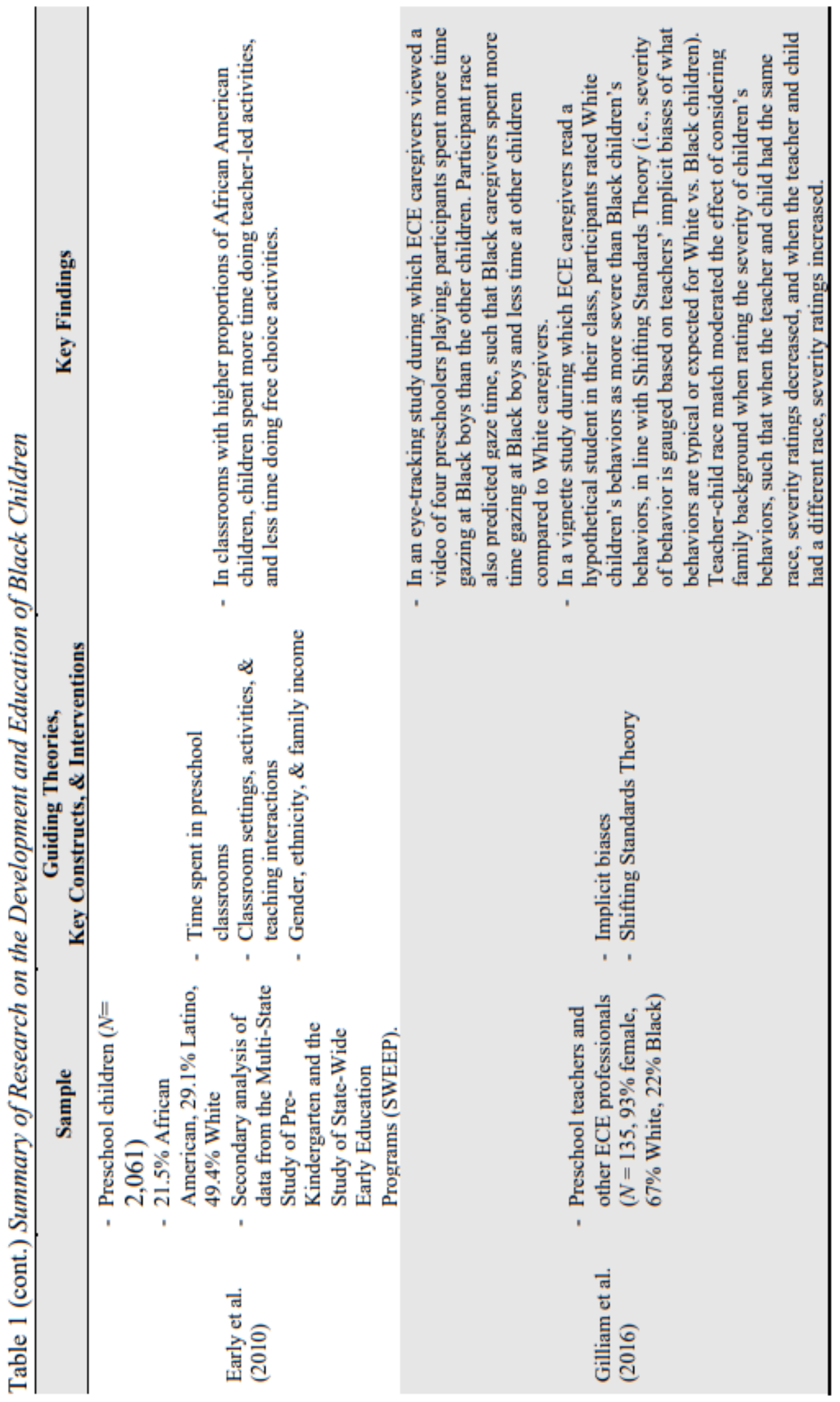




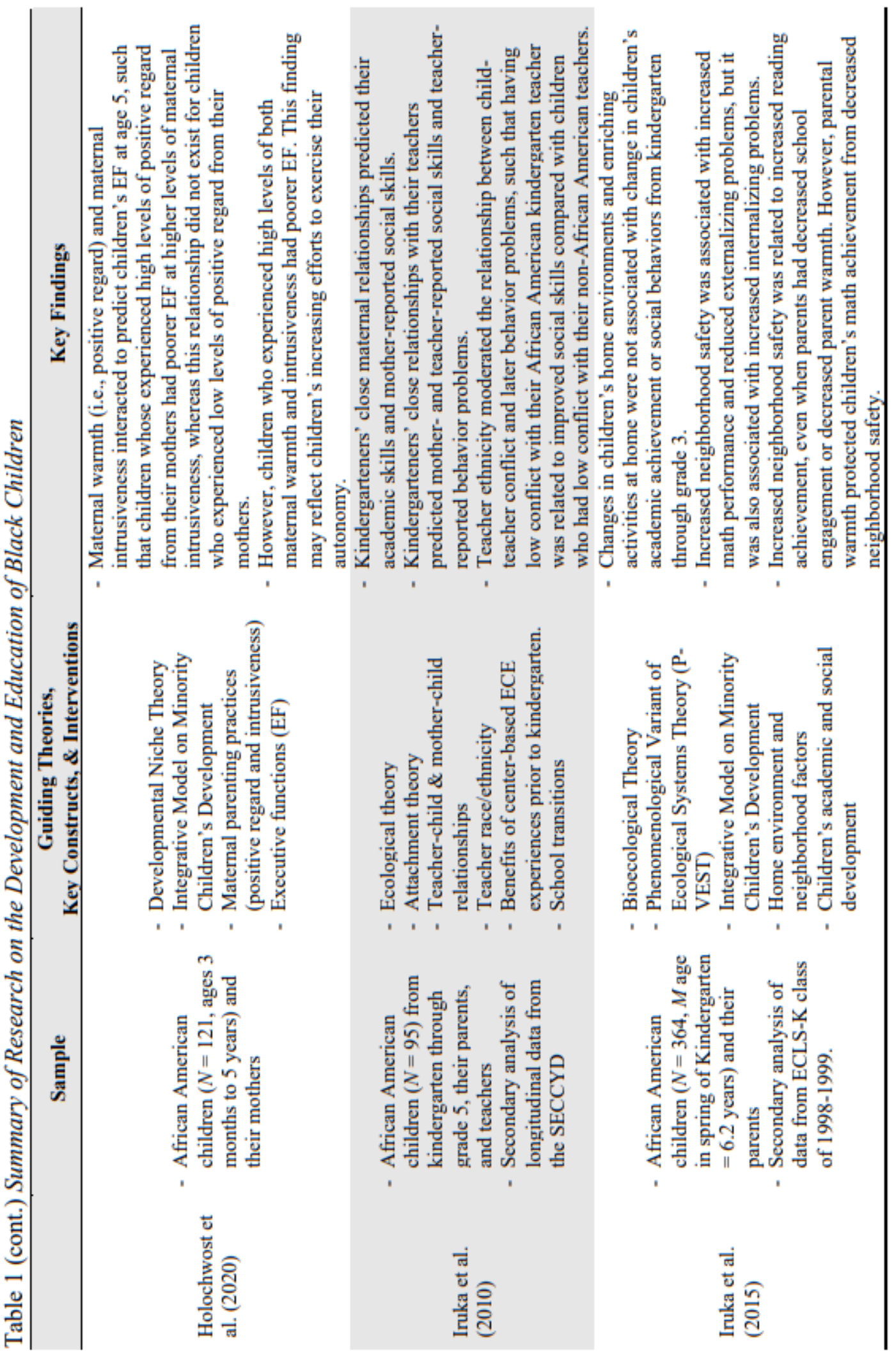




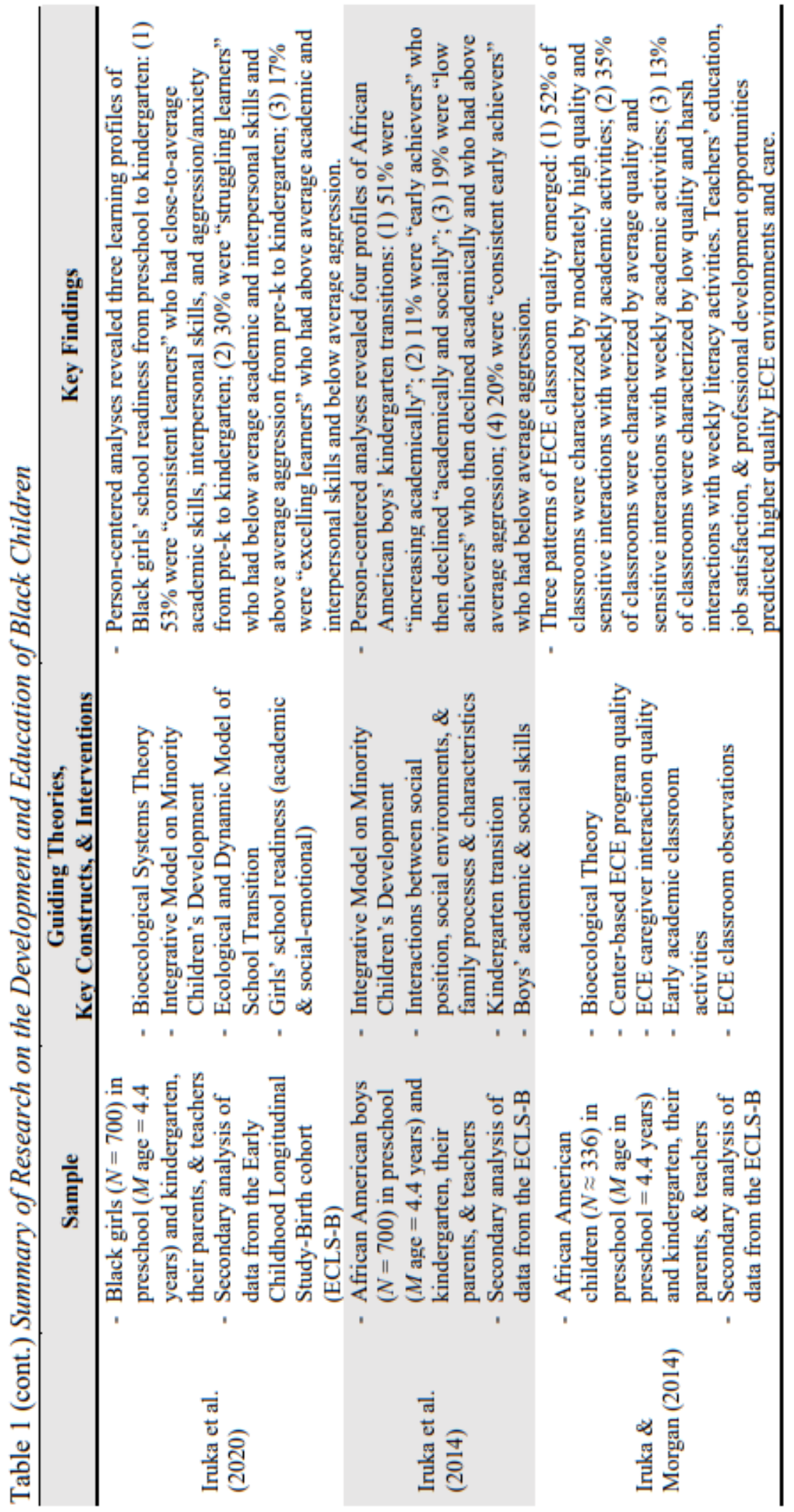




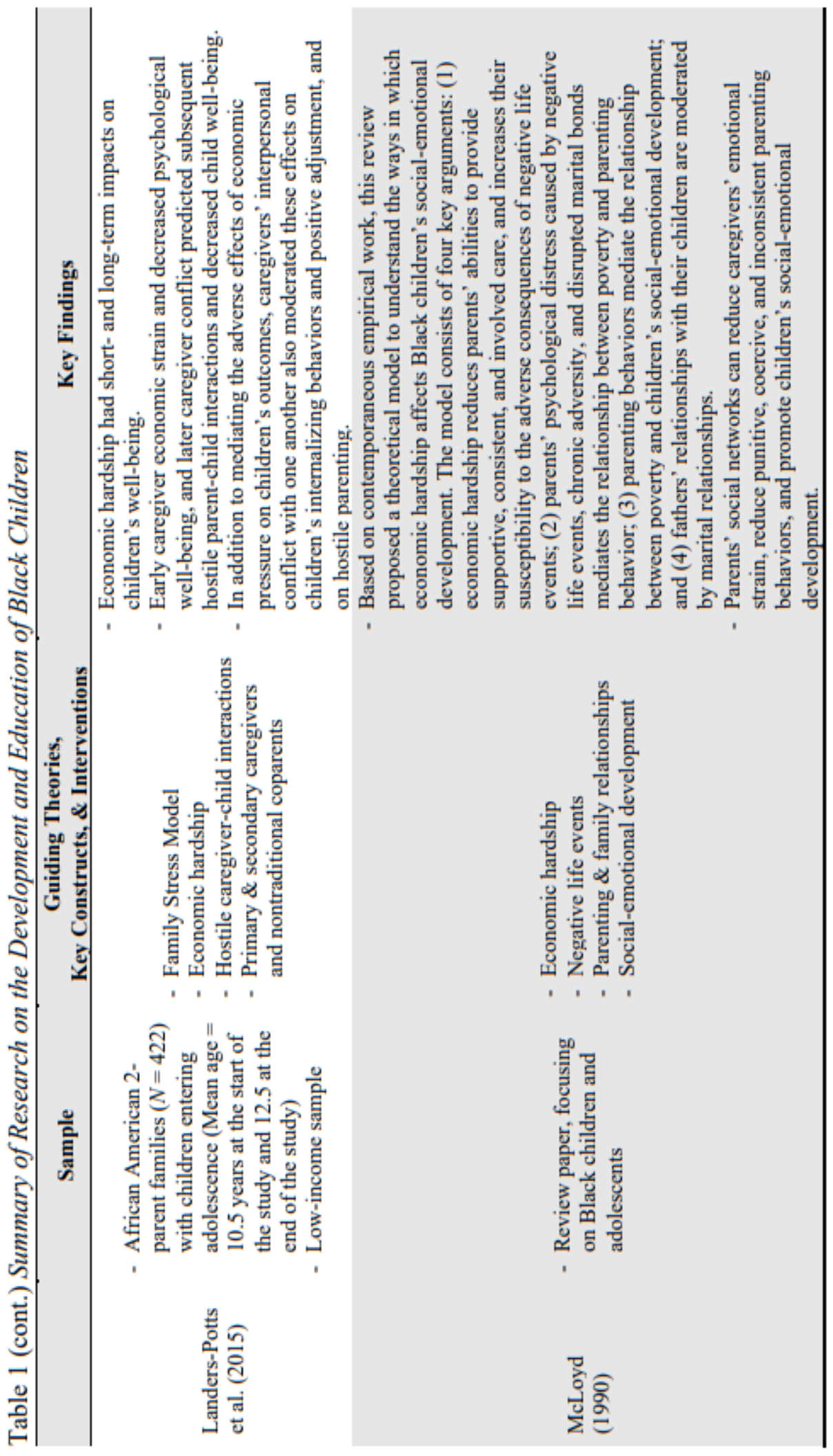




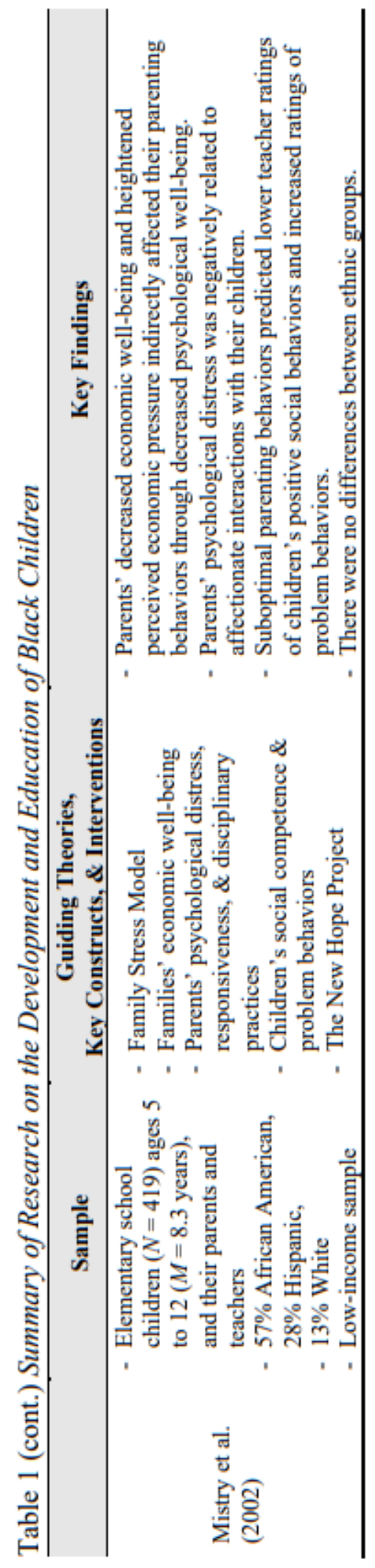




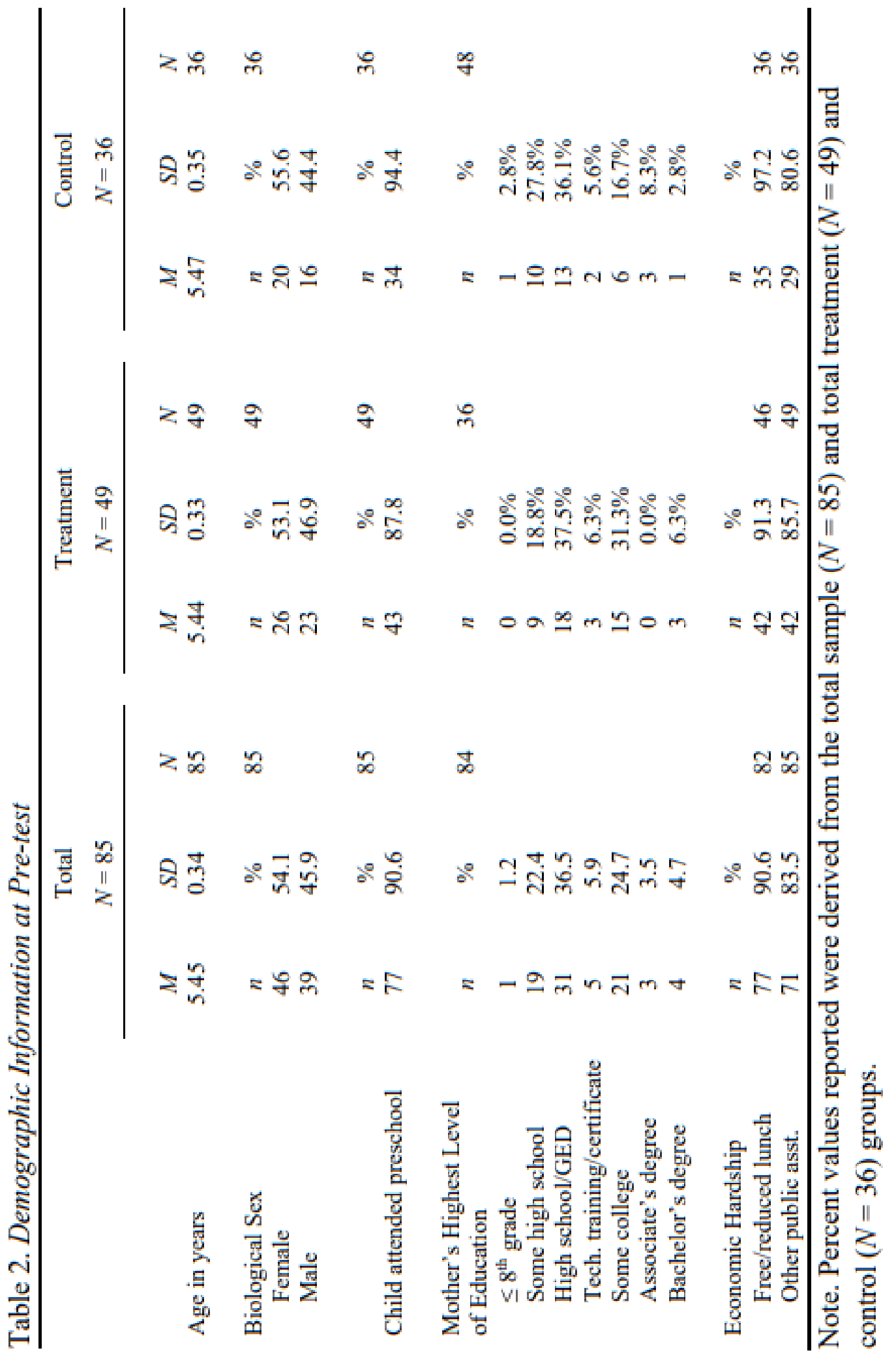




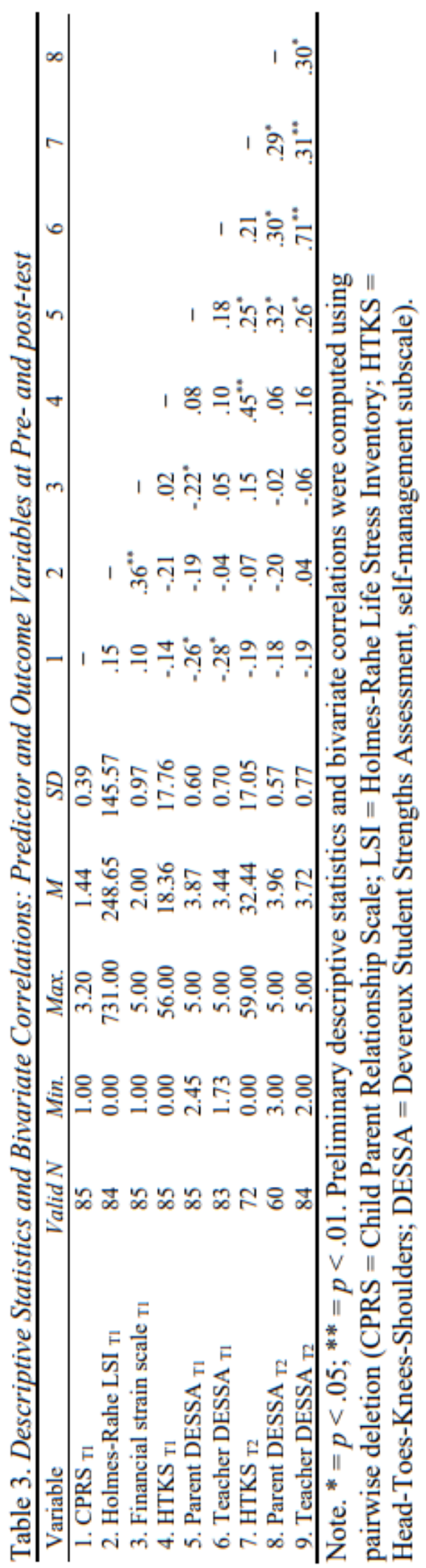


Table 4. Proportions of Missing Data among Predictor and Outcome Variables at Pre-and Post-test.

Predictor variables:

Stressful contexts of parenting

Challenging parent-child relationships $\quad 0.0 \% \quad n a$

Stressful life event

Financial strain

Post-test

$\begin{array}{ll}N=85 & N=85 \\ \begin{array}{l}\text { Percent } \\ \text { missing }\end{array} & \begin{array}{l}\text { Percent } \\ \text { missing }\end{array}\end{array}$

Outcome variables:

Self-regulation

Direct assessments $\quad 0.0 \% \quad 15.3 \%$

$\begin{array}{lll}\text { Parent-reports } & 0.0 \% & 29.4 \%\end{array}$

$\begin{array}{lll}\text { Teacher-reports } & 2.4 \% & 2.4 \%\end{array}$

Table 5. Potential Auxiliary Variables

$\begin{array}{ll}\text { 1. } & \text { School child attended } \\ \text { 2. } & \text { Time of data collection (summer or fall) } \\ \text { 3. Child's age at pre-test } \\ \text { 4. Child's biological sex } \\ \text { 5. Last year, did the child attend preschool or head start? (yes/no) } \\ \text { 6. Has this child been referred for special education services? } \\ \text { 7. How many times has this child moved in the last two years? } \\ \text { 8. Including the child, how many children live in the child's home? } \\ \text { 9. Including the parent, how many adults live in the child's home? } \\ \text { 10. Does the child receive free or reduced lunches at school? (yes/no) } \\ \text { 11. Does the parent currently receive any other types of public assistance? (yes/no) } \\ \text { 12. What is the highest level of education of this child's mother? } \\ \text { 13. What is the primary caregiver's employment status? (full time/part time/unemployed) }\end{array}$




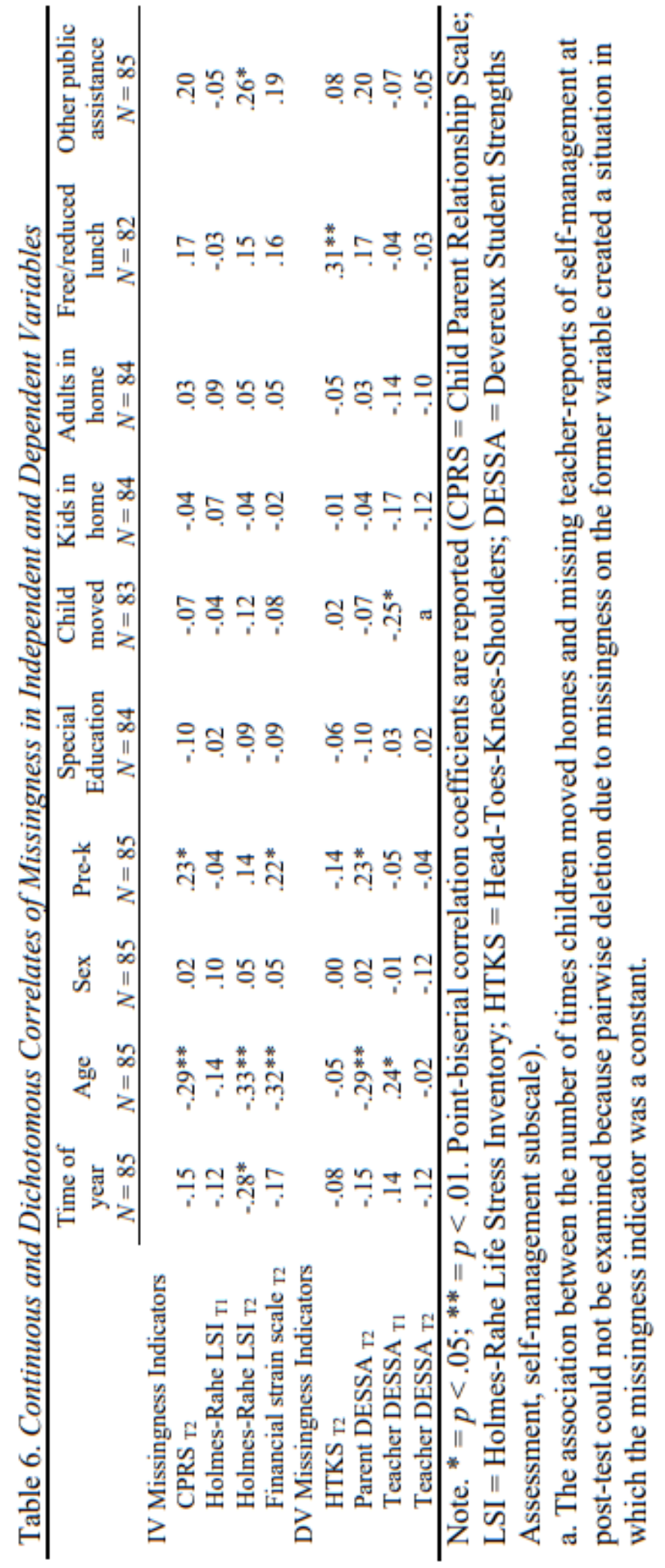


Table 7. Categorical Correlates of Missingness in Independent and Dependent Variables

\begin{tabular}{|c|c|c|c|}
\hline & $\begin{array}{l}\text { School } \\
N=85\end{array}$ & $\begin{array}{c}\begin{array}{c}\text { Mother's } \\
\text { education }\end{array} \\
N=84 \\
\end{array}$ & $\begin{array}{c}\text { Primary caregiver's } \\
\text { employment } \\
N=83 \\
\end{array}$ \\
\hline \multicolumn{4}{|l|}{ IV Missingness Indicators } \\
\hline $\mathrm{CPRS}_{\mathrm{T} 2}$ & .08 & .20 & .08 \\
\hline Holmes-Rahe LSI ${ }_{\mathrm{T} 1}$ & .17 & .14 & .11 \\
\hline Holmes-Rahe LSI ${ }_{\mathrm{T} 2}$ & .02 & .19 & .18 \\
\hline Financial strain scale ${ }_{\mathrm{T} 2}$ & .11 & .21 & .10 \\
\hline \multicolumn{4}{|l|}{ DV Missingness Indicators } \\
\hline HTKS $_{\mathrm{T} 2}$ & .18 & .25 & .20 \\
\hline Parent DESSA ${ }_{T 2}$ & .08 & .20 & .08 \\
\hline Teacher DESSA ${ }_{\mathrm{T} 1}$ & .20 & .20 & .20 \\
\hline Teacher DESSA ${ }_{T 2}$ & .15 & .19 & .11 \\
\hline
\end{tabular}



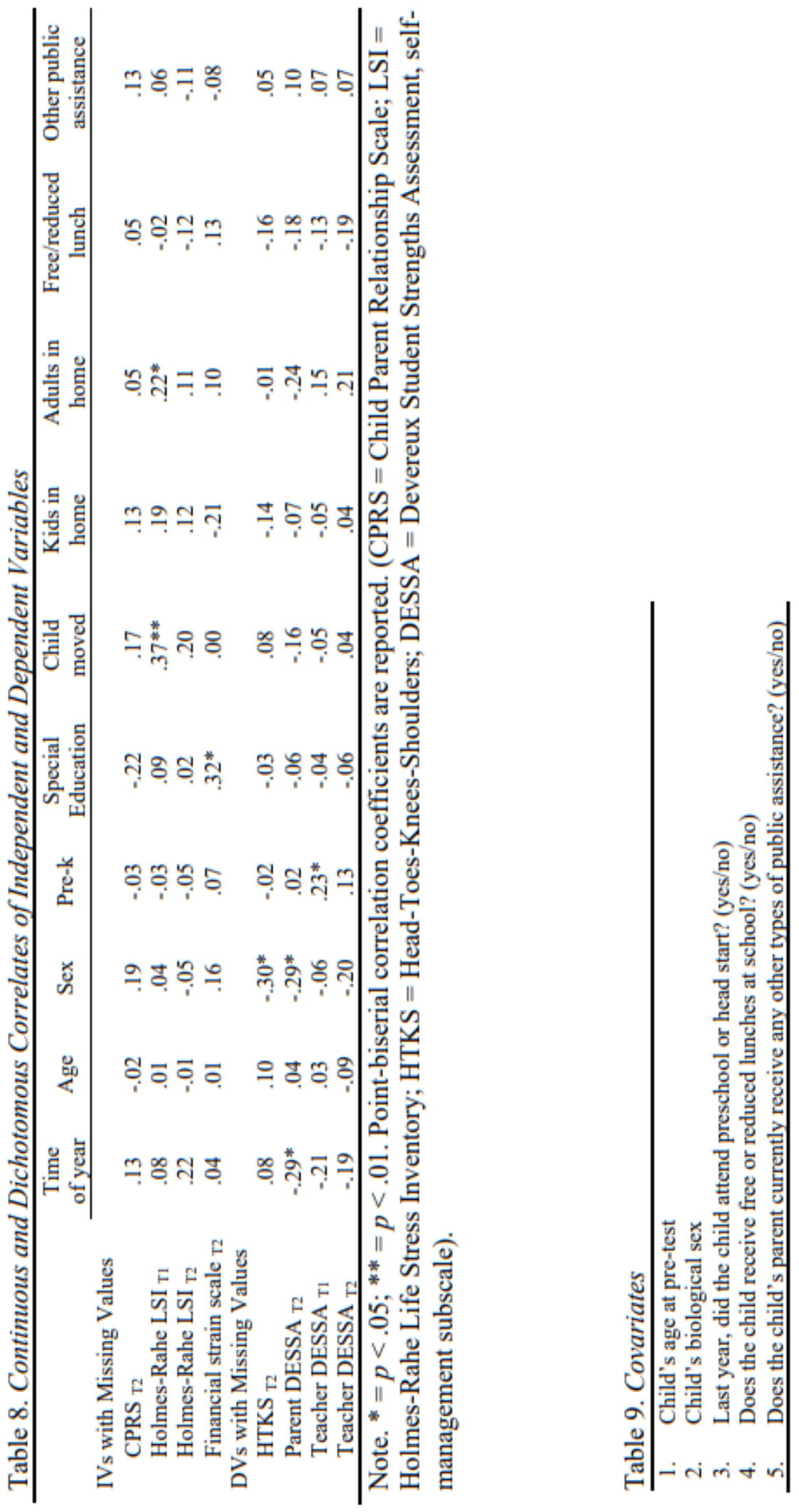
Table 10. RQ1: Regression Analysis Summary for the Stressful Contexts of Parenting Predicting Pre-Test Self-Regulation

\begin{tabular}{|c|c|c|c|c|}
\hline & $B$ & SE & $\beta$ & $95 \% \mathrm{CI}$ \\
\hline \multicolumn{5}{|l|}{ GLM 1: Direct Assessments of SR ${ }_{\mathrm{T} 1}$} \\
\hline Challenging parent-child relationships & -1.32 & 4.21 & -.03 & {$[-9.58,6.94]$} \\
\hline Stressful life events & $-.04 * *$ & .01 & $-.29 * *$ & {$[-.06,-.01]$} \\
\hline Financial strain & 1.92 & 2.32 & .10 & {$[-2.62,6.47]$} \\
\hline \multicolumn{5}{|l|}{ Covariates } \\
\hline Child's age at pre-test & .16 & 5.37 & .00 & {$[-10.37,10.68]$} \\
\hline Child's biological sex & $-9.42 *$ & 3.70 & $-.26 *$ & {$[-16.68,-2.16]$} \\
\hline Child's preschool enrollment status & 1.82 & 7.37 & .03 & {$[-12.63,16.27]$} \\
\hline Child's free/reduced lunch status & -.54 & 6.19 & -.01 & {$[-12.67,11.59]$} \\
\hline Parent's public assistance status & 4.99 & 3.92 & .11 & {$[-2.70,12.67]$} \\
\hline \multicolumn{5}{|l|}{ GLM 2: Parent-Reported SR ${ }_{\mathrm{T} 1}$} \\
\hline Challenging parent-child relationships & -.30 & .17 & -.20 & {$[-.65, .04]$} \\
\hline Stressful life events & -.00 & .00 & -.06 & {$[-.00, .00]$} \\
\hline Financial strain & -.08 & .07 & -.13 & {$[-.22, .06]$} \\
\hline \multicolumn{5}{|l|}{ Covariates } \\
\hline Child's age at pre-test & -.05 & .20 & -.03 & {$[-.44, .35]$} \\
\hline Child's biological sex & -.20 & .12 & -.17 & {$[-.45, .04]$} \\
\hline Child's preschool enrollment status & .25 & .18 & .12 & {$[-.11, .60]$} \\
\hline Child's free/reduced lunch status & -.18 & .24 & -.07 & {$[-.65, .29]$} \\
\hline Parent's public assistance status & -.13 & .19 & -.08 & {$[-.49, .23]$} \\
\hline \multicolumn{5}{|l|}{ GLM 3: Teacher-Reported SR T1 } \\
\hline Challenging parent-child relationships & $-.43 *$ & .17 & $-.24 *$ & {$[-.76,-.10]$} \\
\hline Stressful life events & -.00 & .00 & -.10 & {$[-.00, .00]$} \\
\hline Financial strain & .12 & .09 & .16 & {$[-.06, .31]$} \\
\hline \multicolumn{5}{|l|}{ Covariates } \\
\hline Child's age at pre-test & .14 & .23 & .07 & {$[-.32, .60]$} \\
\hline Child's biological sex & .02 & .16 & .02 & {$[-.30, .34]$} \\
\hline Child's preschool enrollment status & $.59 * *$ & .16 & $.23 * *$ & {$[.27, .91]$} \\
\hline Child's free/reduced lunch status & $-.79 *$ & .30 & $-.27 *$ & {$[-1.37,-.21]$} \\
\hline Parent's public assistance status & .40 & .24 & .22 & {$[-.06, .87]$} \\
\hline
\end{tabular}

Note. $* \mathrm{p}<.05 . * * \mathrm{p}<.01 . \mathrm{GLM}=$ General Linear Model. Analyses were conducted using FIML. 
Table 11. RQ2: Regression Analysis Summary for the Stressful Contexts of Parenting Predicting Post-Test Self-Regulation

\begin{tabular}{|c|c|c|c|c|}
\hline & $B$ & $\mathrm{SE}$ & $\beta$ & $95 \% \mathrm{CI}$ \\
\hline \multicolumn{5}{|l|}{ GLM 4: Direct Assessments of SR $\mathrm{T}_{2}$} \\
\hline Challenging parent-child relationships & -5.83 & 4.18 & -.13 & {$[-14.02,2.35]$} \\
\hline Stressful life events & -.001 & .02 & -.01 & {$[-.03, .03]$} \\
\hline Financial strain & 2.75 & 1.97 & .14 & {$[-1.13,6.62]$} \\
\hline \multicolumn{5}{|l|}{ Covariates } \\
\hline Direct assessments of $\mathrm{SR} T 1$ & $.42 * *$ & .09 & $.42 * *$ & {$[0.24, .60]$} \\
\hline WINGS enrollment & 4.32 & 3.73 & .12 & {$[-2.98,11.63]$} \\
\hline Child's age at pre-test & 2.09 & 5.25 & .04 & {$[-8.20,12.39]$} \\
\hline Child's biological sex & -6.06 & 4.09 & -.17 & {$[-14.08,1.95]$} \\
\hline Child's preschool enrollment status & .81 & 4.62 & .01 & {$[-8.25,9.87]$} \\
\hline Child's free/reduced lunch status & $-16.00 * *$ & 4.88 & $-.22 * *$ & {$[-25.56,-6.44]$} \\
\hline Parent's public assistance status & -2.50 & 6.08 & -.05 & {$[-14.42,9.41]$} \\
\hline \multicolumn{5}{|l|}{ GLM 5: Parent-Reported SR ${ }_{\mathrm{T} 2}$} \\
\hline Challenging parent-child relationships & -.17 & .23 & -.11 & {$[-.63, .29]$} \\
\hline Stressful life events & $-.001 *$ & .000 & $-.27 *$ & {$[-.002,-.000]$} \\
\hline Financial strain & .10 & .07 & .16 & {$[-.03, .24]$} \\
\hline \multicolumn{5}{|l|}{ Covariates } \\
\hline Parent-reported SR $\mathrm{T}_{\mathrm{T}}$ & $.25 *$ & .12 & $.25^{*}$ & {$[.01, .49]$} \\
\hline WINGS enrollment & .13 & .14 & .11 & {$[-.14, .40]$} \\
\hline Child's age at pre-test & .24 & .21 & .13 & {$[-.17, .65]$} \\
\hline Child's biological sex & -.21 & .15 & -.17 & {$[-.50, .09]$} \\
\hline Child's preschool enrollment status & .09 & .15 & .04 & {$[-.19, .38]$} \\
\hline Child's free/reduced lunch status & $-.74 *$ & .30 & $-.30 *$ & {$[-1.33,-.14]$} \\
\hline Parent's public assistance status & $.43^{\dagger}$ & .23 & $.28^{\dagger}$ & {$[-.02, .88]$} \\
\hline \multicolumn{5}{|l|}{ GLM 6: Teacher-Reported SR ${ }_{\mathrm{T} 2}$} \\
\hline Challenging parent-child relationships & -.02 & .15 & -.01 & {$[-.31, .26]$} \\
\hline Stressful life events & .000 & .001 & .09 & {$[-.001, .002]$} \\
\hline Financial strain & $-.11^{\dagger}$ & .06 & $-.13^{\dagger}$ & {$[-.24, .02]$} \\
\hline \multicolumn{5}{|l|}{ Covariates } \\
\hline Teacher-reported SR $\mathrm{T} 1$ & $.75^{* *}$ & .08 & $.70 * *$ & {$[.60, .90]$} \\
\hline WINGS enrollment & .01 & .13 & .01 & {$[-.24, .25]$} \\
\hline Child's age at pre-test & -.18 & .20 & -.08 & {$[-.58, .21]$} \\
\hline Child's biological sex & $-.29 *$ & .12 & $-.19 *$ & {$[-.53,-.05]$} \\
\hline Child's preschool enrollment status & -.09 & .20 & -.04 & {$[-.49, .30]$} \\
\hline Child's free/reduced lunch status & -.19 & .28 & -.06 & {$[-.75, .36]$} \\
\hline Parent's public assistance status & .01 & .18 & .00 & {$[-.35, .37]$} \\
\hline
\end{tabular}

Note. ${ }^{\dagger} p<.10 . * p<.05 . * * p<.01$. GLM = General Linear Model. Analyses were conducted using FIML. 
Table 12. RQ3: Regression Analysis Summary for the Stressful Contexts of Parenting Predicting Post-Test Self-Regulation (Direct Assessments)

\begin{tabular}{|c|c|c|c|c|}
\hline & $B$ & SE & $\beta$ & $95 \% \mathrm{CI}$ \\
\hline \multicolumn{5}{|l|}{ GLM 7: Direct Assessments of SR ${ }_{\mathrm{T} 2}$} \\
\hline \multicolumn{5}{|l|}{ Stressful contexts of parenting (centered) } \\
\hline Challenging parent-child relationships & $-8.26^{\dagger}$ & 4.90 & $-.18^{\dagger}$ & {$[-17.86,1.34]$} \\
\hline Stressful life events & -.000 & .01 & -.003 & {$[-.03, .03]$} \\
\hline Financial strain & 2.41 & 1.95 & .12 & {$[-1.40,6.23]$} \\
\hline \multicolumn{5}{|l|}{ Moderator } \\
\hline WINGS enrollment (centered) & 4.80 & 3.66 & .13 & {$[-2.37,11.97]$} \\
\hline \multicolumn{5}{|l|}{ Interaction } \\
\hline Challenging parent-child relationships $\times$ WINGS & 12.11 & 9.94 & .12 & {$[-7.38,31.59]$} \\
\hline \multicolumn{5}{|l|}{ Covariates } \\
\hline Direct assessments of $\mathrm{SR}_{\mathrm{T} 1}$ & $.43 * *$ & .09 & $.44 * *$ & {$[.26, .61]$} \\
\hline Child's age at pre-test (centered) & 3.38 & 5.38 & .06 & {$[-7.16,13.92]$} \\
\hline Child's biological sex & -5.99 & 3.99 & -.17 & {$[-13.82,1.83]$} \\
\hline Child's preschool enrollment status & .44 & 5.05 & .01 & {$[-9.46,10.34]$} \\
\hline Child's free/reduced lunch status & $-16.45^{* *}$ & 4.86 & $-.22 * *$ & {$[-25.97,-6.93]$} \\
\hline Parent's public assistance status & -2.36 & 6.06 & -.05 & {$[-14.24,9.51]$} \\
\hline \multicolumn{5}{|l|}{ GLM 8: Direct Assessments of $\mathrm{SR}_{\mathrm{T} 2}$} \\
\hline \multicolumn{5}{|l|}{ Stressful contexts of parenting (centered) } \\
\hline Challenging parent-child relationships & -6.38 & 4.17 & -.14 & {$[-14.56,1.80]$} \\
\hline Stressful life events & .000 & .01 & .004 & {$[-.03, .03]$} \\
\hline Financial strain & 2.70 & 1.96 & .14 & {$[-1.14,6.53]$} \\
\hline \multicolumn{5}{|l|}{ Moderator } \\
\hline WINGS enrollment (centered) & 4.38 & 3.62 & .12 & {$[-2.72,11.48]$} \\
\hline \multicolumn{5}{|l|}{ Interaction } \\
\hline Stressful life events $\times$ WINGS & .03 & .03 & .10 & {$[-.03, .08]$} \\
\hline \multicolumn{5}{|l|}{ Covariates } \\
\hline Direct assessments of $\mathrm{SR}_{\mathrm{T} 1}$ & $.43 * *$ & .09 & $.43 * *$ & {$[.24, .61]$} \\
\hline Child's age at pre-test (centered) & 1.24 & 5.37 & .02 & {$[-9.28,11.76]$} \\
\hline Child's biological sex & -5.32 & 4.03 & -.15 & {$[-13.23,2.59]$} \\
\hline Child's preschool enrollment status & 1.88 & 4.84 & .03 & {$[-7.60,11.36]$} \\
\hline Child's free/reduced lunch status & $-16.23 * *$ & 5.10 & $-.22 * *$ & {$[-26.23,-6.23]$} \\
\hline Parent's public assistance status & -2.65 & 6.01 & -.06 & {$[-14.42,9.13]$} \\
\hline \multicolumn{5}{|l|}{ GLM 9: Direct Assessments of SR $\mathrm{T}_{2}$} \\
\hline \multicolumn{5}{|l|}{ Stressful contexts of parenting (centered) } \\
\hline Challenging parent-child relationships & -6.09 & 4.10 & -.13 & {$[-14.12,1.94]$} \\
\hline Stressful life events & -.00 & .02 & -.01 & {$[-.03, .03]$} \\
\hline Financial strain & 2.92 & 1.99 & .15 & {$[-.98,6.81]$} \\
\hline \multicolumn{5}{|l|}{ Moderator } \\
\hline WINGS enrollment (centered) & 4.34 & 3.72 & .12 & {$[-2.96,11.63]$} \\
\hline \multicolumn{5}{|l|}{ Interaction } \\
\hline Financial strain $\times$ WINGS & 0.98 & 3.85 & .03 & {$[-6.57,8.52]$} \\
\hline \multicolumn{5}{|l|}{ Covariates } \\
\hline Direct assessments of $\mathrm{SR}_{\mathrm{T} 1}$ & $.42 * *$ & .09 & $.43 * *$ & {$[.24, .60]$} \\
\hline Child's age at pre-test (centered) & 1.88 & 5.41 & .04 & {$[-8.73,12.49]$} \\
\hline Child's biological sex & -5.96 & 4.11 & -.17 & {$[-14.01,2.09]$} \\
\hline Child's preschool enrollment status & .83 & 4.71 & .01 & {$[-8.41,10.07]$} \\
\hline Child's free/reduced lunch status & $-16.28 * *$ & 5.12 & $-.22 * *$ & {$[-26.32,-6.25]$} \\
\hline Parent's public assistance status & -2.79 & 5.99 & -.06 & {$[-14.54,8.95]$} \\
\hline
\end{tabular}

Note. ${ }^{\dagger} p<.10 .{ }^{*} p<.05 .{ }^{*} p<.01$. GLM $=$ General Linear Model. Analyses were conducted using FIML. 
Table 13. RQ3: Regression Analysis Summary for the Stressful Contexts of Parenting Predicting Post-Test Self-Regulation (Parent-Reports)

GLM 10: Parent-Reported SR T2

\begin{tabular}{cccc}
$B$ & SE & $\beta$ & $95 \%$ CI \\
\hline & & & \\
-.27 & .22 & -.18 & {$[-.69, .15]$} \\
$-.001^{* *}$ & .000 & $-.27 * *$ & {$[-.002,-.000]$} \\
.09 & .07 & .14 & {$[-.03, .22]$} \\
& & & \\
.16 & .14 & .13 & {$[-.11, .43]$} \\
& & & \\
.52 & .40 & .16 & {$[-.26,1.31]$} \\
& & & \\
$.23 \dagger$ & .12 & $.22^{\dagger}$ & {$[-.01, .47]$} \\
.28 & .21 & .16 & {$[-.14, .69]$} \\
-.23 & .15 & -.19 & {$[-.52, .07]$} \\
.08 & .15 & .04 & {$[-.21, .38]$} \\
$-.69 *$ & .30 & $-.28 *$ & {$[-1.28,-.10]$} \\
.43 & .25 & .27 & {$[-.06, .91]$}
\end{tabular}

GLM 11: Parent-Reported SR T2

Stressful contexts of parenting (centered)

Challenging parent-child relationships

Stressful life events

$-.20$

$-.001 *$

.24

.24

$-.13$

Financial strain

.1

$-.25^{*}$

$[-.67, .26]$

Moderator

WINGS enrollment (centered)

Interaction

Stressful life events $\times$ WINGS

Covariates

Parent-reported SR 1

Child's age at pre-test (centered)

Child's biological sex

Child's preschool enrollment status

Child's free/reduced lunch status

.13

.07

.17

$[-.002,-.000]$

$[-.02, .24]$

Parent's public assistance status

GLM 12: Parent-Reported SR T2

Stressful contexts of parenting (centered)

Challenging parent-child relationship

Stressful life events

Financial strain

$\begin{array}{cc}.13 & .14 \\ .001 & .00 \\ & \\ .25^{*} & .12 \\ .21 & .22 \\ -.18 & .16 \\ .08 & .15 \\ -.77^{*} & .30 \\ .43^{\dagger} & .23\end{array}$

Moderator

WINGS enrollment (centered)

Interaction

Financial strain $\times$ WINGS

Covariates

Parent-reported SR $\mathrm{T} 1$

Child's age at pre-test (centered)

Child's biological sex

Child's preschool enrollment status

Child's free/reduced lunch status

$-.1$

$-.001 * *$

.09

.13

$-.03$

$.26^{*}$

.24

$-.21$

.10

$-.73 *$

$.44^{*}$
.11

$[-.14, .40]$

14

.001

.08

$.25 *$

.12

$-.15$

.04

$-.31 *$

$.28^{\dagger}$

$[-.001, .003]$

$[.01, .49]$

$[-.21, .63]$

$[-.50, .14]$

$[-.21, .37]$

[-1.36, -.18]

$[-.02 .88]$ Parent's public assistance status

Note. ${ }^{\dagger} p<.10 . * p<.05 . * * p<.01$. GLM $=$ General Linear Model. Analyses were conducted using FIML. 
Table 14. RQ3: Regression Analysis Summary for the Stressful Contexts of Parenting Predicting Post-Test Self-Regulation (Teacher-Reports)

GLM 13: Teacher-Reported SR T2

Stressful contexts of parenting (centered)

Challenging parent-child relationships

Stressful life events

Financial strain

$B$

SE

$95 \% \mathrm{CI}$

Moderator

WINGS enrollment (centered)

Interaction

Challenging parent-child relationships $\times$ WINGS

Covariates

Teacher -reported SR $\mathrm{T1}$

Child's age at pre-test (centered)

Child's biological sex

Child's preschool enrollment status

Child's free/reduced lunch status

Parent's public assistance status

$\begin{array}{lccc}.01 & .14 & .005 & {[-.26, .28]} \\ .000 & .001 & .09 & {[-.001, .002]} \\ -.10 & .06 & -.13 & {[-.23, .02]} \\ & & & \\ .002 & .12 & .002 & {[-.24, .24]} \\ & & & \\ -.21 & .27 & -.05 & {[-.74, .33]} \\ .75 * * & .08 & .70 * * & {[.60, .90]} \\ -.20 & .20 & -.09 & {[-.59, .20]} \\ -.30 * & .12 & -.20 * & {[-.53,-.06]} \\ -.09 & .21 & -.03 & {[-.50, .32]} \\ -.20 & .28 & -.06 & {[-.75, .36]} \\ -.003 & .19 & -.001 & {[-.37, .37]}\end{array}$

GLM 14: Teacher-Reported SR T2

Stressful contexts of parenting (centered)

Challenging parent-child relationships

Stressful life events

Financial strain

$\begin{array}{cccc}.06 & .13 & .03 & {[-.20, .32]} \\ .000 & .000 & .08 & {[-.000, .001]} \\ -.11^{\dagger} & .06 & -.13^{\dagger} & {[-.23, .01]} \\ & & & \\ -.04 & .11 & -.03 & {[-.26, .18]} \\ & & & \\ -.003 * * & .001 & -.27 * * & {[-.005,-.001]} \\ & & & \\ .75 & .07 & .70 * * & {[.61, .89]} \\ -.11 & .17 & -.05 & {[-.45, .22]} \\ -.39 * * & .11 & -.26 * * & {[-.61,-.18]} \\ -.23 & .19 & -.09 & {[-.61, .15]} \\ -.22 & .29 & -.07 & {[-.79, .35]} \\ -.01 & .17 & -.004 & {[-.34, .32]}\end{array}$

GLM 15: Teacher-Reported SR T2

Stressful contexts of parenting (centered)

Challenging parent-child relationships

Stressful life events

$\begin{array}{lllc}.01 & .14 & .01 & {[-.26, .28]} \\ .001 & .001 & .10 & {[-.001, .002]} \\ -.14 & .08 & -.17 & {[-.30, .01]} \\ & & & \\ -.01 & .13 & -.01 & {[-.25, .24]} \\ & & & \\ -.20 & .13 & -.13 & {[-.46, .06]} \\ & & & \\ .72 & .08 & .68 * * & {[.57, .87]} \\ -.15 & .19 & -.06 & {[-.52, .22]} \\ -.31 & .12 & -.20 * & {[-.55,-.06]} \\ -.09 & .19 & -.03 & {[-.47, .29]} \\ -.20 & .28 & -.06 & {[-.74, .35]} \\ .06 & .19 & .03 & {[-.31, .43]}\end{array}$

Financial strain

Moderator

WINGS enrollment (centered)

Interaction

Financial strain $\times$ WINGS

Covariates

Teacher-reported SR $\mathrm{T} 1$

Child's age at pre-test (centered)

Child's biological sex

Child's preschool enrollment status

Child's free/reduced lunch status

.19

.03

$[-.31, .43]$

Note. ${ }^{\dagger} p<.10 . * p<.05 . * * p<.01$. GLM $=$ General Linear Model. Analyses were conducted using FIML. 
SELF-REGULATION, STRESS, AND SEL IN KINDERGARTEN

Table 15. Summary of Significant Findings: Main Effects of Stressful Contexts of Parenting and Interaction Effects with WINGS Enrollment on Self-Regulatory Development

\begin{tabular}{|c|c|c|c|}
\hline \multirow[t]{2}{*}{ Outcome } & \multicolumn{3}{|c|}{ Stressful Contexts of Parenting $\mathrm{T} 1$} \\
\hline & $\begin{array}{c}\text { Challenging } \\
\text { parent-child relationships }\end{array}$ & Stressful life events & Parents' financial strain \\
\hline \multicolumn{4}{|l|}{ Research Question 1} \\
\hline Direct Assessment $\mathrm{T} 1$ & $n s$ & $-.29 * *$ & $n s$ \\
\hline Parent-Report $\mathrm{T} 1$ & $n s$ & $n s$ & $n s$ \\
\hline Teacher-Report $\mathrm{T} 1$ & $-.24 *$ & $n s$ & $n s$ \\
\hline \multicolumn{4}{|l|}{ Research Question 2} \\
\hline Direct Assessment T2 & $n s$ & $n s$ & $n s$ \\
\hline Parent-Report $\mathrm{T} 2_{2}$ & $n s$ & $-.27 *$ & $n s$ \\
\hline Teacher-Report $\mathrm{T} 2$ & $n s$ & $n s$ & $-.13^{\dagger}$ \\
\hline \multirow[t]{2}{*}{ Outcome } & \multicolumn{3}{|c|}{$\begin{array}{l}\text { Interaction of WINGS Enrollment } \\
\text { and Stressful Contexts of Parenting } \mathrm{T} 1\end{array}$} \\
\hline & $\begin{array}{l}\text { WINGS } \times \text { Challenging } \\
\text { parent-child relationships }\end{array}$ & $\begin{array}{c}\text { WINGS } \times \\
\text { Stressful life events }\end{array}$ & $\begin{array}{c}\text { WINGS } \times \\
\text { Parents' financial strain }\end{array}$ \\
\hline \multicolumn{4}{|l|}{ Research Question 3} \\
\hline Direct Assessment ${ }_{\mathrm{T} 2}$ & $n s$ & $n s$ & $n s$ \\
\hline Parent Report $\mathrm{T}_{2}$ & $n s$ & ns & $n s$ \\
\hline Teacher-Report ${ }_{\mathrm{T} 2}$ & $n s$ & $-.27 * *$ & $n s$ \\
\hline
\end{tabular}

Note. ${ }^{\dagger} p<.10 .{ }^{*} p<.05 .{ }^{*} p<.01$. Standardized coefficients are reported. There were no significant moderating effects of WINGS in any of the models tested. For RQs 1 and 2, each row represents a single GLM. For RQ 3, each cell represents a single GLM. 


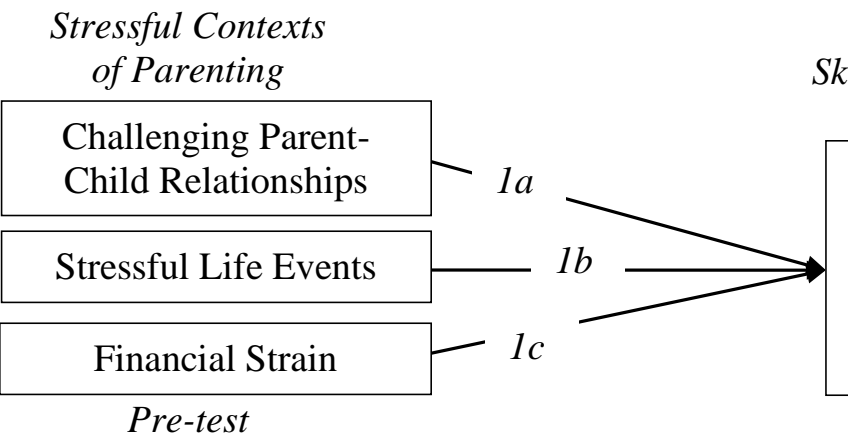

Lower Self-Regulatory

Skills at Kindergarten Entry

Direct Assessments

Parent-Reports

Teacher-Reports

Pre-test

Figure 1. Theoretical model for Research Question 1: Does Black children's exposure to stressful contexts of parenting (i.e., challenging parent-child relationships (Hypothesis 1a), stressful life events (Hypothesis 1b), and financial strain (Hypothesis 1c)) predict lower selfregulatory skills at kindergarten entry, as assessed by direct assessments parent-reports, and teacher-reports?

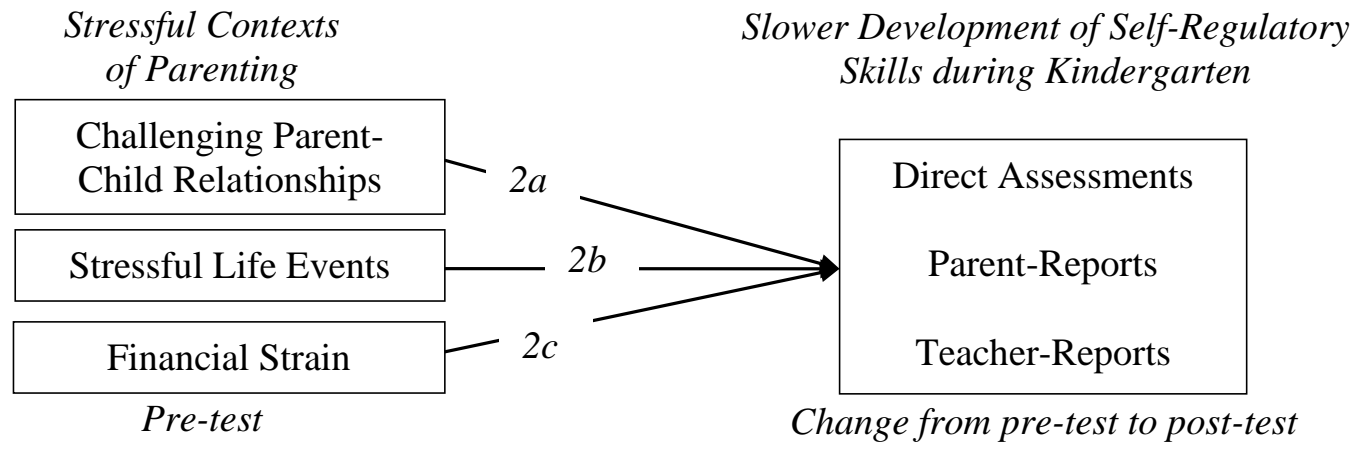

Figure 2. Theoretical model for Research Question 2: Does Black children's exposure to stressful contexts of parenting (i.e., challenging parent-child relationships (Hypothesis 2a), stressful life events (Hypothesis 2b), and financial strain (Hypothesis 2c)) predict slower development of self-regulatory skills during kindergarten entry, as assessed by direct assessments parent-reports, and teacher-reports? 


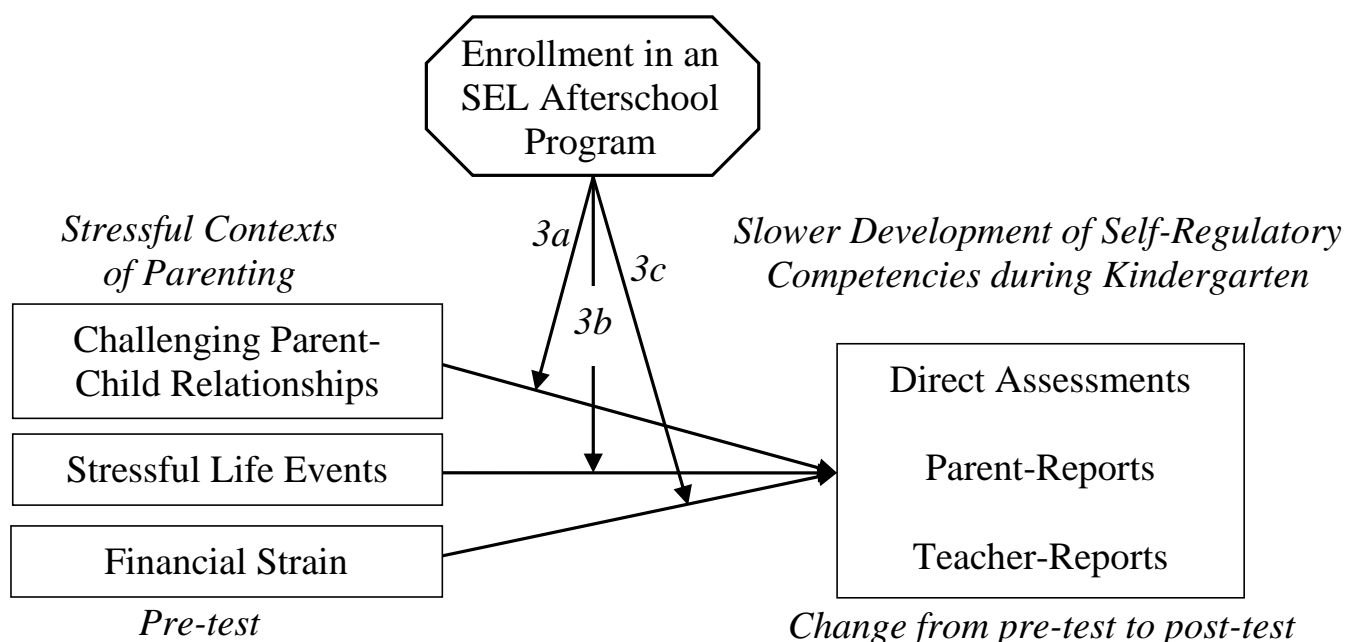

Figure 3. Theoretical model for Research Question 3: Does the negative influence of the stressful contexts of parenting (i.e., challenging parent-child relationships (Hypothesis 3a), stressful life events (Hypothesis 3b), and financial strain (Hypothesis 3c)) on Black children's development of self-regulatory skills during kindergarten depend on whether kindergarteners are enrolled in a social-emotional learning afterschool program? 
High Self-

Regulation

Low Self-
Regulation
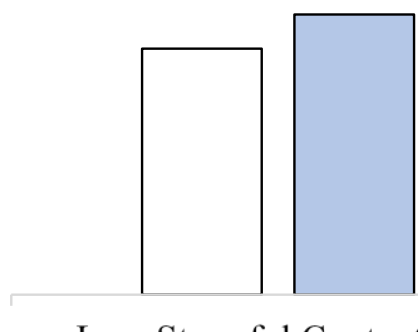

A

Low Stressful Contexts of

Parenting

High Stressful Contexts of

Parenting

$\square$ Control $\quad \square$ WINGS Afterschool

\section{High Self-}

Regulation

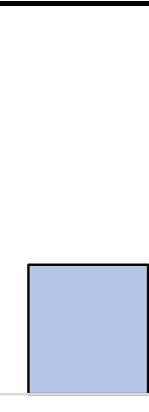

\section{DWINGS Afterschool}

Regulation

Pre-Test

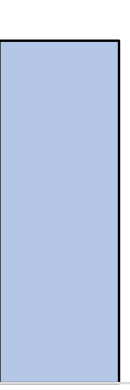

B

$\square$ Control $\square$ WINGS Afterschool

High Self-

Regulation

Low Self-

Regulation

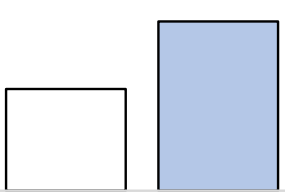

Pre-Test
C

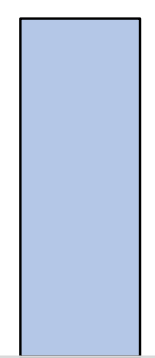

Post-Test

$\square$ Highly Stressful Contexts of Parenting

$\square$ Low Stressful Contexts of Parenting

Figure 4. Panel A: Illustration of the hypothesized buffering effect of WINGS enrollment on the adverse impacts of the stressful contexts of parenting on the development of children's selfregulatory skills. Panel B: Illustration of a possible amplifying interaction effect. Panel C: Illustration of a possible compensatory interaction effect. 
Exposure to stress

at home (pre-test)

A

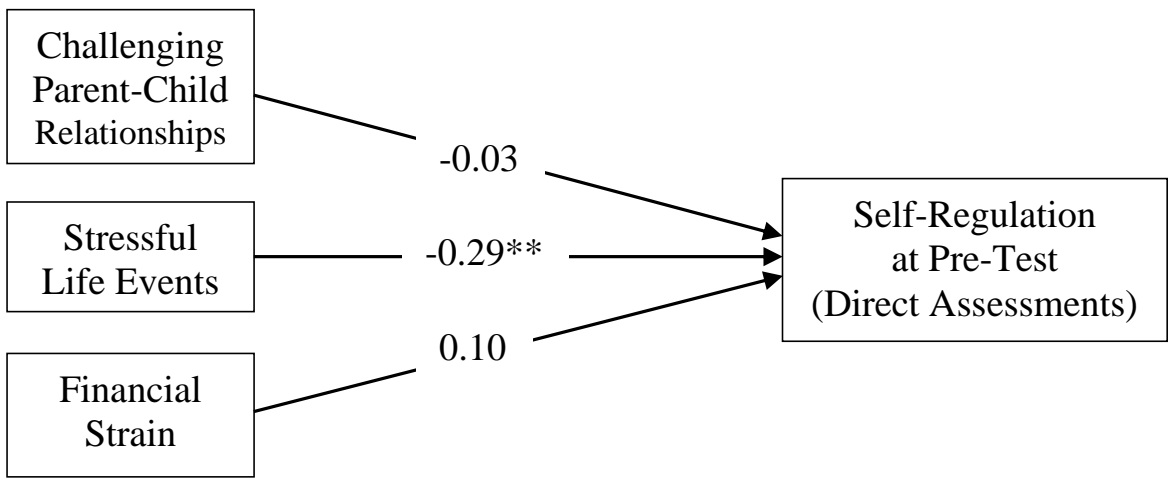

Exposure to stress

B

at home (pre-test)

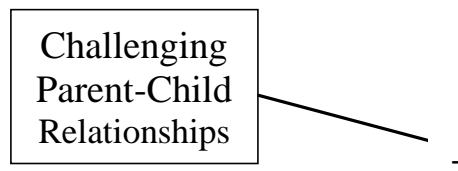

Parent-Child
Relationships
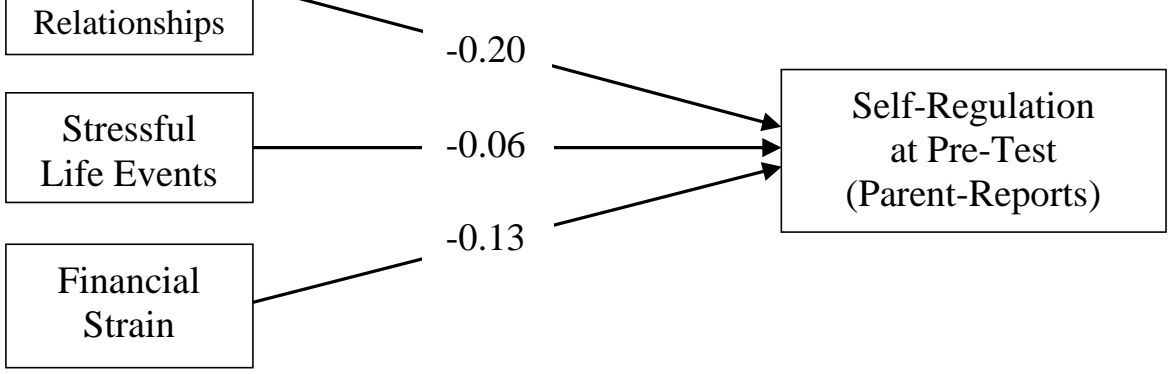

Exposure to stress
at home (pre-test)

C

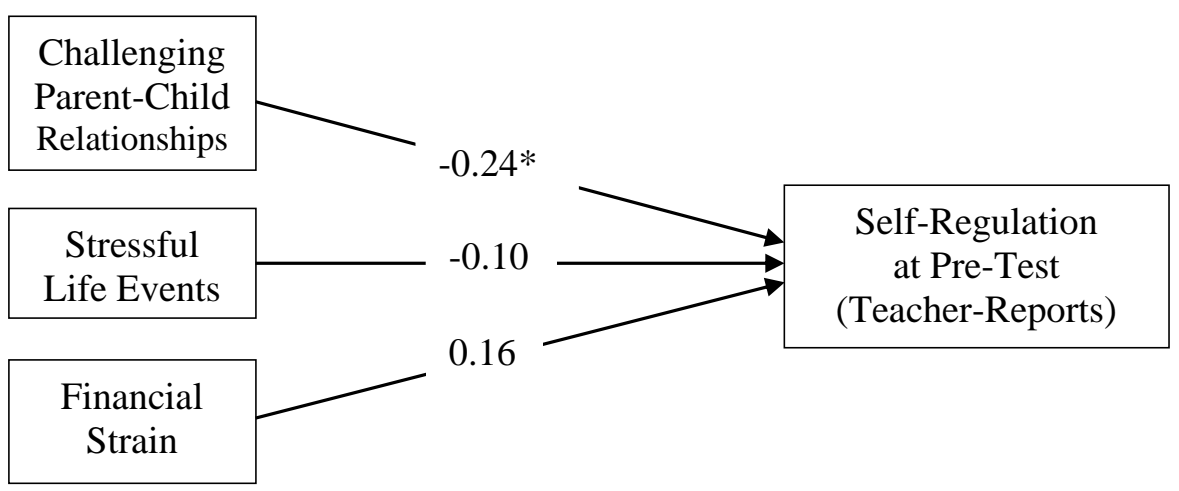

Figure 5. RQ1: Standardized regression coefficients of the main effects of the stressful contexts of parenting on children's self-regulatory abilities at pre-test for GLMs 1 (panel A), 2 (panel B), and 3 (panel C). 

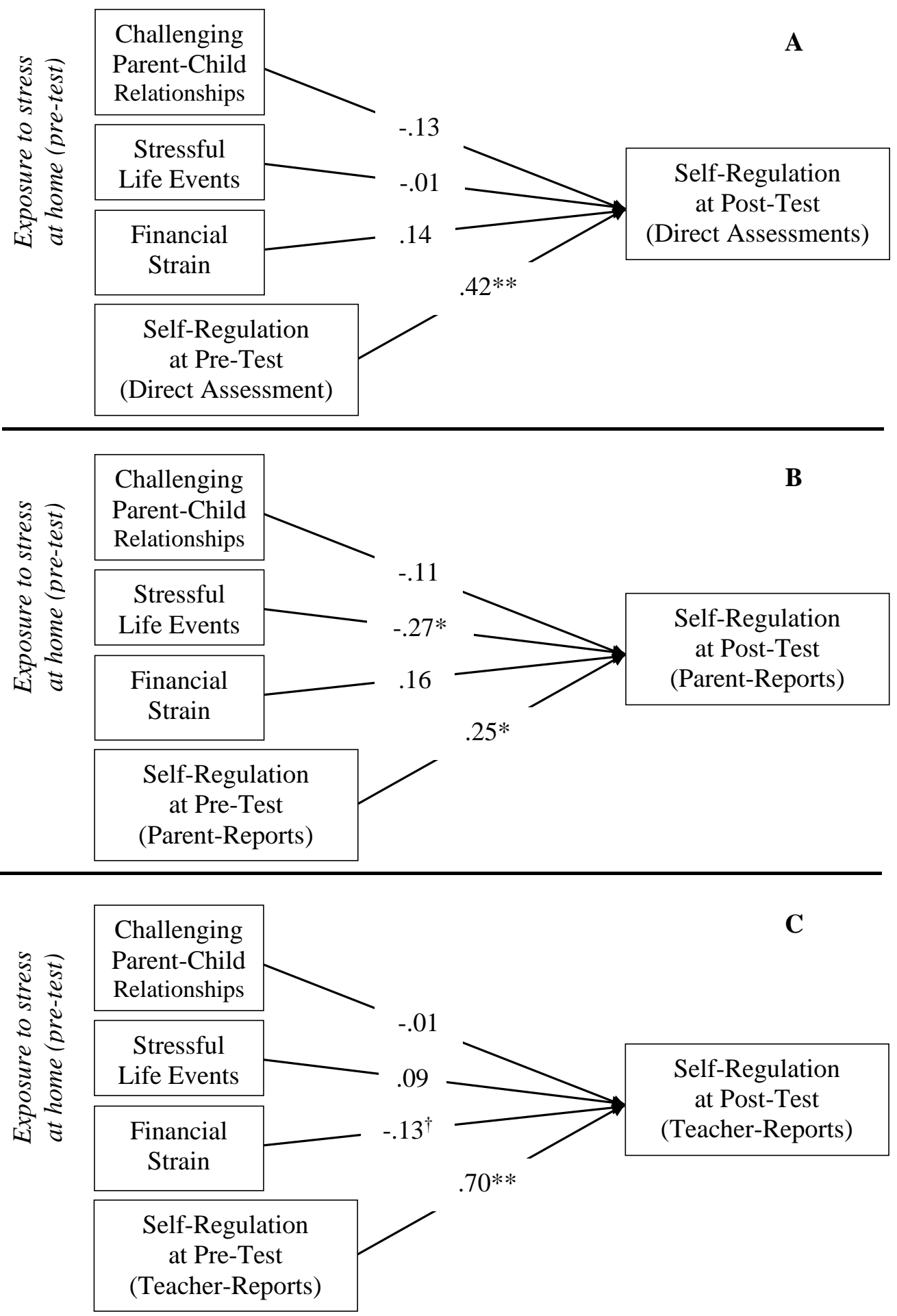

Figure 6. RQ 2: Standardized regression coefficients of the main effects of the stressful contexts of parenting on children's self-regulatory abilities at post-test (controlling for baseline self-regulation) for GLMs 4 (panel A), 5 (panel B), and 6 (panel C). 

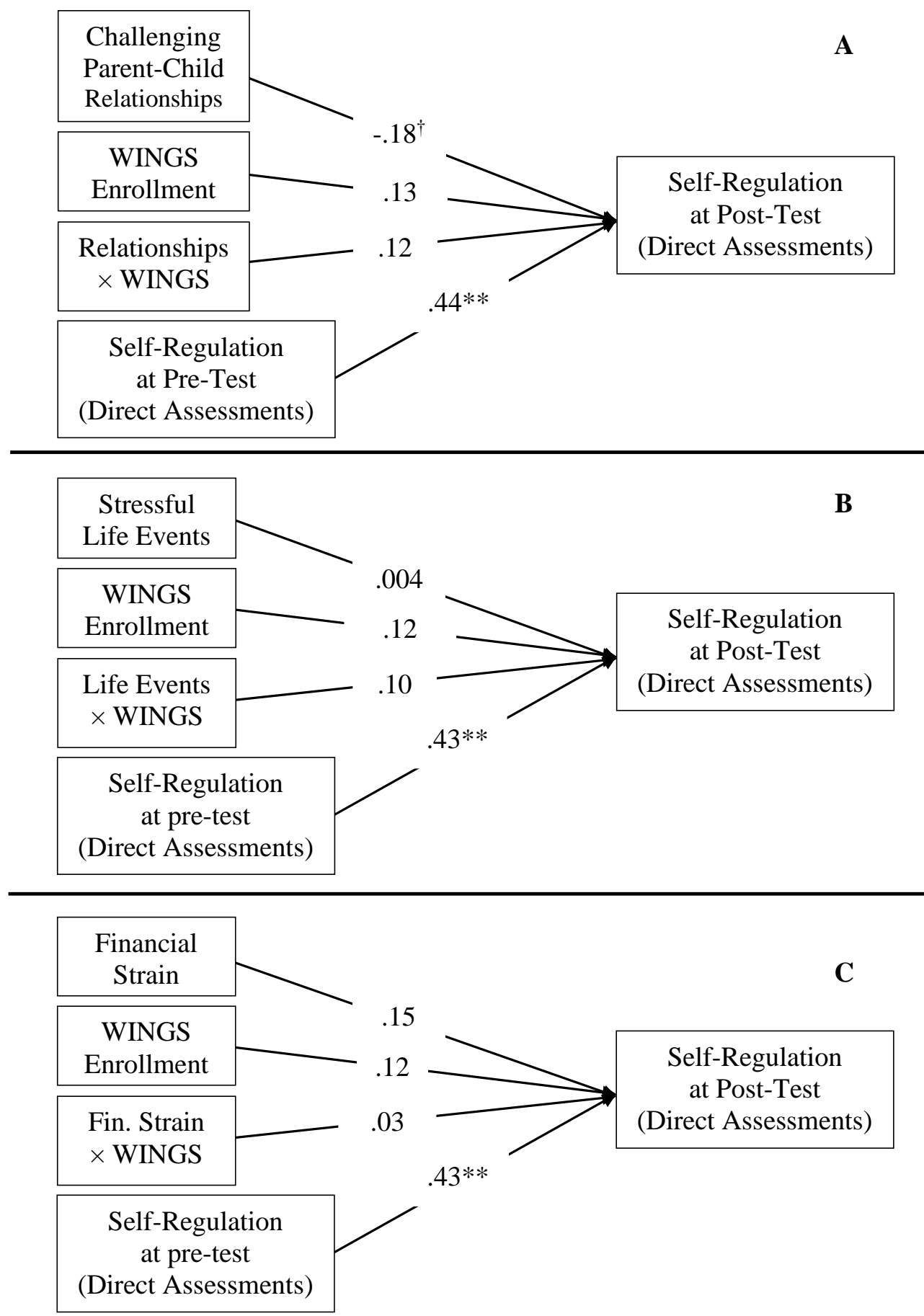

Figure 7. RQ 3: Standardized regression coefficients of the main effects of the stressful contexts of parenting, WINGS enrollment, and their interactions on direct assessments of children's self-regulatory abilities at post-test (controlling for baseline direct assessments of self-regulation) for GLMs 7 (panel A), 8 (panel B), and 9 (panel C). 


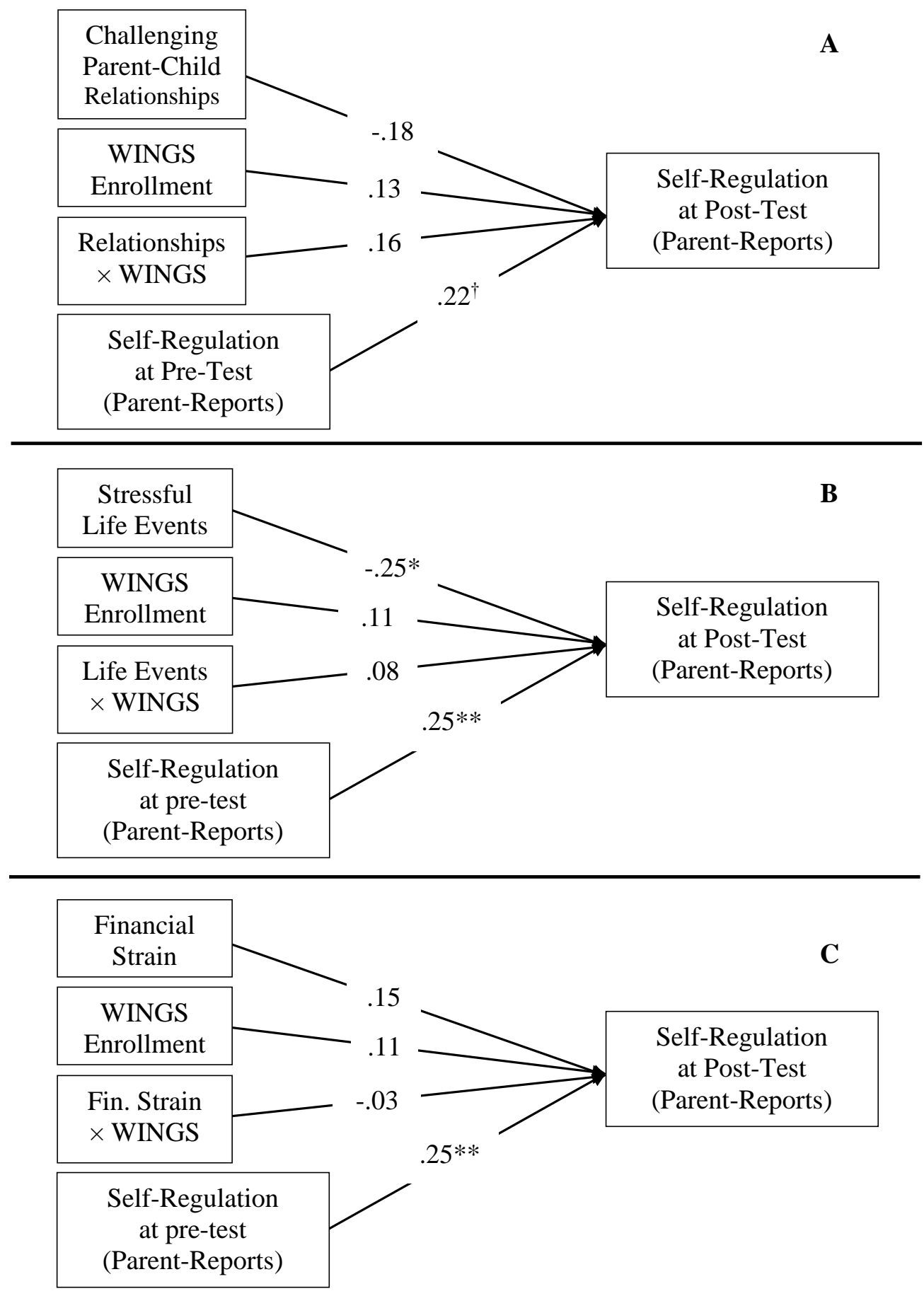

Figure 8. RQ 3: Standardized regression coefficients of the main effects of the stressful contexts of parenting, WINGS enrollment, and their interactions on parent-reports of children's self-regulatory abilities at post-test (controlling for baseline parent-reports of self-regulation) for GLMs 10 (panel A), 11 (panel B), and 12 (panel C). 

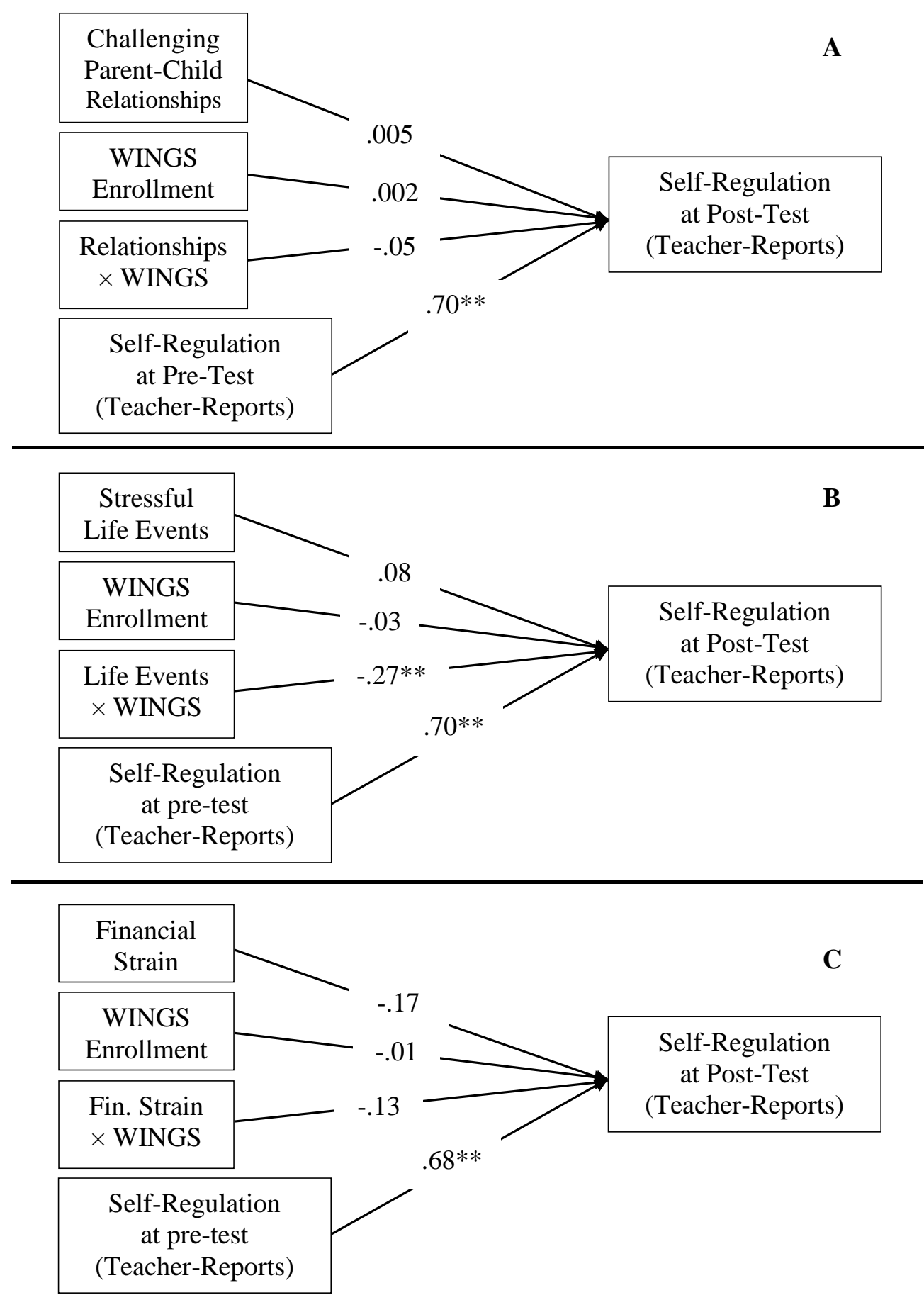

Figure 9. RQ3: Standardized regression coefficients of the main effects of the stressful contexts of parenting, WINGS enrollment, and their interactions on teacher-reports of children's selfregulatory abilities at post-test (controlling for baseline teacher-reports of self-regulation) for GLMs 13 (panel A), 14 (panel B), and 15 (panel C). 


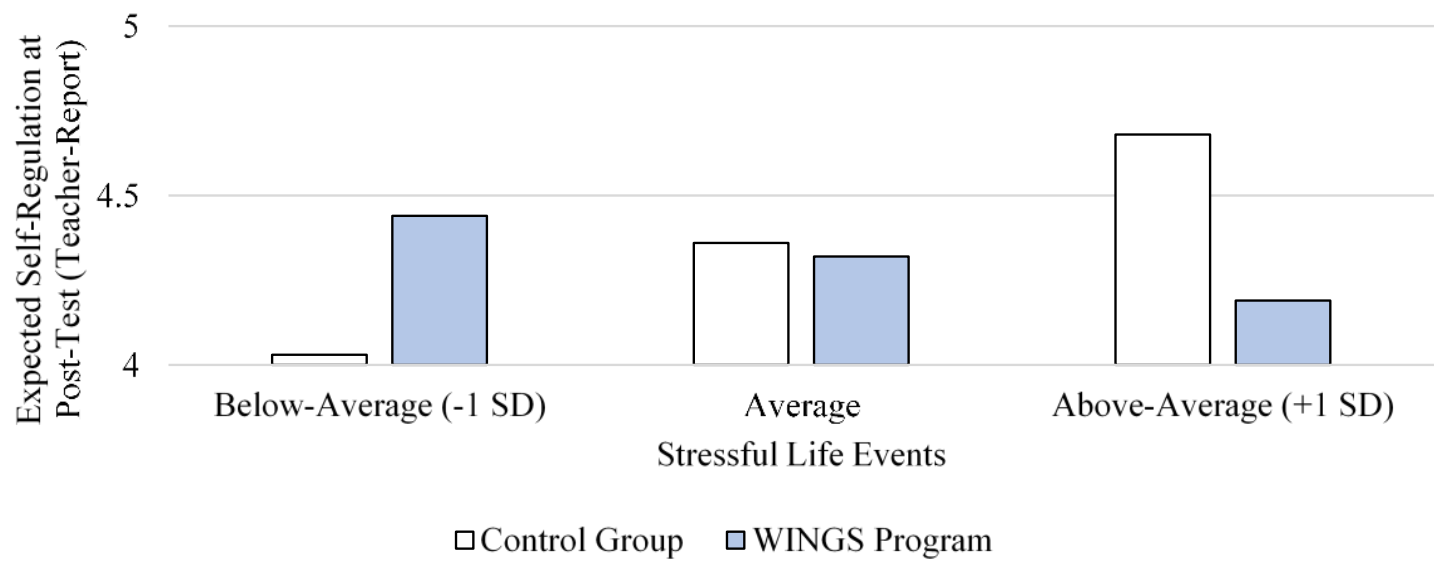

Figure 10. Interaction between parents' stressful life events and children's WINGS enrollment in predicting teacher-reported self-regulation at post-test. 
SELF-REGULATION, STRESS, AND SEL IN KINDERGARTEN

\section{References}

Anderson, T. W. (1957). Maximum likelihood estimates for a multivariate normal distribution when some observations are missing. Journal of the American Statistical Association, 52(278), 200-203.

Baker, C. E., \& Iruka, I. U. (2013). Maternal psychological functioning and children's school readiness: The mediating role of home environments for African American children. Early Childhood Research Quarterly, 28(3), 509-519. https://doi.org/10.1016/j.ecresq.2013.02.004

Baraldi, A. N., \& Enders, C. K. (2010). An introduction to modern missing data analyses. Journal of School Psychology, 48(1), 5-37. https://doi.org/10.1016/j.jsp.2009.10.001

Barbarin, O., Iruka, I. U., Harradine, C., Winn, D. C., McKinney, M. K., \& Taylor, L. C. (2013). Development of social-emotional competence in boys of color: A crosssectional cohort analysis from pre-K to second grade. American Journal of Orthopsychiatry, 83(2-3), 145-155. https://doi.org/10.1111/ajop.12023

Barnett, W. S., Jung, K., Yarosz, D. J., Thomas, J., Hornbeck, A., Stechuk, R., \& Burns, S. (2008). Educational effects of the Tools of the Mind curriculum: A randomized trial. Early Childhood Research Quarterly, 23(3), 299-313. https://doi.org/10.1016/j.ecresq.2008.03.001

Bassok, D., Latham, S., \& Rorem, A. (2016). Is kindergarten the new first grade? AERA Open, 2(1), 1-31. https://doi.org/10.1177/2332858415616358 
SELF-REGULATION, STRESS, AND SEL IN KINDERGARTEN

Best, J. R., \& Miller, P. H. (2010). A developmental perspective on executive function. Child Development, 81(6), 1641-1660. https://doi.org/10.1111/j.14678624.2010.01499.x

Bierman, K. L., Domitrovich, C. E., Nix, R. L., Gest, S. D., Welsh, J. A., Greenberg, M. T., Blair, C., Nelson, K. E., \& Gill, S. (2008). Promoting Academic and SocialEmotional School Readiness: The Head Start REDI Program. Child Development, 79(6), 1802-1817. https://doi.org/10.1111/j.1467-8624.2008.01227.x

Blair, C. (2002). School readiness: Integrating cognition and emotion in a neurobiological conceptualization of children's functioning at school entry. American Psychologist, 57(2), 111-127. https://doi.org/10.1037/0003-066X.57.2.111

Blair, C., \& Diamond, A. (2008). Biological processes in prevention and intervention: The promotion of self-regulation as a means of preventing school failure. Development and Psychopathology, 20(3), 899-911. https://doi.org/10.1017/S0954579408000436

Blair, C., Granger, D. A., Willoughby, M., Mills-Koonce, R., Cox, M., Greenberg, M. T., Kivlighan, K. T., Fortunato, C. K., \& the FLP Investigators. (2011). Salivary Cortisol Mediates Effects of Poverty and Parenting on Executive Functions in Early Childhood: Cortisol and Cognition. Child Development, 82(6), 1970-1984. https://doi.org/10.1111/j.1467-8624.2011.01643.x

Blair, C., \& Raver, C. C. (2012). Individual development and evolution: Experiential canalization of self-regulation. Developmental Psychology, 48(3), 647-657. https://doi.org/10.1037/a0026472 
Blair, C., \& Raver, C. C. (2015). School readiness and self-regulation: A developmental psychobiological approach. Annual Review of Psychology, 66, 711-731. https://doi.org/10.1146/annurev-psych-010814-015221

Blair, C., \& Razza, R. P. (2007). Relating effortful control, executive function, and false belief understanding to emerging math and literacy ability in kindergarten. Child Development, 78(2), 647-663. https://doi.org/10.1111/j.1467-8624.2007.01019.x

Bodrova, E., \& Leong, D. J. (2007). Tools of the mind: The Vygotskian approach to early childhood education (2nd ed.). Columbus, OH: MerrillPrentice Hall.

Bowman, B. T. (1999). Kindergarten practices with children from low-income families. In R. C. Pianta \& M. J. Cox (Eds.), The transition to kindergarten (pp. 281-301). Bradley, R. H. (2007). Parenting in the breach: How parents help children cope with developmentally challenging circumstances. Parenting, 7(2), 99-148. https://doi.org/10.1080/15295190701306896

Bronfenbrenner, U., \& Morris, P. A. (1998). The ecology of developmental processes. In W. Damon \& R. M. Lerner (Eds.), Handbook of child psychology: Theoretical models of human development (pp. 993-1028). John Wiley \& Sons.

Burchinal, M., McCartney, K., Steinberg, L., Crosnoe, R., Friedman, S. L., McLoyd, V., Pianta, R., \& NICHD Early Child Care Research Network. (2011). Examining the Black-White achievement gap among low-income children using the NICHD Study of Early Child Care and Youth Development. Child Development, 82(5), 1404-1420. https://doi.org/10.1111/j.1467-8624.2011.01620.x 
SELF-REGULATION, STRESS, AND SEL IN KINDERGARTEN

Cheema, J. R. (2014). Some general guidelines for choosing missing data handling methods in educational research. Journal of Modern Applied Statistical Methods, 13(2), 53-75. https://doi.org/10.22237/jmasm/1414814520

Cohen, J., Cohen, P., West, S. G., \& Aiken, L. S. (2003). Applied multiple regression/correlation analysis for the behavioral sciences (3rd ed). Lawrence Erlbaum Associates.

Coll, C. G., Lamberty, G., Jenkins, R., McAdoo, H. P., Crnic, K., Wasik, B. H., \& Garcia, H. V. (1996). An integrative model for the study of developmental competencies in minority children. Child Development, 67(5), 1891-1914.

Collaborative for Academic, Social, and Emotional Learning. (2005). Safe and Sound: An Educational Leader's Guide to Evidence-Based Social and Emotional Learning (SEL) Programs, Illinois Edition. Chicago, IL: Author.

Collins, L. M., Schafer, J. L., \& Kam, C.-M. (2001). A comparison of inclusive and restrictive strategies in modern missing data procedures. Psychological Methods, 6(4), 330-351. https://doi.org/10.1037/1082-989X.6.4.330

Conger, K. J., Rueter, M. A., \& Conger, R. D. (2000). The role of economic pressure in the lives of parents and their adolescents: The family stress model. In L. Crockett \& R. Silbereisen (Eds.), Negotiating adolescence in times of social change (pp. 201-223). Cambridge University Press.

Conger, R. D., \& Conger, K. J. (2002). Resilience in midwestern families: Selected findings from the first decade of a prospective, longitudinal study. Journal of Marriage and Family, 64(2), 361-373. 
SELF-REGULATION, STRESS, AND SEL IN KINDERGARTEN

Dong, Y., \& Peng, C.-Y. J. (2013). Principled missing data methods for researchers. SpringerPlus, 2(1). https://doi.org/10.1186/2193-1801-2-222

Dotterer, A. M., Iruka, I. U., \& Pungello, E. (2012). Parenting, race, and socioeconomic status: Links to school readiness. Family Relations, 61(4), 657-670. https://doi.org/10.1111/j.1741-3729.2012.00716.x

Driscoll, K., \& Pianta, R. C. (2011). Mothers' and fathers' perceptions of conflict and closeness in parent-child relationships during early childhood. Journal of Early Childhood and Infant Psychology, 7, 1-24.

Duncan, G. J., Dowsett, C. J., Claessens, A., Magnuson, K., Huston, A. C., Klebanov, P., Pagani, L. S., Feinstein, L., Engel, M., Brooks-Gunn, J., Sexton, H., Duckworth, K., \& Japel, C. (2007). School readiness and later achievement. Developmental Psychology, 43(6), 1428-1446. https://doi.org/10.1037/0012-1649.43.6.1428

Duran, C. A. K., Cottone, E., Ruzek, E. A., Mashburn, A. J., \& Grissmer, D. W. (2018). Family stress processes and children's self-regulation. Child Development. https://doi.org/10.1111/cdev.13202

Durlak, J. A. (2010). The importance of doing well in whatever you do: A commentary on the special section, "Implementation research in early childhood education." Early Childhood Research Quarterly, 25(3), 348-357. https://doi.org/10.1016/j.ecresq.2010.03.003

Durlak, J. A., Weissberg, R. P., Dymnicki, A. B., Taylor, R. D., \& Schellinger, K. B. (2011). The impact of enhancing students' social and emotional learning: A meta- 
SELF-REGULATION, STRESS, AND SEL IN KINDERGARTEN

analysis of school-based universal interventions. Child Development, 82(1), 405432. https://doi.org/10.1111/j.1467-8624.2010.01564.X

Durlak, J. A., Weissberg, R. P., \& Pachan, M. (2010). A meta-analysis of after-school programs that seek to promote personal and social skills in children and adolescents. American Journal of Community Psychology, 45, 294-309. https://doi.org/10.1007/s10464-010-9300-6

Early, D. M., Iruka, I. U., Ritchie, S., Barbarin, O. A., Winn, D.-M. C., Crawford, G. M., Frome, P. M., Clifford, R. M., Burchinal, M., Howes, C., Bryant, D. M., \& Pianta, R. C. (2010). How do pre-kindergarteners spend their time? Gender, ethnicity, and income as predictors of experiences in pre-kindergarten classrooms. Early Childhood Research Quarterly, 25(2), 177-193. https://doi.org/10.1016/j.ecresq.2009.10.003

Eisenberg, N., \& Sulik, M. J. (2012). Emotion-related self-regulation in children. Teaching of Psychology, 39(1), 77-83. https://doi.org/10.1177/0098628311430172

Enders, C., \& Bandalos, D. (2001). The relative performance of Full Information Maximum Likelihood estimation for missing data in structural equation models. Structural Equation Modeling, 8(3), 430-457. https://doi.org/10.1207/S15328007SEM0803_5

Enders, C. K. (2010). Applied missing data analysis. Guilford Press.

Enders, C. K. (2011). Analyzing longitudinal data with missing values. Rehabilitation Psychology, 56(4), 267-288. https://doi.org/10.1037/a0025579 
Enders, C. K. (2013). Dealing with missing data in developmental research. Child Development Perspectives, 7(1), 27-31. https://doi.org/10.1111/cdep.12008

Entwisle, D. R., \& Alexander, K. L. (1999). Early schooling and social stratification. In R. C. Pianta \& M. J. Cox (Eds.), The Transition to Kindergarten (pp. 13-38). Brookes Publishing Co.

Evans, G. W. (2004). The environment of childhood poverty. American Psychologist, 59(2), 77-92. https://doi.org/10.1037/0003-066X.59.2.77

Evans, G. W., \& English, K. (2002). The environment of poverty: Multiple stressor exposure, psychophysiological stress, and socioemotional adjustment. Child Development, 73, 1238-1248.

Evans, G. W., \& Kim, P. (2007). Childhood Poverty and Health: Cumulative Risk Exposure and Stress Dysregulation. Psychological Science, 18(11), 953-957. https://doi.org/10.1111/j.1467-9280.2007.02008.x

Evans, G. W., \& Kim, P. (2013). Childhood poverty, chronic stress, self-regulation, and coping. Child Development Perspectives, 7(1), 43-48. https://doi.org/10.1111/cdep.12013

Fairchild, A. J., \& McQuillin, S. D. (2010). Evaluating mediation and moderation effects in school psychology: A presentation of methods and review of current practice. Journal of School Psychology, 48(1), 53-84. https://doi.org/10.1016/j.jsp.2009.09.001

Fitzpatrick, C., McKinnon, R. D., Blair, C. B., \& Willoughby, M. T. (2014). Do preschool executive function skills explain the school readiness gap between 
SELF-REGULATION, STRESS, AND SEL IN KINDERGARTEN

advantaged and disadvantaged children? Learning and Instruction, 30, 25-31. https://doi.org/10.1016/j.learninstruc.2013.11.003

Gilliam, W. S., Maupin, A. N., Reyes, C. R., Accavitti, M., \& Shic, F. (2016). Do early educators' implicit biases regarding sex and race relate to behavior expectations and recommendations of preschool expulsions and suspensions? Yale University Child Study Center.

Gottlieb, G. (1991). Experiential canalization of behavioral development: Theory. Developmental Psychology, 27(1), 4-13.

Greenberg, M. T., Weissberg, R. P., O’Brien, M. U., Zins, J. E., Fredericks, L., Resnik, H., \& Elias, M. J. (2003). Enhancing school-based prevention and youth development through coordinated social, emotional, and academic learning. American Psychologist, 58(6-7), 466-474. https://doi.org/10.1037/0003066X.58.6-7.466

Hamre, B. K., \& Pianta, R. C. (2007). Learning opportunities in preschool and early elementary classrooms. In R. C. Pianta, M. J. Cox, \& K. Snow (Eds.), School readiness, early learning and the transition to kindergarten (pp. 49-84). Brookes.

Hayes, A. F. (2018). Introduction to mediation, moderation, and conditional process analysis: A regression-based approach (Second edition). Guilford Press.

Holmes, T. H., \& Rahe, R. H. (1967). The social readjustment rating scale. Journal of Psychosomatic Research, 11(2), 213-218. https://doi.org/10.1016/00223999(67)90010-4 
SELF-REGULATION, STRESS, AND SEL IN KINDERGARTEN

Holochwost, S. J., Volpe, V. V., Iruka, I. U., \& Mills-Koonce, W. R. (2020). Maternal warmth, intrusiveness, and executive functions in early childhood: Tracing developmental processes among African American children. Early Child Development and Care, 190(2), 210-218.

https://doi.org/10.1080/03004430.2018.1461096

Iruka, I. U., Burchinal, M., \& Cai, K. (2010). Long-term effect of early relationships for African American children's academic and social development: An examination from kindergarten to fifth grade. Journal of Black Psychology, 36(2), 144-171. https://doi.org/10.1177/0095798409353760

Iruka, I. U., Curenton, S. M., \& Gardner, S. (2015). How changes in home and neighborhood environment factors are related to change in Black children's academic and social development from kindergarten to third grade. The Journal of Negro Education, 84(3), 282-297. https://doi.org/10.7709/jnegroeducation.84.3.0282

Iruka, I. U., Curenton, S. M., Sims, J., Blitch, K. A., \& Gardner, S. (2020). Factors associated with early school readiness profiles for Black girls. Early Childhood Research Quarterly, 51, 215-228. https://doi.org/10.1016/j.ecresq.2019.10.012

Iruka, I. U., Gardner-Neblett, N., Matthews, J. S., \& Winn, D.-M. C. (2014). Preschool to kindergarten transition patterns for African American boys. Early Childhood Research Quarterly, 29(2), 106-117. https://doi.org/10.1016/j.ecresq.2013.11.004 Iruka, I. U., \& Morgan, J. (2014). Patterns of Quality Experienced by African American Children in Early Education Programs: Predictors and Links to Children's 
SELF-REGULATION, STRESS, AND SEL IN KINDERGARTEN

Preschool and Kindergarten Academic Outcomes. The Journal of Negro

Education, 83(3), 235-255. https://doi.org/10.7709/jnegroeducation.83.3.0235

Kochanska, G., Coy, K. C., \& Murray, K. T. (2001). The development of self-regulation in the first four years of life. Child Development, 72(4), 1091-1111. https://doi.org/10.1111/1467-8624.00336

Landers-Potts, M. A., Wickrama, K. A. S., Simons, L. G., Cutrona, C., Gibbons, F. X., Simons, R. L., \& Conger, R. (2015). An extension and moderational analysis of the Family Stress Model focusing on African American adolescents. Family Relations, 64(2), 233-248. https://doi.org/10.1111/fare.12117

Lang, K. M., \& Little, T. D. (2018). Principled missing data treatments. Prevention Science, 19(3), 284-294. https://doi.org/10.1007/s11121-016-0644-5

LeBuffe, P. A., Shapiro, V. B., \& Naglieri, J. A. (n.d.). Introduction to the Devereux Student Strengths Assessment (DESSA). Devereux Center for Resilient Children.

LeBuffe, P. A., Shapiro, V. B., \& Naglieri, J. A. (2009). The Devereux Student Strengths Assessment (DESSA): Assessment, technical manual, and user's guide. Devereux Center for Resilient Children.

Liew, J. (2012). Effortful control, executive functions, and education: Bringing selfregulatory and social-emotional competencies to the table. Child Development Perspectives, 6(2), 105-111. https://doi.org/10.1111/j.1750-8606.2011.00196.x

Little, R. J. A. (1988). A test of Missing Completely at Random for multivariate data with missing values. Journal of the American Statistical Association, 83(404), 11981202. 
SELF-REGULATION, STRESS, AND SEL IN KINDERGARTEN

Little, T. D., Jorgensen, T. D., Lang, K. M., \& Moore, E. W. G. (2014). On the joys of missing data. Journal of Pediatric Psychology, 39(2), 151-162. https://doi.org/10.1093/jpepsy/jst048

Loomis, A. M., \& Mogro-Wilson, C. (2019). Effects of cumulative adversity on preschool self-regulation and student-teacher relationships in a highly dense hispanic community: A pilot study. Infants \& Young Children, 34(2), 107-122. https://doi.org/10.1097/IYC.0000000000000139

Mashburn, A. J., \& Henry, G. T. (2004). Assessing school readiness: Validity and bias in preschool and kindergarten teachers' ratings. Educational Measurement, Issues and Practice, 23(4), 16-30. https://doi.org/10.1111/j.1745-3992.2004.tb00165.x

Mashburn, A. J., \& Pianta, R. C. (2006). Social relationships and school readiness. Early Education \& Development, 17(1), 151-176. https://doi.org/10.1207/s15566935eed1701_7

Mashburn, A. J., \& Pianta, R. C. (2010). Opportunity in early education: Improving teacher-child interactions and child outcomes. In A. Reynolds, A. Rolnick, M. Englund, \& J. Temple (Eds.), Childhood programs and practices in the first decade of life: A human capital integration (pp. 243-265).

Mashburn, A. J., Pianta, R. C., Hamre, B. K., Downer, J. T., Barbarin, O. A., Bryant, D., Burchinal, M., Early, D. M., \& Howes, C. (2008). Measures of classroom quality in prekindergarten and children's development of academic, language, and social skills. Child Development, 79(3), 732-749. https://doi.org/10.1111/j.14678624.2008.01154.x 
SELF-REGULATION, STRESS, AND SEL IN KINDERGARTEN

McClelland, M. M., \& Cameron, C. E. (2012). Self-Regulation in Early Childhood: Improving Conceptual Clarity and Developing Ecologically Valid Measures: SelfRegulation in Early Childhood: Improving Conceptual Clarity and Measures. Child Development Perspectives, 6(2), 136-142. https://doi.org/10.1111/j.17508606.2011.00191.x

McClelland, M. M., Cameron, C. E., Connor, C. M., Farris, C. L., Jewkes, A. M., \& Morrison, F. J. (2007). Links between behavioral regulation and preschoolers' literacy, vocabulary, and math skills. Developmental Psychology, 43(4), 947-959. https://doi.org/10.1037/0012-1649.43.4.947

McClelland, M. M., Cameron, C. E., Duncan, R., Bowles, R. P., Acock, A. C., Miao, A., \& Pratt, M. E. (2014). Predictors of early growth in academic achievement: The head-toes-knees-shoulders task. Frontiers in Psychology, 5. https://doi.org/10.3389/fpsyg.2014.00599

McClelland, M. M., Geldhof, G. J., Cameron, C. E., \& Wanless, S. B. (2015). Development and Self-Regulation. In R. M. Lerner (Ed.), Handbook of Child Psychology and Developmental Science (7th ed.). John Wiley \& Sons, Inc. https://doi.org/10.1002/9781118963418.childpsy114

McClelland, M. M., Morrison, F. J., \& Holmes, D. L. (2000). Children at risk for early academic problems: The role of learning-related social skills. Early Childhood Research Quarterly, 15(3), 307-329. https://doi.org/10.1016/S08852006(00)00069-7 
SELF-REGULATION, STRESS, AND SEL IN KINDERGARTEN

McClelland, M. M., Tominey, S. L., Schmitt, S. A., \& Duncan, R. (2017). SEL interventions in early childhood. Social and Emotional Learning, 27(1), 33-47. https://doi.org/10.1353/foc.2017.0002

McIntyre, L. L., Eckert, T. L., Fiese, B. H., DiGennaro, F. D., \& Wildenger, L. K. (2007). Transition to kindergarten: Family experiences and involvement. Early Childhood Education Journal, 35(1), 83-88. https://doi.org/10.1007/s10643-007-0175-6

McLoyd, V. C. (1990). The impact of economic hardship on black families and children: Psychological distress, parenting, and socioemotional development. Child Development, 61(2), 311-346.

Mistry, R. S., Vandewater, E. A., Huston, A. C., \& McLoyd, V. C. (2002). Economic well-being and children's social adjustment: The role of family process in an ethnically diverse low-income sample. Child Development, 73(3), 935-951. https://doi.org/10.1111/1467-8624.00448

Myers, J. L., Well, A., \& Lorch, R. F. (2010). Research design and statistical analysis (3. ed). Routledge.

National Education Goals Panel. (1995). National Education Goals report executive summary: Improving education through family-school-community partnerships. Washington, DC: U.S. Government Printing Office.

NCES. (2015). Children living in poverty. National Center for Education Statistics. https://nces.ed.gov/programs/coe/pdf/Indicator_CCE/coe_cce_2015_05.pdf 
Neppl, T. K., Senia, J. M., \& Donnellan, M. B. (2016). Effects of economic hardship: Testing the family stress model over time. Journal of Family Psychology, 30(1), 12-21. https://doi.org/10.1037/fam0000168

Nickerson, A. B., \& Fishman, C. (2009). Convergent and divergent validity of the Devereux Student Strengths Assessment. School Psychology Quarterly, 24(1), 48-59. https://doi.org/10.1037/a0015147

Noone, P. A. (2017). The Holmes-Rahe Stress Inventory. Occupational Medicine, 67(7), 581-582. https://doi.org/10.1093/occmed/kqx099

Panter, J. E., \& Bracken, B. A. (2000). Promoting school readiness. In K. M. Minke \& G. G. Bear (Eds.), Preventing school problems - Promoting school success: Strategies and programs that work (pp. 101-142).

Payton, J., Weissberg, R. P., Durlak, J. A., Dymnicki, A. B., Taylor, R. D., Schellinger, K. B., \& Pachan, M. (2008). The positive impact of social and emotional learning for kindergarten to eight-grade students: Findings from three scientific reviews. Collaborative for Academic, Social, and Emotional Learning (CASEL).

Peugh, J. L., \& Enders, C. K. (2004). Missing data in educational research: A review of reporting practices and suggestions for improvement. Review of Educational Research, 74(4), 525-556. https://doi.org/10.3102/00346543074004525

Pianta, R. C. (1992). Child-Parent Relationship Scale. Charlottesville, VA: University of Virginia. 
SELF-REGULATION, STRESS, AND SEL IN KINDERGARTEN

Pianta, R. C. (1997). Adult-child relationship processes and early schooling. Early Education and Development, 8(1), 11-26. https://doi.org/10.1207/s15566935eed0801_2

Rahe, R. H., Biersner, R. J., Ryman, D. H., \& Arthur, R. J. (1972). Psychosocial Predictors of Illness Behavior and Failure in Stressful Training. Journal of Health and Social Behavior, 13(4), 393. https://doi.org/10.2307/2136831

Rahe, R. H., Mahan, J. L., \& Arthur, R. J. (1970). Prediction of near-future health change from subjects' preceding life changes. Jounral of Psychosomatic Research, 14, 401-406.

Raver, C. C., Blair, C., Willoughby, M., \& 2013. (2013). Poverty as a predictor of 4-yearolds' executive function: New perspectives on models of differential susceptibility. Developmental Psychology, 49(2), 292-304. https://doi.org/10.1037/a0028343

Raver, C. C., Jones, S. M., Li-Grining, C., Zhai, F., Bub, K., \& Pressler, E. (2011). CSRP's impact on low-income preschoolers' preacademic skills: Self-regulation as a mediating mechanism. Child Development, 82(1), 362-378. https://doi.org/10.1111/j.1467-8624.2010.01561.x

Rimm-Kaufman, S. E., \& Pianta, R. C. (2000). An ecological perspective on the transition to kindergarten: A theoretical framework to guide empirical research. Journal of Applied Developmental Psychology, 21(5), 491-511. 
Rimm-Kaufman, S. E., Pianta, R. C., \& Cox, M. J. (2000). Teachers' judgments of problems in the transition to kindergarten. Early Childhood Research Quarterly, 15(2), 147-166. https://doi.org/10.1016/S0885-2006(00)00049-1

Robson, D. A., Allen, M. S., \& Howard, S. J. (2020). Self-regulation in childhood as a predictor of future outcomes: A meta-analytic review. Psychological Bulletin, 146(4), 324-354. https://doi.org/10.1037/bul0000227

Rosseel, Y. (2021). Latent Variable Analysis.

Rubin, D. B. (1976). Inference and missing data. Biometrika, 63(3), 581-592.

Sameroff, A. (2010). A unified theory of development: A dialectic integration of nature and nurture. Child Development, 81(1), 6-22.

Schafer, J. L., \& Graham, J. W. (2002). Missing data: Our view of the state of the art. Psychological Methods, 7(2), 147-177. https://doi.org/10.1037/1082989X.7.2.147

Schulting, A. B., Malone, P. S., \& Dodge, K. A. (2005). The effect of school-based kindergarten transition policies and practices on child academic outcomes. Developmental Psychology, 41(6), 860-871. https://doi.org/10.1037/00121649.41.6.860

Serpell, Z. N., \& Mashburn, A. J. (2012). Family-school connectedness and children's early social development. Social Development, 21(1), 21-46. https://doi.org/10.1111/j.1467-9507.2011.00623.x

Skinner, E. A., \& Zimmer-Gembeck, M. J. (2016). The development of coping: Stress, neurophysiology, social relationships, and resilience during childhood and 
SELF-REGULATION, STRESS, AND SEL IN KINDERGARTEN

adolescence. Springer International Publishing. https://doi.org/10.1007/978-3$319-41740-0$

The American Institute of Stress (AIS). (2020). The Holmes-Rahe Stress Inventory. https://www.stress.org/holmes-rahe-stress-inventory

Thomas, D., \& Fry, R. (2020). Prior to COVID-19, child poverty rates had reached record lows in U.S. Pew Research Center. https://www.pewresearch.org/facttank/2020/11/30/prior-to-covid-19-child-poverty-rates-had-reached-record-lowsin-u-s/

Ursache, A., Blair, C., \& Raver, C. C. (2012). The Promotion of self-regulation as a means of enhancing school readiness and early achievement in children at risk for school failure: Promotion of self-regulation in school. Child Development Perspectives, 6(2), 122-128. https://doi.org/10.1111/j.1750-8606.2011.00209.x

U.S. Department of Health and Human Services. (2015). Head Start Early Learning Outcomes Framework: Ages Birth to Five. Washington, DC: Administration for Children \& Families. https://eclkc.ohs.acf.hhs.gov/sites/default/files/pdf/elof-ohsframework.pdf

Wadsworth, M. E. (2015). Development of maladaptive coping: A functional adaptation to chronic, uncontrollable stress. Child Development Perspectives, 9(2), 96-100. https://doi.org/10.1111/cdep.12112

Wanless, S. B., McClelland, M. M., Tominey, S. L., \& Acock, A. C. (2011). The influence of demographic risk factors on children's behavioral regulation in 
SELF-REGULATION, STRESS, AND SEL IN KINDERGARTEN

prekindergarten and kindergarten. Early Education and Development, 22(3), 461488. https://doi.org/10.1080/10409289.2011.536132

Webster-Stratton, C., Jamila Reid, M., \& Stoolmiller, M. (2008). Preventing conduct problems and improving school readiness: Evaluation of the Incredible Years Teacher and Child Training Programs in high-risk schools. Journal of Child Psychology and Psychiatry, 49(5), 471-488. https://doi.org/10.1111/j.14697610.2007.01861.x

Willoughby, M. T., Blair, C. B., Wirth, R. J., Greenberg, M., \& The Family Life Project Investigators. (2012). The measurement of executive function at age 5:

Psychometric properties and relationship to academic achievement. Psychological Assessment, 24(1), 226-239. https://doi.org/10.1037/a0025361

WINGS for Kids. (2020). WINGS Afterschool. https://www.wingsforkids.org/sel/programs/wings-afterschool/

Yuan, K.-H., \& Bentler, P. M. (2006). Asymptotic robustness of standard errors in multilevel structural equation models. Journal of Multivariate Analysis, 97(5), 1121-1141. https://doi.org/10.1016/j.jmva.2005.06.003

Zill, N. (1999). Promoting educational equity and excellence in kindergarten. In R. C. Pianta \& M. J. Cox (Eds.), The Transition to Kindergarten (pp. 67-105). Brookes Publishing Co.

Zins, J. E., Elias, M. J., Greenberg, M. T., \& Weissberg, R. P. (2000). Promoting social and emotional competence in children. In K. M. Minke \& G. G. Bear (Eds.), 
SELF-REGULATION, STRESS, AND SEL IN KINDERGARTEN

Preventing school problems - Promoting school success: Strategies and programs that work (pp. 71-99). 


\section{Appendix A: Teacher Survey Measure}

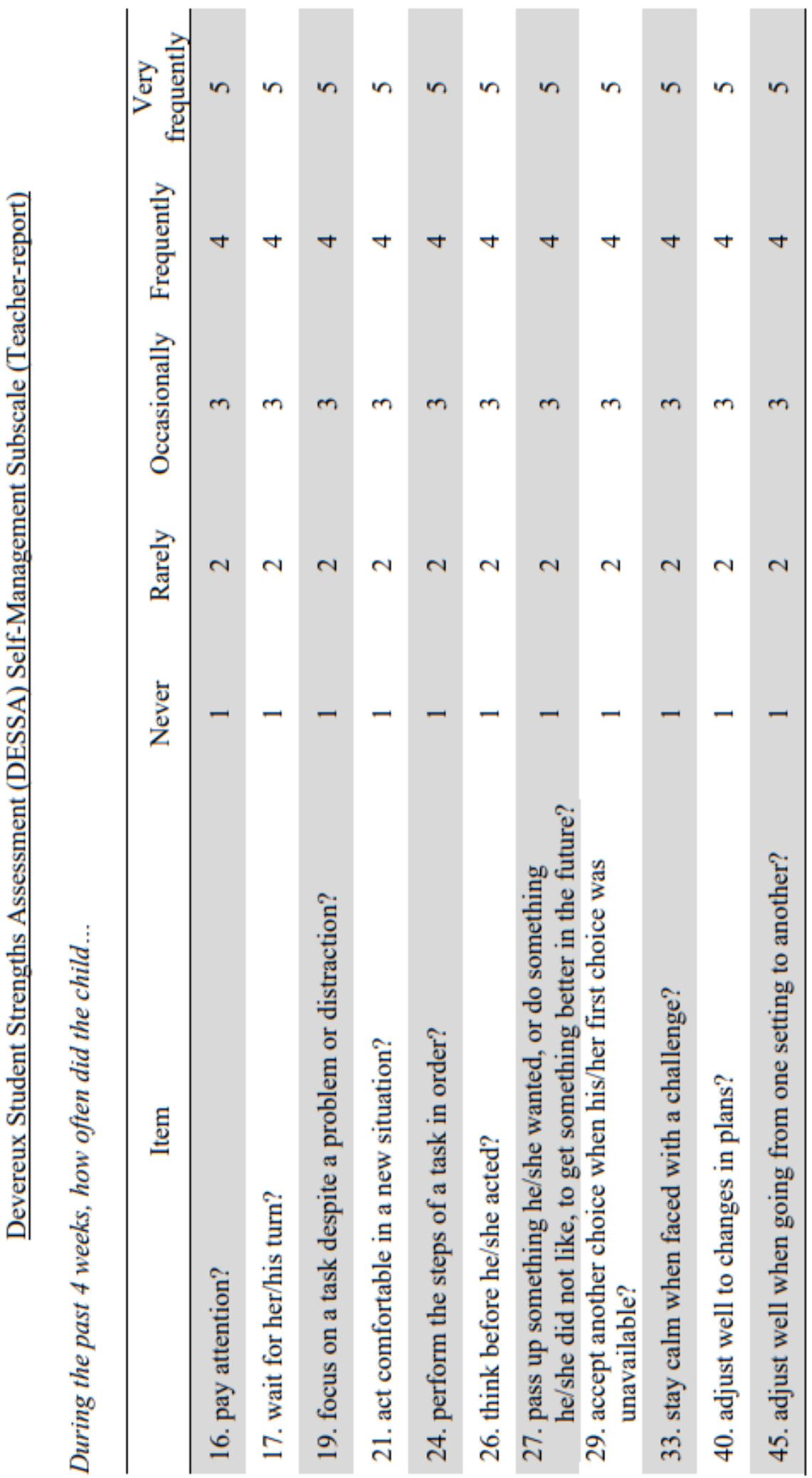


Appendix B: Parent Interview Measures

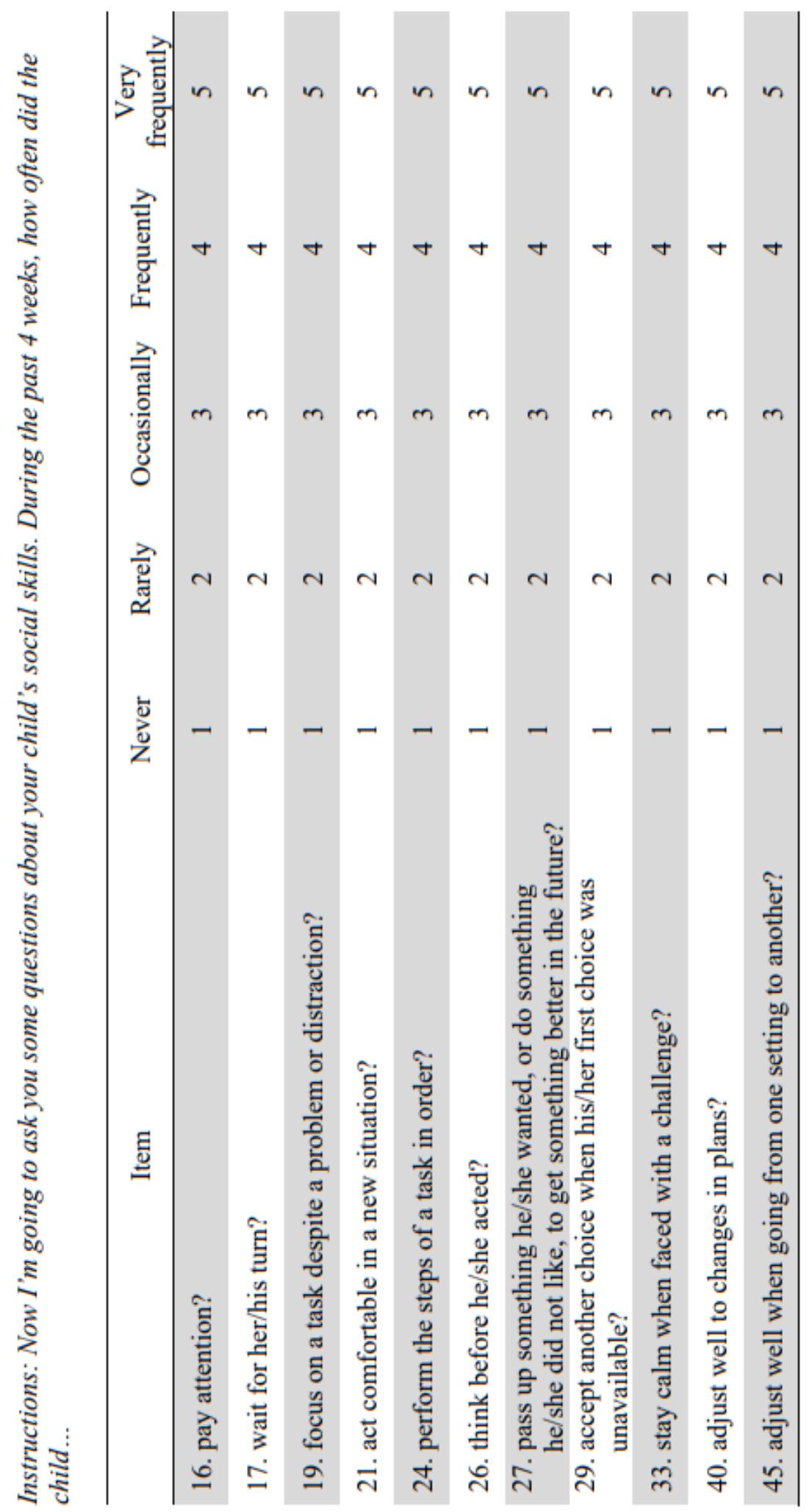




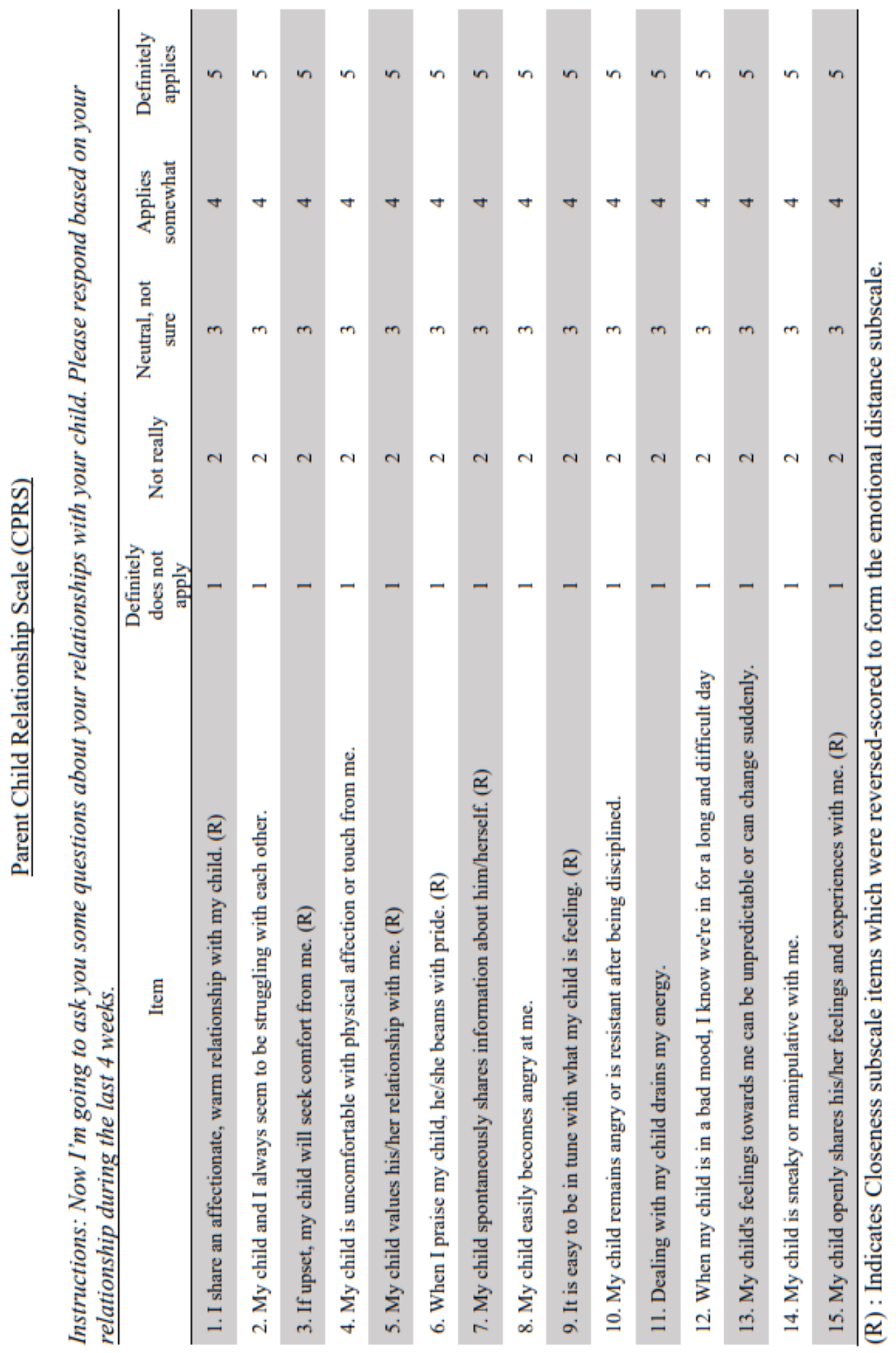




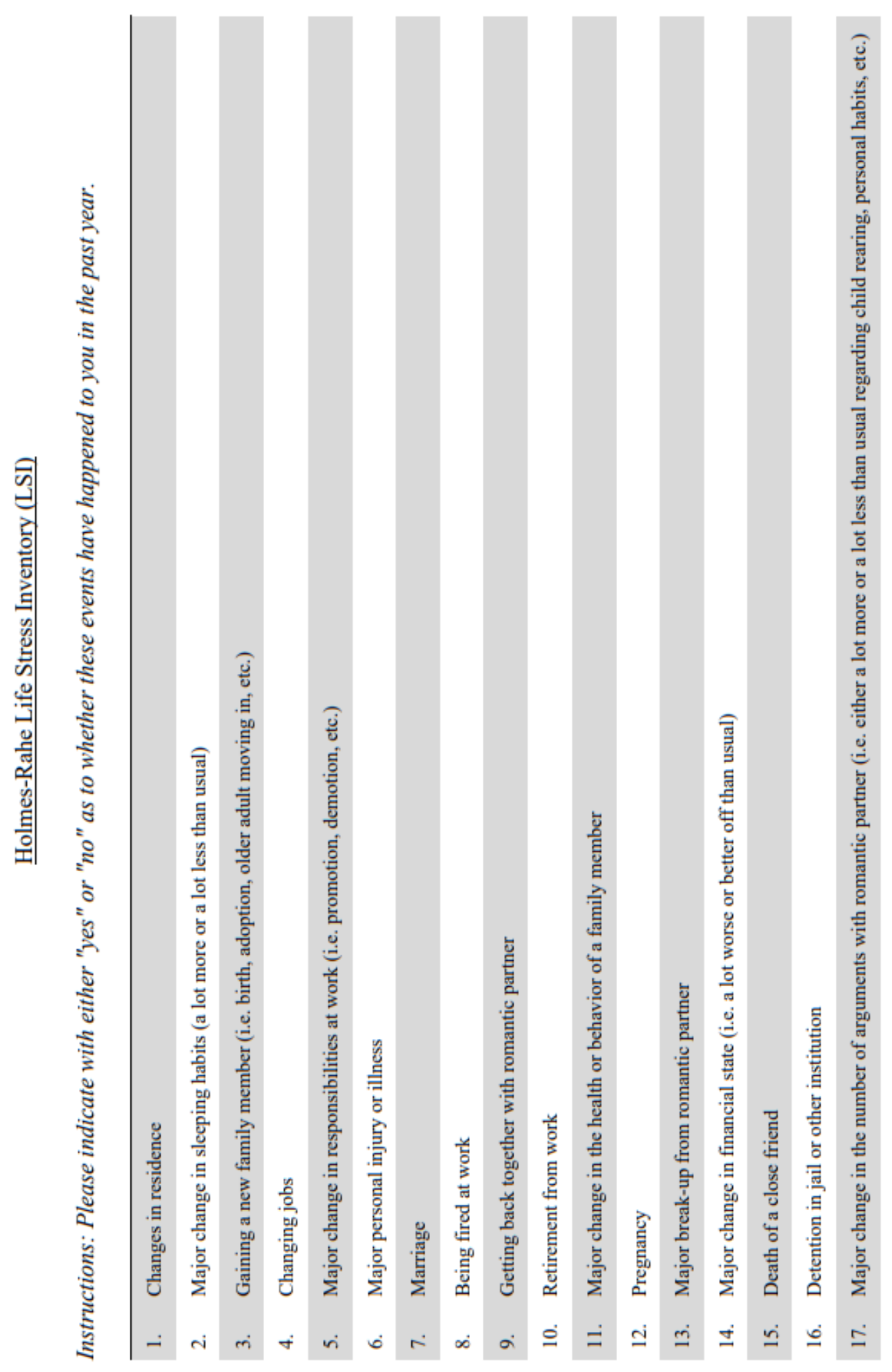




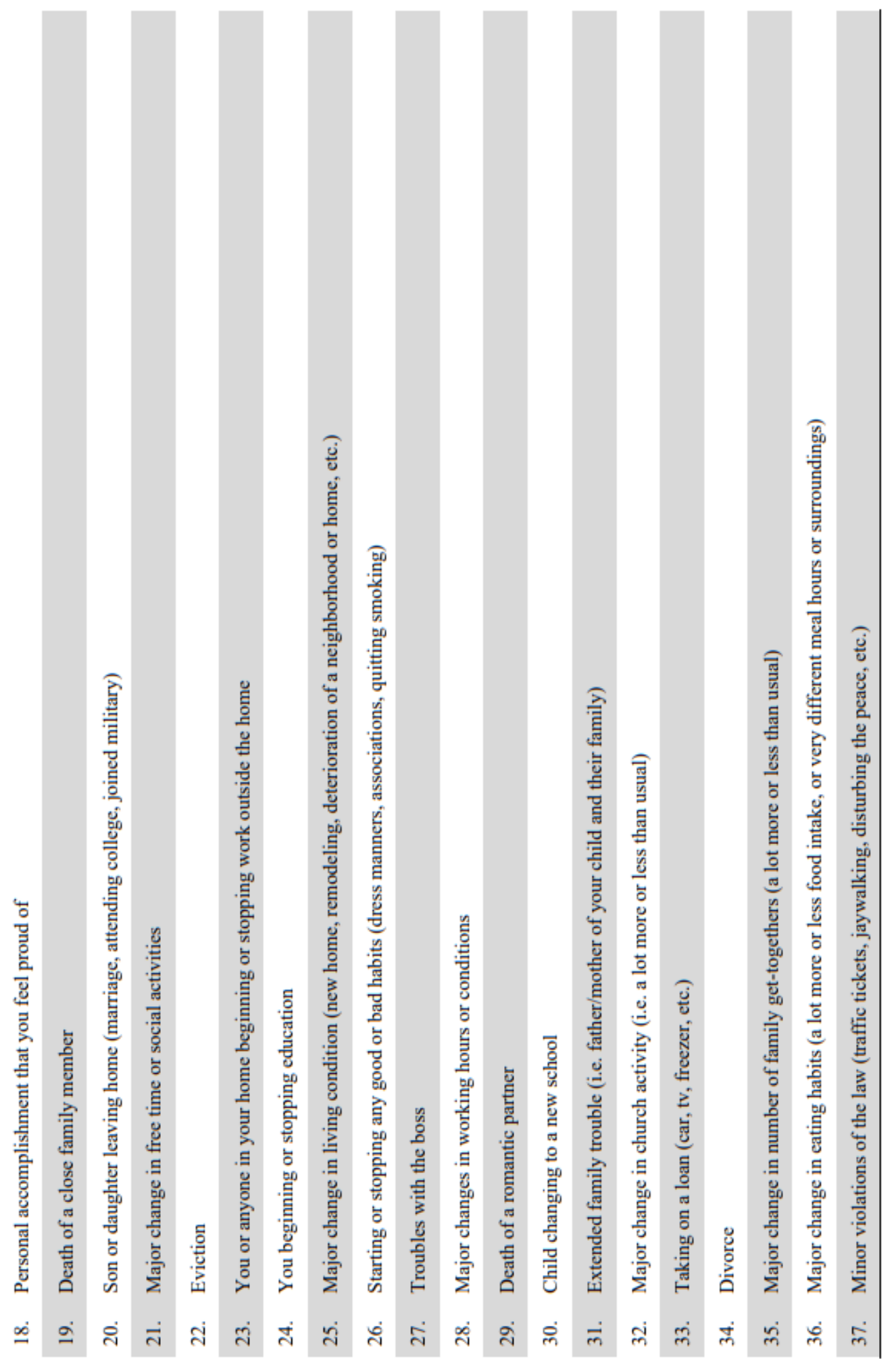




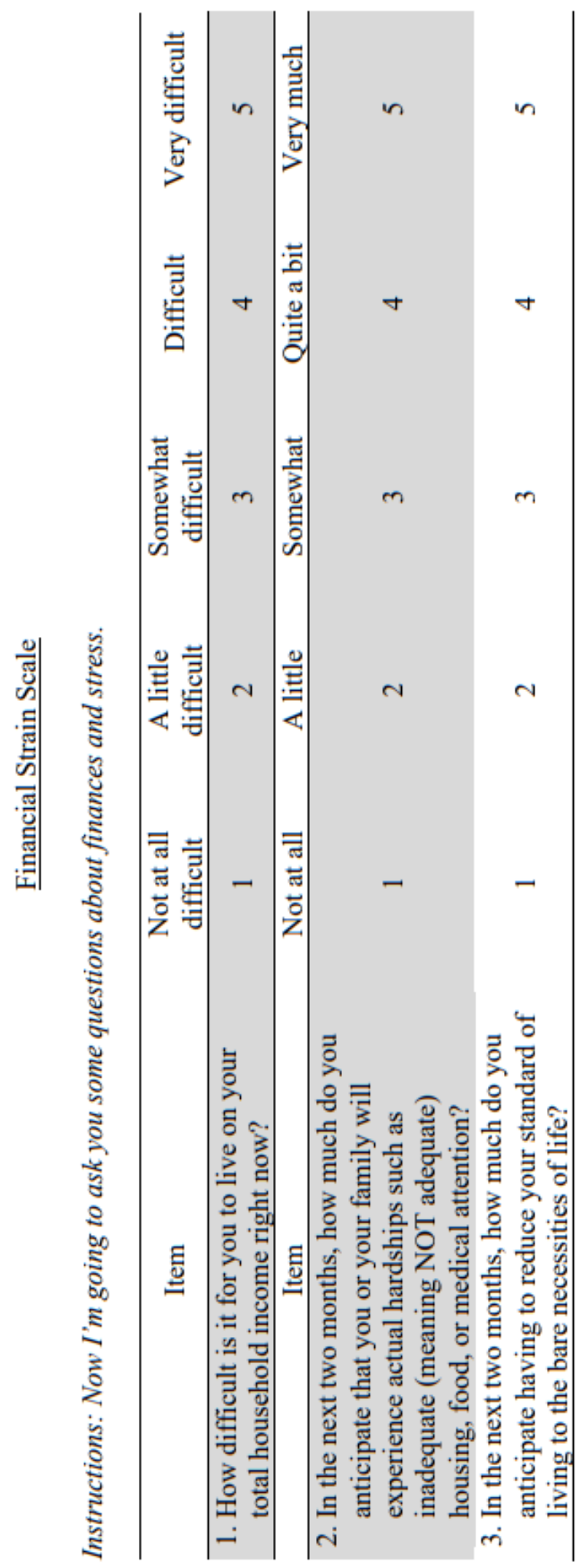

